\title{
Taiwanese Composer Tyzen Hsiao: Pedagogical Aspects of Selected Piano Solo Works
}

\author{
Tzu-Nung Lin
}

Follow this and additional works at: https://researchrepository.wvu.edu/etd

\section{Recommended Citation}

Lin, Tzu-Nung, "Taiwanese Composer Tyzen Hsiao: Pedagogical Aspects of Selected Piano Solo Works" (2017). Graduate Theses, Dissertations, and Problem Reports. 6092.

https://researchrepository.wvu.edu/etd/6092

This Dissertation is protected by copyright and/or related rights. It has been brought to you by the The Research Repository @ WVU with permission from the rights-holder(s). You are free to use this Dissertation in any way that is permitted by the copyright and related rights legislation that applies to your use. For other uses you must obtain permission from the rights-holder(s) directly, unless additional rights are indicated by a Creative Commons license in the record and/ or on the work itself. This Dissertation has been accepted for inclusion in WVU Graduate Theses, Dissertations, and Problem Reports collection by an authorized administrator of The Research Repository @ WVU.

For more information, please contact researchrepository@mail.wvu.edu. 
Taiwanese Composer Tyzen Hsiao:

Pedagogical Aspects of Selected Piano Solo Works

\author{
Tzu-Nung Lin
}
Research Document submitted to the College of Creative Arts
at West Virginia University in partial fulfillment of the requirements
for the degree
Doctor of Musical Arts
in
Piano Performance
Peter Amstutz, D.M.A., Committee Chair and Research Advisor William Haller, DMA Andrea Houde AD Ching-Wen Hsiao DMA
Bruce Kang PhD
School of Music

Morgantown, West Virginia 2017

Keywords: Taiwanese composers, Taiwanese music, Tyzen Hsiao, Folk songs, Pentatonic scales, Memories of Home, The Angel from Formosa, Farewell Etude 


\begin{abstract}
The Musical Background and Pedagogical Aspects of the Taiwanese Composer Tyzen Hsiao and His Selected Piano Solo Works

Tzu-Nung Lin
\end{abstract}

This research project examines selected piano works by Taiwanese composer Tyzen Hsiao, who was born in 1938 and passed away in February, 2015. While Hsiao's music reveals influences from several different cultures, his main focus was the music of Taiwan, even though he decided to leave his homeland for the United States and was unable to return for more than 18 years because of volatile political issues within Taiwan. In his works, he uses the materials and compositional techniques of the $19^{\text {th }}$ and $20^{\text {th }}$ centuries, along with pentatonic scales and church styles; frequently, he also includes Taiwanese folk elements in the music.

Although Tyzen Hsiao is fairly well known in Taiwan, it is still difficult to find published sources about his many piano works, even in his home country. In addition to a few individual books and dissertations about Hsiao and his music, most of the published materials are articles from newspapers and journals. Most of Hsiao's works for solo piano have not been performed frequently.

This paper highlights Tyzen Hsiao's musical background and writing styles and it offers pedagogical suggestions regarding two of his solo-piano pieces. Many of his piano works are also suitable for children. It is my hope that, instead of only assigning music from other countries, Taiwanese piano teachers can also encourage their young students to work on excellent pieces like these from their own country.

The paper concludes with a summary of the piano pieces discussed in the document and with an appreciation for Tyzen Hsiao's contributions to Taiwanese society. 


\section{ACKNOWLEDGEMENTS}

To my beloved parents-- Wei-Chih Lin and Yu-Chin Kuo, who have been supporting and encouraging me throughout my study in the United States.

I would like to express gratitude to several people who have embarked on this educational journey with me. First, thank you to my parents, who allowed me to learn how to play the piano and flute when I was a child. Learning to master an instrument is a very long process. However, no matter how tough life could be sometimes, my parents never stopped my music lessons. Thanks to my family and friends in Taiwan and the United States who have been cheering for me nonstop during my study abroad. Thank you to my former teachers Emmy Chen, Rudieger Steinfatt, Richard Reber, and Dr. Steven Spooner, who made me understand how much I love playing the piano and reading books about piano literature. A huge thank you to my piano teachers at West Virginia University, Dr. Peter Amstutz and Dr. Ching-Wen Hsiao. I'm grateful to you for never giving up on me, even at those times when I struggled to maintain my motivation for playing the piano. Both of you have been so kind and supportive to me. Thanks also to my committee members Dr. William Haller, Prof. Andrea Houde, and Dr. Bruce Kang for your support along this journey. 


\section{CONTENTS}

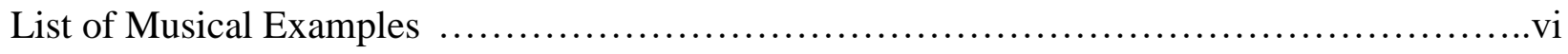

Chapter 1: Life and Music Background of Tyzen Hsiao ................................... 1

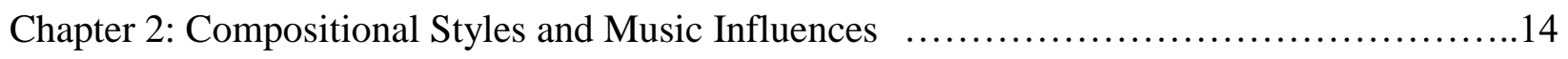

Chapter 3: Memories of Home, Op. 49 (1987) .......................................

Chapter 4: The Angel from Formosa $(1999) \quad$ ….................................... 80

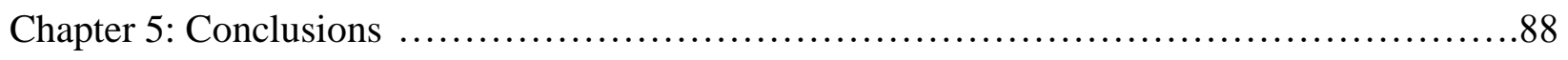

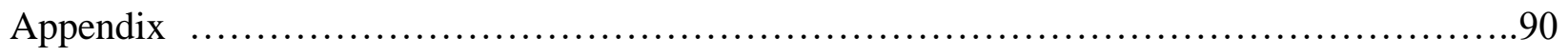

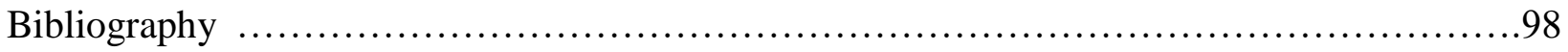




\section{LIST OF MUSICAL EXAMPLES}

Example 2.1: Chopin "Prelude" in E Minor, mm. 1-8.....................................14

Example 2.2: Hsiao Piano Concerto in C Minor, mm. 76-87 .............................. 15

Example 2.3: Chopin "Mazurkas" for Piano," mm. 1-18 .................................16

Example 2.4: Hsiao Piano Concerto in C Minor, mm. 42-44 .................................. 17

Example 2.5: Rachmaninoff "Morceaux de Fantaisie," op. 3 mm. 1-12 .......................18

Example 2.6: Hsiao Piano Concerto in C Minor, mm. 7-15 ............................. 19

Example 2.7: Rachmaninoff Piano Concerto in C Minor, mm. 1-12 ........................20

Example 2.8: Hsiao Formosa Fantasia for Flute and Piano ...............................22

Example 2.9: Hsiao Formosa Fantasia for Flute and Piano, 1-2 ............................23

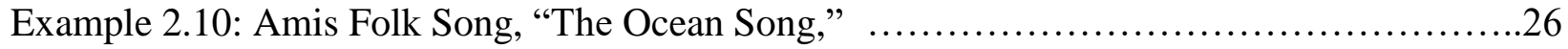

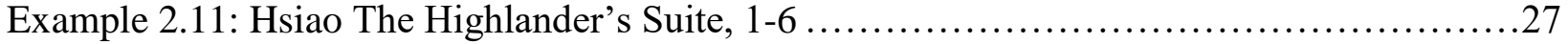

Example 2.12: Amis Folk Song, "The Ocean Song," 5-8 …...........................28

Example 2.13: Hsiao The Highlander's Suite, 26-31 .....................................29

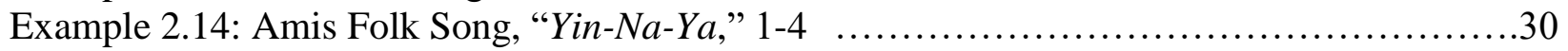

Example 2.15: Hsiao "The Highlander's Suite," 25-30 ................................. 31

Example 2.16: Amis Folk Song, "Moon Appreciation Dance," 1-12 . .......................32

Example 2.17: Hsiao "The Highlander's Suite," 61-66........................................ 33

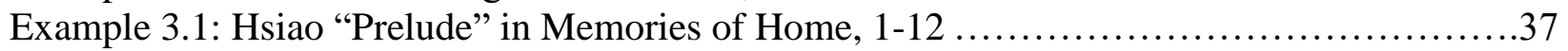

Example 3.2: Hsiao "Prelude" in Memories of Home, 17-24 ............................... 38

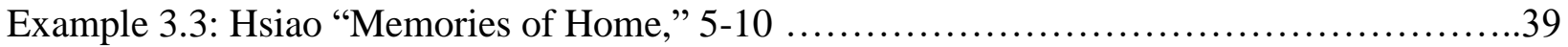

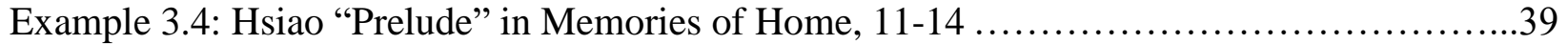

Example 3.5: Hsiao "Prelude" in Memories of Home, 17-22 ............................40

Example 3.6: Hsiao "Prelude" in Memories of Home, 27-32 ...............................41

Example 3.7: Hsiao "The Vegabond," 1-20 .......................................43

Example 3.8: Hsiao "Memory" in Memories of Home, 1-9 .............................45

Example 3.9: Chopin "Nocturne," Op. 72, No. 1, 1-9...................................46

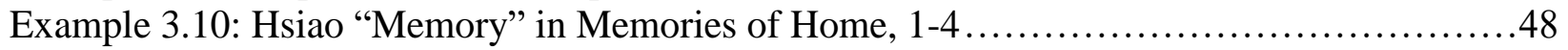

Example 3.11: Hsiao "Memory" in Memories of Home, 34-36 ..............................49

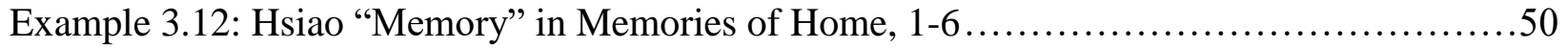

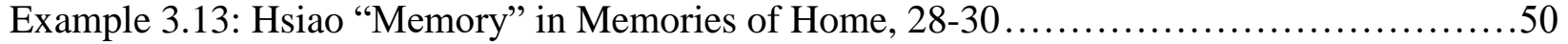

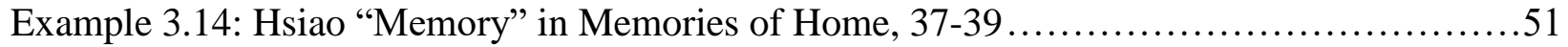

Example 3.15: Hsiao "Memory" in Memories of Home, 19-27 .............................52

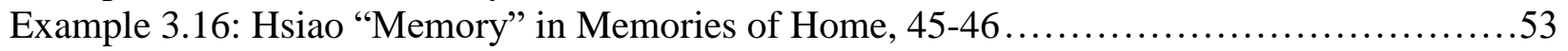

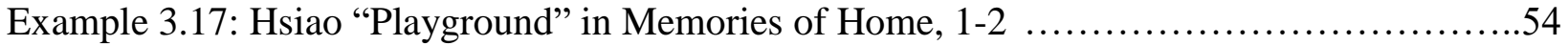

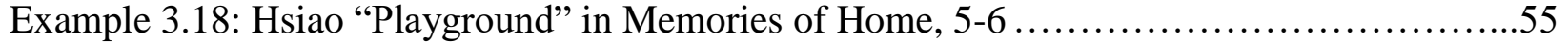

Example 3.19: Hsiao "Playground" in Memories of Home, 13-16 .............................55

Example 3.20: Hsiao "Playground" in Memories of Home, 29-30 ............................56

Example 3.21: Hsiao "Playground" in Memories of Home, 43-44 .........................56

Example 3.22: Hsiao "Playground" in Memories of Home, 19-61 ...........................57

Example 3.23: Hsiao "Playground" in Memories of Home, 13-30 ..........................58

Example 3.24: Hsiao "Playground" in Memories of Home, $33-36 \ldots \ldots \ldots \ldots \ldots \ldots \ldots \ldots \ldots \ldots . . . \ldots 59$ 
Example 3.25: Hsiao "Playground" in Memories of Home, 37-47 .............................59

Example 3.26: Hsiao "Playground" in Memories of Home, 49-52 ..........................60

Example 3.27: Hsiao "Playground" in Memories of Home, 57-61 ..........................60

Example 3.28: Hsiao "Ancient Taiwanese Melody" in Memories of Home, 1-16 ...............62

Example 3.29: Hsiao "Ancient Taiwanese Melody" in Memories of Home, 21-32 .............63

Example 3.30: Hsiao "Ancient Taiwanese Melody" in Memories of Home, 37-40 ...............64

Example 3.31: Hsiao "Elegy" in Memories of Home, 1-4 .................................66

Example 3.32: Hsiao "Elegy" in Memories of Home, 9 ..................................66

Example 3.33: Hsiao "Elegy" in Memories of Home, 9-16 ...............................67

Example 3.34: Hsiao "Elegy" in Memories of Home, 17-20 ..............................68

Example 3.35: Hsiao "Elegy" in Memories of Home, 21-22 ..................................69

Example 3.36: Hsiao "Elegy" in Memories of Home, 21-22 .................................69

Example 3.37: Hsiao "Elegy" in Memories of Home, 44-47 .................................. 70

Example 3.38: Hsiao "Elegy" in Memories of Home, 48-49 ................................ 70

Example 3.39: Hsiao "Elegy" in Memories of Home, 1-3 ................................ 72

Example 3.40: Hsiao "Frolic" in Memories of Home, 4-18 .................................. 73

Example 3.41: Hsiao "Frolic" in Memories of Home, 13-15 ................................ 74

Example 3.42: Hsiao "Frolic" in Memories of Home, 13-15 ................................ 74

Example 3.43: Hsiao "Frolic" in Memories of Home, 22-27 ................................ 75

Example 3.44: Hsiao "Frolic" in Memories of Home, 40-54 ............................... 76

Example 3.45: Hsiao "Frolic" in Memories of Home, 46-54 ................................... 77

Example 3.46: Hsiao "Frolic" in Memories of Home, 55-60 ............................... 78

Example 4.1: Hsiao "The Angel from Formosa," 5-8 ...................................... 80

Example 4.2: Hsiao "The Angel from Formosa," 9-16 ..................................... 81

Example 4.3: Hsiao "The Angel from Formosa," 32-46 ...................................... 83

Example 4.4: Hsiao "The Angel from Formosa," 38-40 .....................................8

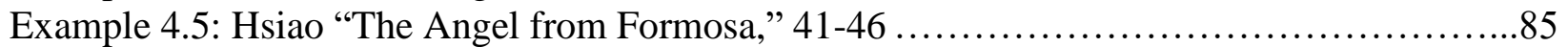

Example 4.6: Hsiao "The Angel from Formosa," 59-62 ................................... 86 


\section{LIST OF TABLES}

Table 3.1: Structure of "The Vagabond" ...............................................44

Table 3.2: Structure of "Playground" ....................................................54

Table 3.3: Structure of "Ancient Taiwanese Melody" ....................................61

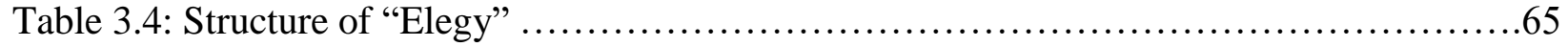




\section{Chapter One}

\section{Life and Musical Background of Tyzen Hsiao}

Tyzen Hsiao (1938-2015) grew up in a family of music and Christian faith in Kaohsiung, ${ }^{1}$ Taiwan. He frequently used religious quotes and scripture references in his works. Both of his parents enjoyed classical music, which was a strong influence on Hsiao from an early age. When he talked about his childhood, he often told the interviewer how lucky he was to be born into a musical family; this was very rare in Taiwan before 1940, when Taiwan was still a colony of Japan. Hsiao said, "It was such a heavenly bliss then to own a piano at home. So, that is why I just said "I was born lucky!", As described in "An Interview with Hsiao Tyzen," he divided his music compositions into three periods: the early period from 1967-1977, the middle period from 1977-1985, and the late period from 1985 to present. $^{3}$

\section{A. Childhood to Early Period (1938-1967)}

Hsiao was born on January 1, 1938, in Kaohsiung, Taiwan, to a dentist father, who eventually wanted Hsiao to become a medical doctor, and a pianist mother, who was considered one of the earliest Taiwanese students to study music in Japan. His grandfather was a minister at a Presbyterian church. Hsiao started taking piano lessons at the age of five with his mother Hsiao Lin Xueyun, who frequently enjoyed listening to Handel's Messiah at home, while his father preferred violin music such as Beethoven's Violin Concerto. ${ }^{4}$

\footnotetext{
${ }^{1}$ A port city in the southern part of Taiwan.

${ }^{2}$ Chi-Min Chen, Catalogue of Tyzen Hsiao's Compositions (Council for Cultural Affairs, Taiwan, 2009), 27.

${ }^{3}$ Zong-Rong Lee, An Interview with Tyzen Hsiao, In Romanticism with Deep Affection (Taipei: Wang-Chuan-Feng, 1999), 34-35.

${ }^{4}$ Hua-Rong Yen, The Romantic Taiwanese (Taipei: Times Culture, 2002), 16.
} 
As a deeply religious person, Hsiao thought hymns were the best materials for him to learn music. He also thought that hymns were the best teaching-method books as well, because he believed that these pieces were written by amazing composers, both from western countries and also from Taiwan. To him, church music was not only for liturgy or services. This feeling led him to explore the beauty of church music, along with the compositions of Beethoven and Mozart, whose music he had heard throughout his childhood.

When Tyzen Hsiao was 16, he started taking piano lessons at a Presbyterian church; he regarded these lessons very seriously. During his high school years, he had several arguments with his father about Hsiao's decision to be a musician. However, the president of his high school told his father, "If your son becomes a doctor then he will be an ordinary one in his career, because he has no desire for it; if he becomes a musician, his future will be brilliant and unlimited." That was the moment when Hsiao's father decided to support Hsiao and encourage him to pursue his dream. In 1956, he enrolled in the music department of Provincial Taiwan Normal University. ${ }^{6}$ Five years later, he started being fascinated with composing music. In that same year, 1961, he composed his very first work for chorus, entitled "Farewell," under the guidance of a distinguished Taiwanese professor and composer Hsu Tsang-Houei (1929-2001), who had graduated from the Paris Conservatory in 1959. In Hsiao's early years of composing, he was drawn to writing music for churches and children's choirs, which for him were readily accessible.

\footnotetext{
${ }^{5}$ Yen, 22.

${ }^{6}$ Now National Teachers Normal University (NTNU), located in Taipei, a northern city of Taiwan.
} 
After graduating from the university, Hsiao married Ms. Gao Renci, the daughter of a well-known family in Tainan. In the same year, Hsiao became a music teacher in a secondary high school in Kaohsiung. This lasted for a year and a half; but soon he discovered that this was not fulfilling his wish to accumulate more musical knowledge. In 1965, he went to Japan with his wife, enrolled at the keyboard department of Musashino Academy of Music, and started his music study in Japan. ${ }^{7}$ At Musashino, he studied piano with Nakane Nobue and composition with Fujimoto Hideo. During his study in Japan, Hsiao and his colleagues found many talented pianists competing with each other; but he did not consider himself as competitive as the others. That was also when Hsiao decided to focus on composing instead of performing. Another interesting thing he observed when he was in Japan was an inverted sense of musical ethnicity. That is, people played and listened to classical music from the western world; but the Japanese local music and folk songs were rarely heard in public other than during the carnival and festival seasons. In response, Hsiao decided to write music about Taiwan, including Taiwanese folk elements, so that this music could be heard worldwide. ${ }^{8}$ At that time, he was 29 years old

\section{B. First Compositional Period (1967-1977)}

In 1967, Hsiao graduated from Musashino and returned to Taiwan. He was immediately hired to teach music at Wenzo Ursuline Female Junior College of Modern Languages, and Provincial Kaohsiung Female Teachers' Junior College, ${ }^{9}$ Private Tainan Junior College of Home Economics, ${ }^{10}$ and the music department of Tainan Theological College and Seminary (his grandfather's alma mater). He had a very busy schedule of teaching, performing, and taking

\footnotetext{
${ }^{7}$ Chi-Min Chen, Catalogue of Tyzen Hsiao's Compositions (Council for Cultural Affairs, Taiwan, 2009), 155.

${ }^{8}$ Ibid.

${ }^{9}$ Now called National Kaohsiung Normal University (NKNU).

${ }^{10}$ Now the Tainan University of Technology.
} 
piano and composition lessons with Prof. Robert Scholz (1902-1986), ${ }^{11}$ whom he considered not only his teacher, but also a father and friend. ${ }^{12}$ When Hsiao was an adjunct professor in Tainan, he also met Ms. Isabel Taylor (1909-1992), ${ }^{13}$ whose performance was so sophisticated and delicate that Hsiao found it fascinating. Tsai suggests that Taylor's performing style influenced both Hsiao's belief in Christianity and also his writing of religious music. ${ }^{14}$

In his first music period, Hsiao was not only a teacher, but also performed several concertos with orchestra in Taiwan. The most notable concerts he gave were performances of Grieg's Piano Concerto in A minor with Tainan B.B.B. Orchestra in 1967 and Beethoven's Piano Concerto No. 3 with Kaohsiung Symphony Orchestra in 1972.

It was during this period that Prof. Sholz encouraged him to write instrumental music. He wrote several instrumental works including 台灣頌 (The Song of Taiwan) (1970) for violin and piano, 前奏與賦格 (Prelude and Fugue) (1970) for violin, cello, and piano, 夢幻的恆春小調 (A Fantastic Heng-Chun ${ }^{15}$ Melody) (1973) for violin and piano, 冥想曲 (Meditation) (1975) for violin and piano, and 華麗的華爾滋 (Waltz Brilliant) (1973) for two pianos, op. 38, which he dedicated to his teacher and friend, Prof. Sholz. His orchestral works include two light operettas: 快樂的農村 (Happy Farmhouse) (1968) and 我家花園真美麗 (How Beautiful is My Garden) (1969). Two collections for solo piano, and several chamber and vocal pieces were published between 1974 and 1977: 詩影 I (Poetic Echo I), 詩影 II (Poetic Echo II), 蕭泰然的合唱曲集與

\footnotetext{
${ }^{11}$ An Austrian musician who traveled to Taiwan as a Fulbright lecturer and later married a Taiwanese pianist. Until his death, Scholz stayed in Taiwan, which he called his permanent home.

${ }^{12}$ Hen-Zhe Lin, A Collection of Tyzen Hsiao's Musicological Forum and Articles (Taipei: Wang-Chun-Feng Wen-Hua, 1999), 22.

${ }^{13}$ Isabel Taylor was a Canadian missionary who was sent to Taiwan to be a music teacher when she was eighteen.

${ }^{14}$ Ming-Yuen Tsai, The world-class Taiwanese composer, Tyzen Hsiao (Taipei: Yu-San-She, 2006), 86-87.

${ }^{15}$ Heng-Chun is the southernmost township in Taiwan. It is also the entryway to the famous Kenting National Park.
} 
聖歌 (Hsiao Tyzen Chorale Collection and Sacred Songs), and a transcription of his 思鄉曲

(Nostalgia for Home) (1976) as an orchestral work. 鄉愁 (Miss Home) was requested by

Taiwanese conductor Guo Meizhen for the Huamei Youth String Orchestra. Ms. Guo took the orchestra on a tour to the United States to perform this piece. It was also the first time one of Hsiao's pieces was heard in the United States.

Among all his compositions in this period, Jesus Christ (1971) was the biggest and most important work. This was Hsiao's first oratorio and he used Bible stories selected by his father as the libretto of the work. The instrumentation includes two flutes, two oboes, two clarinets, two bassoons, four horns, three trumpets, three trombones, tuba, timpani, percussion, piano, strings, and a four-part chorus. ${ }^{16}$

\section{Second Compositional Period (1977-1985)}

In 1977, Hsiao was swindled by a close friend, leaving his finances in ruins. His wife, hoping to alleviate the stress of this financial disaster, suggested and ultimately encouraged him to stay with her younger sister in Atlanta, Georgia. Hsiao bought the ticket and brought three hundred dollars with him, hoping to make a new start and help his family get through the difficulty. As circumstances unfolded after his arrival in America, he could not return to Taiwan until 1995. After moving to Los Angeles in 1978, Hsiao made a living by teaching piano in the Taiwanese community there and by selling gifts and souvenirs in a shop he rented in a mall. In

\footnotetext{
${ }^{16}$ Pei-Ning Ku, Songs by Hsiao Tyzen: The Interaction Between His Music And Taiwan. DMA dissertation, University of Nevada (Las Vegas, 2014), 19.
} 
the shop, he kept a rented Steinway piano, which he played for his friends when business was slow.

Hsiao began to struggle with depression as the reality settled in regarding his financial situation and the enormous distance between him and his family. There was a whole year during which Tyzen Hsiao did not complete any new compositions, until he began participating in a church that met every Saturday evening at a Taiwanese member's house. During the meetings, he discovered that these immigrants, who had left their country to pursue a better life for their families, enjoyed singing his arrangements of Taiwanese folk and popular songs. This experience began to inspire him to write music again.

During this time, he composed many songs for Taiwanese immigrants who were away from their homeland, such as 出外人 (The Vagabond) (1978) and 點心擔 (The Street Vendors) (1978). When his friends in Los Angeles asked him if he could compose some new songs for them to sing, he immediately consented, in part because he also felt the need to compose modern art songs that were specifically intended for Taiwanese people. This is how "The Vagabond" was born. After he finished writing this song, it was immediately heard by many Taiwanese immigrants all over the world. They recorded the song onto cassette tapes so that anyone could listen to it in the car. Hsiao received letters from many people after they heard this song. They said, "Prof. Hsiao, thank you for writing the song. Your music is an expression of our feelings, feelings we have forgotten were there after so many years abroad." ${ }^{17}$ Another group of people wrote to him and let him know about their reaction after listening to this song - they had cried. Here are the lyrics of the song, in Chen's translation:

\footnotetext{
${ }^{17}$ Chi-Min Chen, Catalogue of Tyzen Hsiao's Compositions (Council for Cultural Affairs, Taiwan, 2009), 33.
} 
We are all vagabonds here from the faraway Taiwan,

Though I can speak English fluently, yet it can't speak to my heart.

We are all vagabonds here from the faraway Taiwan,

Where there are our friends and family to miss from time to time.

They say the America is heaven, and they long to move there;

But, if they ask me, "Is that true?",

I will reply, "No, my heaven is not here". ${ }^{18}$

The lyrics immediately spoke to their heart, expressing their nostalgic feelings and love for their homeland, Taiwan. Right after Hsiao composed “The Vagabond,” he wrote 出頭天進行曲

(March of Democracy) (1980), which changed his life by getting him put on a blacklist ${ }^{19}$

maintained by the Kuomintang (KMT), which was the leading political party in Taiwan during

that time. As a result, Hsiao was forbidden from returning to Taiwan, a ban which lasted until

1995, when the new government eliminated him from the blacklist. ${ }^{20}$

“The March of Democracy," composed in 1980, became very popular in the Taiwanese

immigrants' community; his friend Pi-Long Hsu, who had been supporting him in California,

wrote the lyrics. Hsiao directly borrowed from the famous gospel song "We Shall Overcome," a

non-violent protest song and unofficial anthem associated with the American civil rights

movement, through which the oppressed African-American population sought equal rights

shared by other Americans. ${ }^{21}$

Hsiao and his friend Pi-Long Hsu organized the North American Taiwanese Humanities

and Arts Association in 1983, in part to promote Taiwanese music. Hsiao started writing more

\footnotetext{
18 Ibid.

${ }^{19}$ It will be referred later.

${ }^{20}$ Hsiao was famous for supporting Taiwan's independence, which was not accepted at the time and which is still a controversial topic in the world, especially to China. During that time, the KMT banned news and all publications which might promote this thought to the public. Hsiao was placed on the blacklist due to the songs he wrote that promote freedom for Taiwanese people.

${ }^{21}$ Pei-Ning Ku, Songs by Hsiao Tyzen: The Interaction Between His Music And Taiwan. DMA dissertation, University of Nevada (Las Vegas, 2014), 20.
} 
religious songs for both solo and mixed voices, arrangements of Taiwanese folk songs, and popular songs for solo instruments and ensembles. In 1982, Hsiao and Hsu held two Southern California Thanksgiving concerts at the Crystal Cathedral in Orange County. The main purpose of these concerts was introducing works of Taiwanese composers such as Weyne Jiang, TzuYuan Kuo, and Tsang-Houei Hsu, who had been Hsiao's teacher during his college years in Taiwan. ${ }^{22}$ In 1983, Hsiao took the North America Taiwanese Humanities and Arts Association chamber orchestra to perform in Singapore for the first time; they also performed in ten cities of the United States.

\section{Late Period (1985-2015)}

When Hsiao was composing and arranging Taiwanese songs, he discovered the need to learn about modern compositional forms and styles. At the age of 48 , he enrolled to begin his Master's program at California State University, Los Angeles, where he studied composition with Dr. Byong Kon Kim and piano performance with Dr. Milton Stern; Stern later became a close friend and mentor for Hsiao. ${ }^{23}$

During his study at CSULA, he received helpful guidance on both composition and piano playing. He composed several orchestral works, including his graduation piece Formosa Symphony, op. 49 (1987), ${ }^{24}$ Violin Concerto in D Minor, op. 50 (1988), Cello Concerto in C Major, op. 52 (1990), Piano Concerto in C Minor, op. 53 (1992), and 1947 Overture (1994). On

\footnotetext{
${ }^{22} \mathrm{Ku}, 21$.

${ }^{23}$ Hen-Zhe Lin, A Collection of Tyzen Hsiao's Musicological Forum and Articles (Taipei: Wang-Chun-Feng Wen-Hua, 1999), 33.

${ }^{24}$ In 1542, Portuguese sailors on their way to Japan came across an island not identified on their maps. Amazed at the forestcloaked land, they shouted, "Ilha Formosa," meaning "Beautiful Island." The island had thus come to be known as Formosa, which was to become what we know today as Taiwan.
} 
February 28, 1947, a tragedy which caused tens of thousands of deaths to happen in Taiwan.

Hsiao dedicated his "1947 Overture" to the victims who died in this massacre.

The 1947 conflict flared after Chinese Nationals troops, also known as the Kuomintang (KMT), arrived in Taiwan at the end of WWII. The Japanese had ruled Taiwan as a colony for 43 years, and most of the ethnic Chinese living on the island welcomed the soldiers coming to free them. But excitement waned as the KMT looted houses and used Taiwan's resources to support its ongoing civil war with the Communists, creating food shortages and runaway inflation. Those coming from China looked suspiciously at the Japanese-influenced Taiwanese, while the Taiwanese grew resentful at the influx of mainlanders, or waishengren.

Pent-up frustrations came to a head Feb. 27 after police beat a woman selling contraband cigarettes and accidentally shot and killed a bystander. The next day, crowds gathered at a government building in Taipei demanding justice, and Chinese Gov. Chen Yi allowed officers to open fire on the crowd, killing several people and setting off uprisings around the island. In response, the KMT declared martial law and called in troops from China, who "indulged in three days of indiscriminate killing and looting," according to a March 1947 New York Times article. Yi's troops killed many of Taiwan's elite, suspecting them of instigating the uprisings or siding with the Japanese. A period known as "White Terror" followed, as the KMT continued cracking down on those they suspected of opposition - either real or imagined-labeling them communist spies. Both those living in Taiwan and those who escaped from China were targeted, leading to more than 140,000 imprisonments and thousands of deaths.

The February 28 death toll is estimated somewhere between 10,000 and 30,000, although the exact number is unknown. Many victims' families kept silent for the next 50 years out of fear of reprisals. By the time martial law had lifted in 1987 and democracy allowed for openness about the events, many who had lived through it had already passed away and their children knew little about what happened. ${ }^{25}$

When Hsiao was working on the Violin Concerto in D Minor, his father passed away and his mother was very sick in bed. Despite his painful family situation, Hsiao still worked on this composition 18 hours per day for three months. After he finished the work and handed it to the Taiwanese-American violinist Cho-Liang Lin, who read it through; Lin immediately congratulated Hsiao and told him how grateful and amazed he was. At the world premiere, the conductor of the San Diego Symphony Orchestra, Ohyama Heiichiro, led the orchestra with Cho-Liang Lin on November 13, 1992. After the concert ended, Hsiao, Lin, and Heiichiro received a five-minute-long standing ovation from the audience. During an interview, Hsiao said,

\footnotetext{
${ }^{25}$ Angela Lu, Taiwan Remembers 1947 Massacre. world.wng.org/2015/03/taiwan_remembers_1947_massacre. Posted March 2
} 2015. 
"I accomplished this concerto in one attempt so as to be my final testament to all the Taiwanese people." 26

From the year of 1988 to 1990, he wrote the Cello Concerto in C Major, which was premiered by Felix Fang, the son of his close friend Qingliang Fang, with the San Diego Symphony Orchestra in May 1995. Before he started working on the Piano Concerto in C Minor, his friend Dr. Hen-Zhe Lin, who was the president of Taiwanese United Fun (TUF) in Southern California, introduced a pianist friend, Ms. Fangyu Chen, who later wrote an essay entitled "The Analysis of Tyzen Hsiao's Piano Works"; her presentation of the essay to Hsiao encouraged him to write a piano concerto. In April 1994, his Piano Concerto in C minor was performed in the Orpheum Theater in Vancouver by Taiwanese pianist Jonathan Tang and the Vancouver Symphony Orchestra. Later on, Hsiao's friend and former teacher, Dr. Milton Stern, premiered this piano concerto in 1995 in the United States and, in 1996, in Taiwan. After Dr. Stern's concert in Taiwan in 1996, Ms. Chen told a journalist,

Hsiao's three concertos were truly monumental in his whole life. Friendship, nostalgia, and faith emanated from his music of such confused emotions. What he created was the essence which deeply reflected his pureness and his own inspiration, and what he achieved was, just like Titan, directing to an eternal victory. ${ }^{27}$

After 1994, due to poor health, Tyzen Hsiao did not compose as much as he had previously done. When he was working on the second page of "1947 Overture" before Christmas in 1993, he was rushed to the hospital and underwent emergency surgery to repair a ruptured aorta hemangioma. When he was suffering from pain, he prayed to God,

\footnotetext{
${ }^{26}$ Chi-Min Chen, Catalogue of Tyzen Hsiao's Compositions (Council for Cultural Affairs, Taiwan, 2009), 48.
}

${ }^{27}$ Chen, 50. 
Ah! Please do not take my life away now. Let me finish my music. But, if You cannot wait to summon me back to Heaven from my post, You have to write it for me then. ${ }^{28}$

Fortunately, Hsiao recovered from the surgery and he was finally allowed to return to his Taiwan, his beloved homeland, in 1995. When he arrived in Taiwan, many concerts and interviews were waiting for him. He was appointed the resident composer of Young Musicians Foundation Debut Orchestra by the Council for Cultural Affairs, Taiwan, for a year. He started conducting his own pieces in 1995, including the premier of "1947 Overture" at National Dr. Sun Yat-Sen Memorial Hall in Taipei; in the same year, Hsiao conducted this piece again, with the Hocheng Symphony Orchestra at the National Concert Hall in Taiwan in December. After finishing his "Formosa Symphony" in 1987, Hsiao had not been able to have it performed with orchestra. This changed when he met the conductor of the Russian Federal Orchestra, Vakhtang Jordania, through Hsiao’s former piano student Wen-Wan Chen in Vancouver in 1998, after Hsiao's concert there. Jordania was very impressed by Hsiao’s works because they were full of Hsiao's passion and love for Taiwan. Maestro Jordania decided to premiere Hsiao's "Formosa Symphony" at the Tchaikovsky Concert Hall in Moscow in January, 1999. Even though Hsiao's doctor recommended against making the trip, Hsiao still wanted to witness the world premiere of this symphony in Moscow, because having his works performed in Moscow had been a dream of his. As Maestro Jordania lifted his baton, Hsiao's dreams were woven into the orchestra melodies. The concert was a huge success and the thunderous applause from the audience made Hsiao feel overwhelmed with emotion. ${ }^{29}$

\footnotetext{
${ }^{28}$ Chen, 27.
}

${ }^{29}$ Chen, 59. 
Hsiao's “1947 Overture” with a large chorus and Piano Concerto in C Minor were performed in Moscow in April, 2000, conducted by Jordania. Hsiao recalled the two concerts in this way:

The Russia Federal Symphony Orchestra played my music, and the most peculiar thing was they sang the Taiwanese lyrics of my music with an amazing accurate and beautiful pronunciation. It came to me that we used to learn foreign languages to sing German and Italian songs, however, reversely, we now see foreigners who began to learn our language. An old saying: "every dog has its day" came to my mind: we used to learn to sing foreign songs before but it's their turn now to learn our songs. Therefore, I believe that it is a wonderful way to sing our Taiwanese language to the whole world. ${ }^{30}$

Between 1994 and 2001, despite ongoing health problems, Hsiao still managed to finish several significant works. These range from songs to small chamber works and a large-scale orchestral cantata. Here is a listing of these works:

Ode to New Taiwan (1996) (art song)

Piano Trio, op. 58 (1996)

The Spirit of Taiwan (1998) (art song)

Song of Scars (1999) (art song)

Ode to Yushan ${ }^{31}$ (1999) (choral piece for mixed voices)

The Prodigal Son (2000) (cantata)

Ihla Formosa Requiem for Martyr di Formosa, op. 63 (2001). ${ }^{32}$

The Hsiao Tyzen Foundation was formed in 1998 to provide and promote publication of Hsiao's art songs and other compositions. When he was composing another large-scale orchestral work, 愛河交響曲 (Love River ${ }^{33}$ Symphony) (2001), he suffered another aortic aneurysm in November 2001 and a stroke in December 2002. These two health emergencies

\footnotetext{
${ }^{30}$ Chen, 36.

${ }^{31}$ Yushan, also known as Jade Mountain, is the highest mountain in Taiwan and the fourth highest mountain on an island.

${ }^{32}$ Pei-Ning Ku, Songs by Hsiao Tyzen: The Interaction Between His Music And Taiwan. DMA dissertation, University of Nevada (Las Vegas, 2014), 23.

${ }^{33}$ Love River is a river in the southern Taiwan. It originates in Renwu District in Kaohsiung City, which is the biggest city in the southern Taiwan. Love River is the spine of Kaohsiung. It plays an important role as a cultural spot for tourists.
} 
stopped him from finishing this symphony. In 2013, Hsiao was diagnosed with nasopharyngeal cancer and received 35 chemotherapy treatments that made him feel even weaker. ${ }^{34}$ Tyzen Hsiao passed away in Los Angeles, California, on February 24, 2015, at the age of 77.

\section{Chapter Two}

\section{Compositional Styles and Musical Influences}

In addition to the effects of his early training, Tyzen Hsiao was deeply influenced by his Christian faith and by being for many years an immigrant who could not return to his homeland. His music reveals traces of many different compositional styles, including hymn tunes,

\footnotetext{
${ }^{34}$ Pei-Ning Ku, Songs by Hsiao Tyzen: The Interaction Between His Music And Taiwan. D.M.A. dissertation, University of Nevada (Las Vegas, 2014), 24.
} 
Romanticism, and Taiwanese folk tunes. Hsiao himself has mentioned being influenced by Mozart, Chopin, Debussy, Bartok, and Rachmaninoff. ${ }^{35}$ He said, “Although I have studied all kinds of music, from Medieval to contemporary, the Romantic period music is my favorite repertoire."36

This chapter discusses four aspects of his compositional characteristics: Neo-Romanticism, contemporary style, church influence, and Taiwanese cultural elements.

\section{A. Neo-Romanticism}

A friend of Hsiao's used to tell him that Hsiao was very good at resolving dissonance to a more colorful sound. He tended to write long and lyrical melodic lines, to present a singing effect. In Hsiao's work, the home tonality of the piece usually is not fully established until the end. It is typical to see that one of his compositions might end in $\mathrm{C}$ major, but start in another key instead. His use of chromatic scales and modulation seems to relate to some of Chopin's writing styles. In the book Tyzen Hsiao: Piano Concerto in C Minor, op. 53, Kuo says, "In his harmonic treatment, he divined the appropriate chords, and showed preference for chromatic progression and modulations, which he felt heightened the emotional content of the music."37 Hsiao also used the traditional diatonic major/minor system as the foundation of harmonic modulations in his music. The term cantabile appears in many of his pieces, such as the solo piano work "The Angel from Formosa" and the second piece of "Memories of Home."

Hen-Zhe Lin, the author of A Collection of Tyzen Hsiao's Musicological Forum and Articles, believes that the early period of Hsiao's music was influenced by Chopin. He compares

\footnotetext{
${ }^{35}$ Hen-Zhe Lin, A Collection of Tyzen Hsiao's Musicological Forum and Articles (Taipei: Wang-Chun-Feng Wen-Hua, 1999), 152.

${ }^{36}$ Hua-Rong Yen, The Romantic Taiwanese (Taipei Times Culture, 2002), 43.

${ }^{37}$ Rita C. Kuo, Tyzen Hsiao: Piano Concerto in C Minor, Op. 53 (California: Taiwanese Composers Foundation, 1993$), 40$.
} 
Chopin's Prelude in E Minor with Hsiao's Piano Concerto in C Minor. The opening of Chopin's prelude and theme two of the first-movement exposition of Hsiao's piano concerto both reveal a chromatic melodic line in the top voice that helps to create harmonic flow. We see these similarities in the examples below:
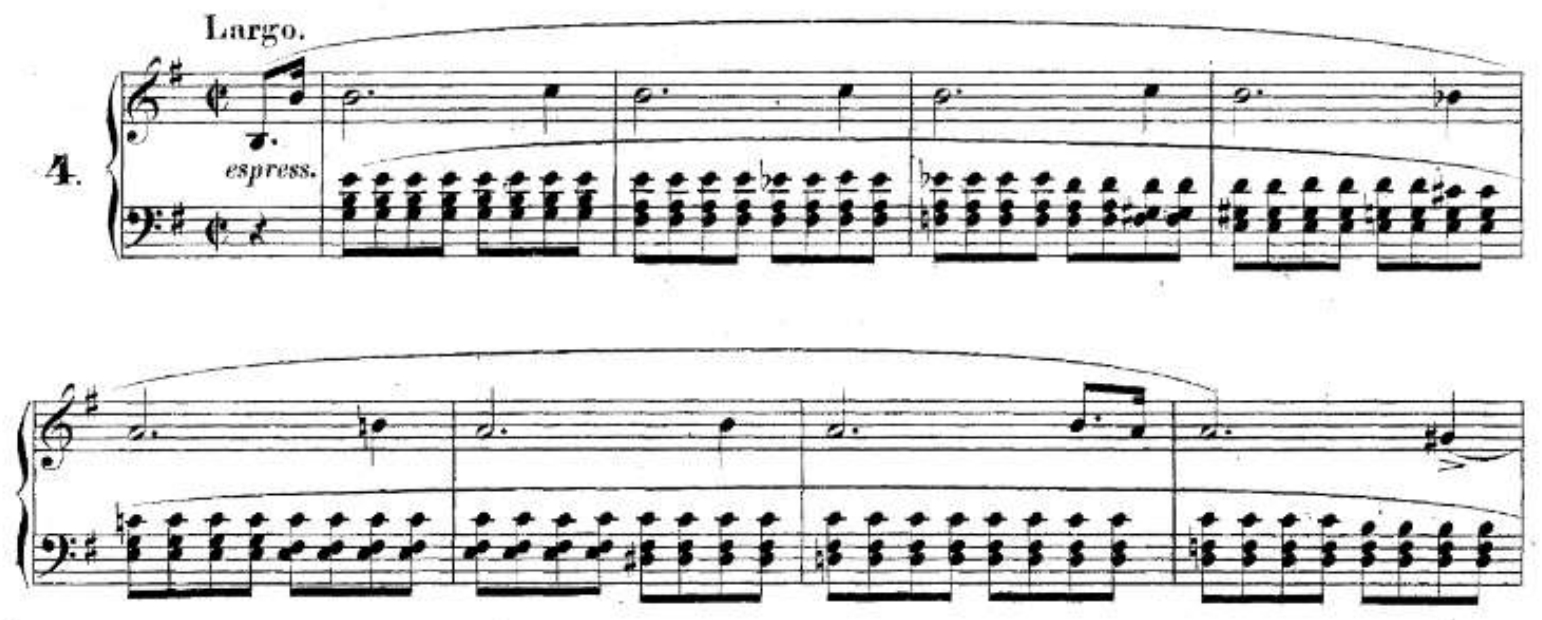

(C) 1878 by Breitkopf und Härtel. Used with Permission

Example 2.1. Frederic Chopin, Prelude in E Minor, mm. 1-8. ${ }^{38}$

\footnotetext{
${ }^{38}$ Frederic Chopin, Preludes for Piano (Leipzig: Breitkopf und Härtel, 1878), 4.
} 

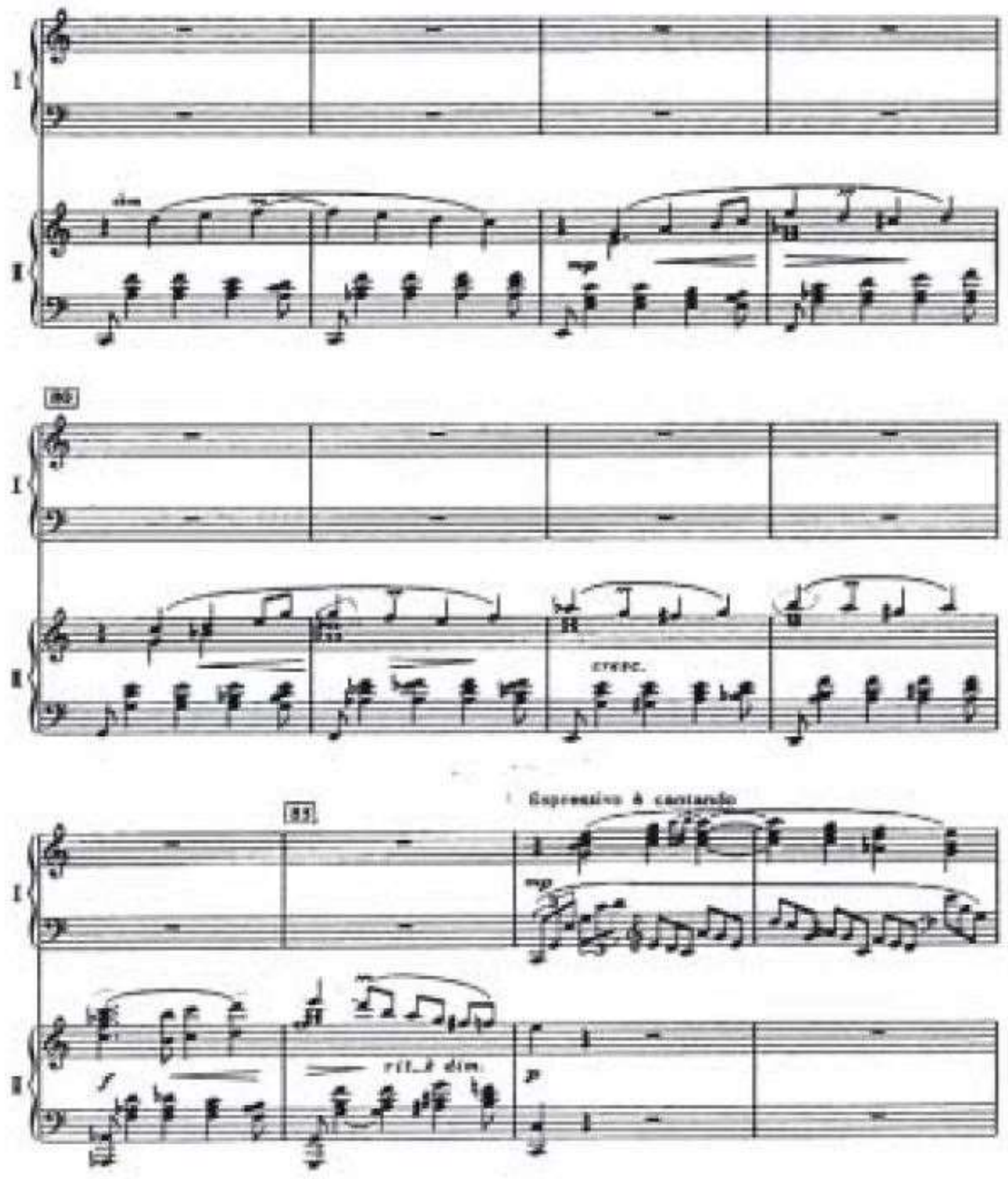

(C) 1992 by Formosa Singers Publisher. Used with Permission

Example 2.2. Tyzen Hsiao, Piano Concerto in C Minor, mm. 76-87. ${ }^{39}$

The Taiwanese pianist Fang-Yu Chen thinks that Hsiao's piano concerto not only shows his strong feelings for Taiwan, but also brings out the lyrical parts by the touch and sound

${ }^{39}$ Lan-Fang Lin, The Study of Hsiao Tyzen's Piano Music with an Analysis of Piano Concerto in C Minor, Op. 53 (National Sun Yat-Sen University, 2003), 27. 
of the piano. ${ }^{40}$ The pianist has to be as sensitive to sound as a singer, because this piece requires precise control of volume and dynamics. The performer must also convey a sense of movement, like a dancer on the stage. To Chen, these are necessary requirements for playing Hsiao's piano concerto.

Lin's article also mentions rubato in Chopin's Mazurka op. 6, no. 1. This term 'rubato" does not mean playing with an extremely free tempo; rather, it means to play with flexibility without losing control. ${ }^{41}$

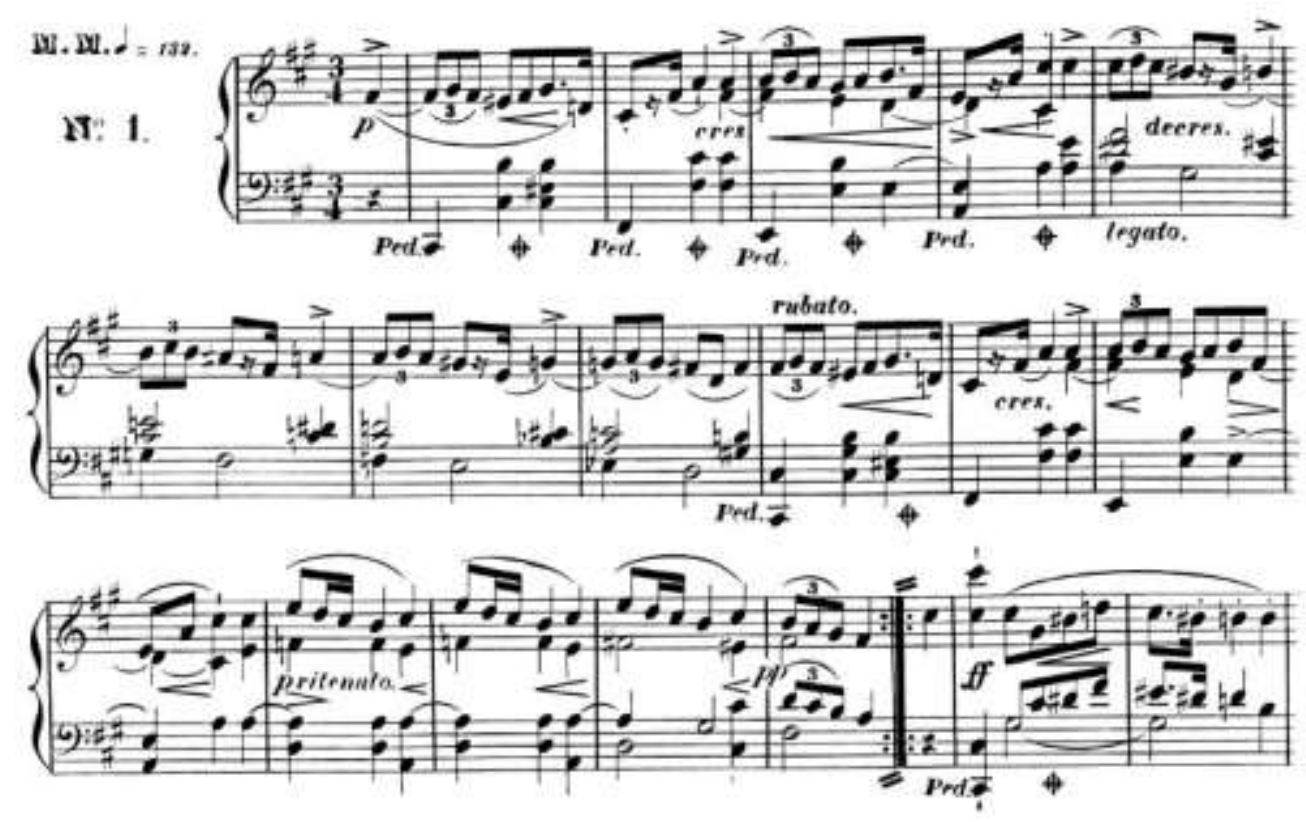

(C) 1880 by Breitkopf und Härtel. Used with Permission

Example 2.3. Frederic Chopin, Mazurkas for Piano, Op. 6, No. 1, mm. 1-18. ${ }^{42}$

Hsiao was influenced not only by Chopin but also by Rachmaninoff. As Rachmaninoff was a Russian Romantic composer, many of his works contain rich chords and harmonies in a Russian national style. Lan-Fang Lin uses Rachmaninoff's Elegie and Piano Concerto in C

\footnotetext{
${ }^{40}$ Hsieh, Pei-Chun, A Study of Structure and Performance Interpretation of Tyzen Hsiao's Piano Music: Memories of Home and Selections from Piano Pieces for Children. Master's dissertation, Fu Jen Catholic University, (Taipei, 2012 ), 10.

${ }^{41}$ Hen-Zhe Lin, A Collection of Tyzen Hsiao's Musicological Forum and Articles (Taipei: Wang-Chun-Feng Wen-Hua, 1999), 118.

${ }^{42}$ Frederic Chopin, Mazurkas for Piano (Leipzig: Breitkopf und Härtel, 1880), 1.
} 
Minor as examples to show his influences on Hsiao's piano concerto. The third movement of Hsiao's piano concerto shows a compositional technique which is similar to the beginning melodic line in the right hand of Rachmaninoff's Elegie. We can also see the arpeggio-like motions in the left hand in both works. ${ }^{43}$

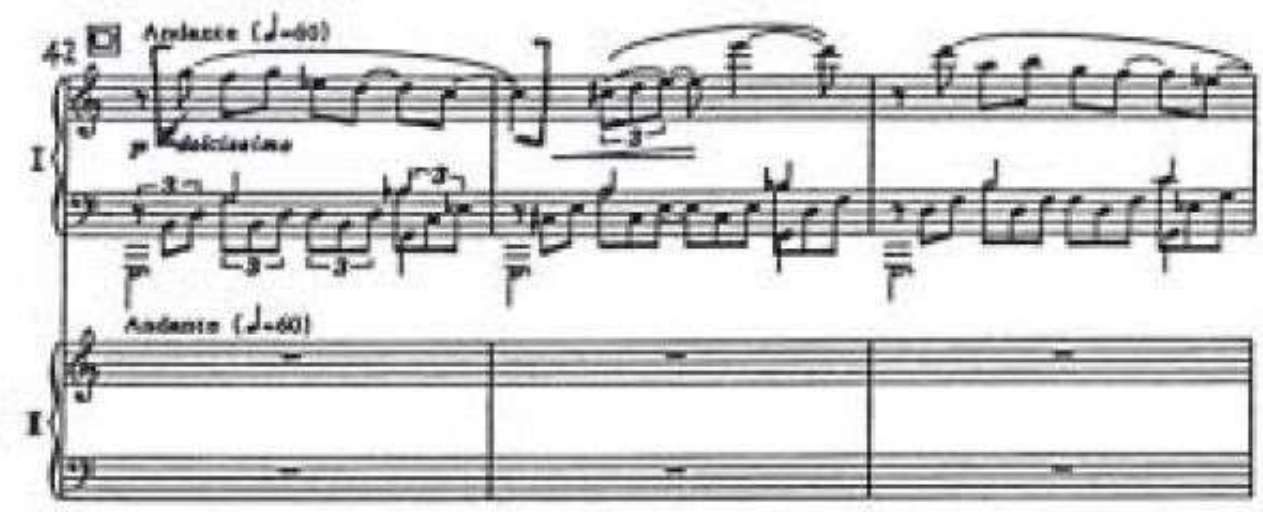

(C) 1992 by Formosa Singers Publisher. Used with Permission

Example 2.4. Tyzen Hsiao, Piano Concerto in C Minor, mm. 42-44. ${ }^{44}$

\footnotetext{
${ }^{43}$ Lan-Fang Lin, The Study of Hsiao Tyzen's Piano Music with an Analysis of Piano Concerto in C Minor, Op. 53 (National Sun Yat-Sen University, 2003), 28.

${ }^{44}$ Ibid.
} 


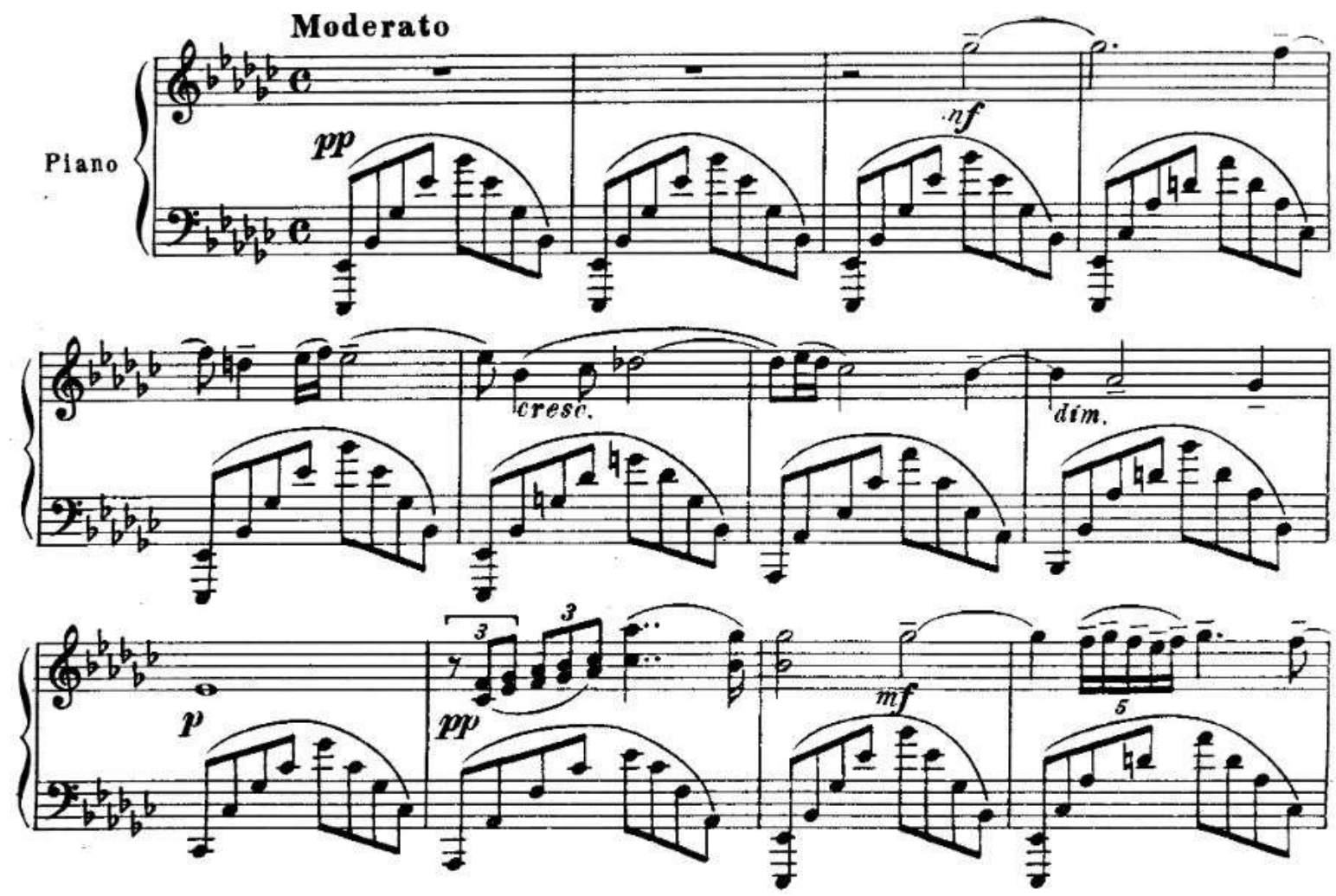

(C) 1947 by Muzgiz. Used with Permission

Example 2.5. Sergei Rachmaninoff, Morceaux de Fantaisie, Op. 3 mm. 1-12.45

Hsiao chose triplet rhythms for the left hand, instead of the duplet eighth notes we see in the Rachmaninoff example. In the openings of both piano concertos, the composers use the orchestra to play the melodic line, having the soloist play the accompaniment part.

\footnotetext{
${ }^{45}$ Sergei Rachmaninoff, Morceaux de fantaisie, Op.3 (Moscow: Muzgiz, 1947), 1.
} 

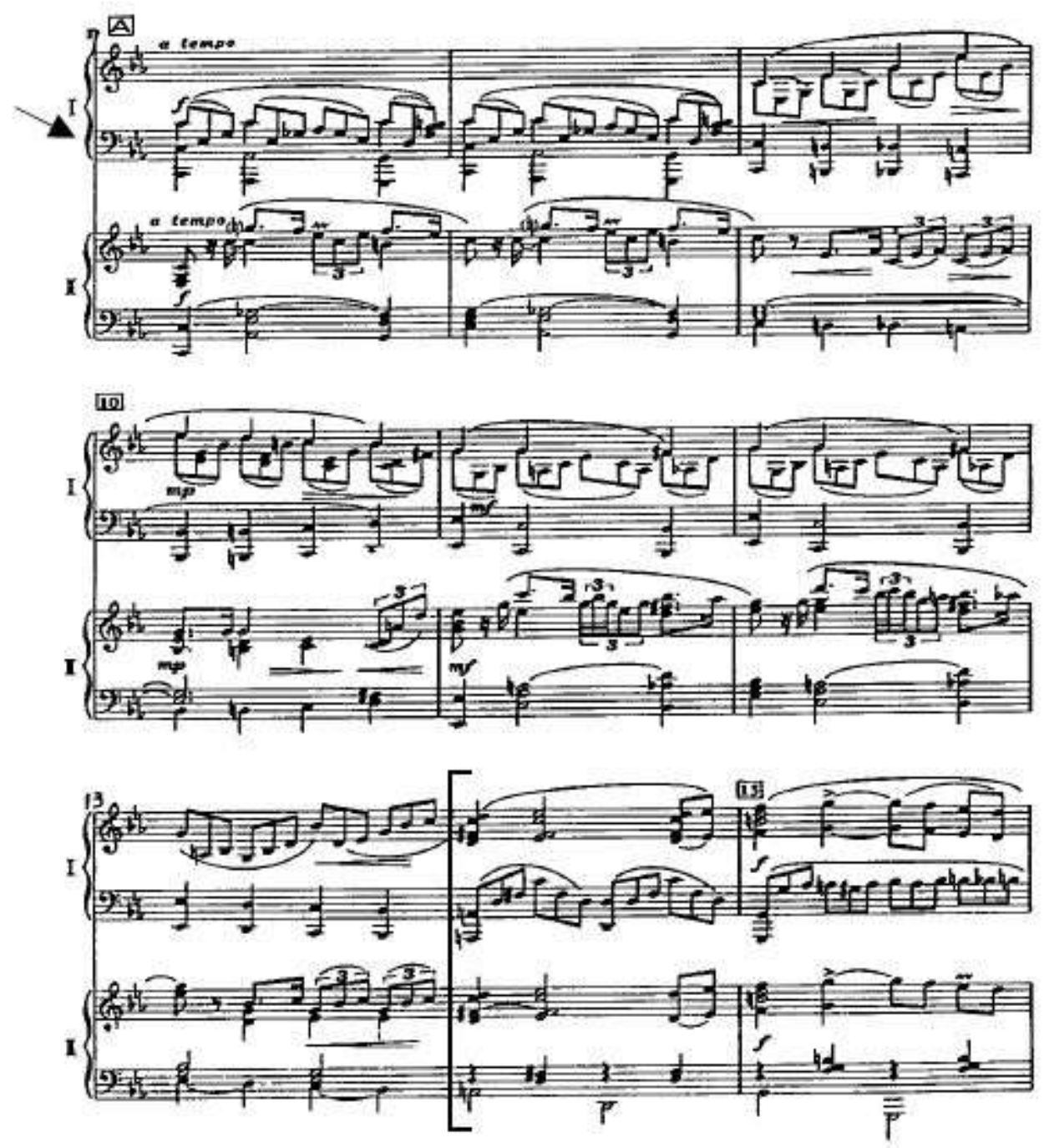

(C) 1992 by Formosa Singers Publisher. Used with Permission

Example 2.6. Tyzen Hsiao, Piano Concerto in C Minor, mm. 7-15. ${ }^{46}$

${ }^{46}$ Lan-Fang Lin, The Study of Hsiao Tyzen's Piano Music with an Analysis of Piano Concerto in C Minor, Op. 53 (National Sun Yat-Sen University, 2003), 31. 


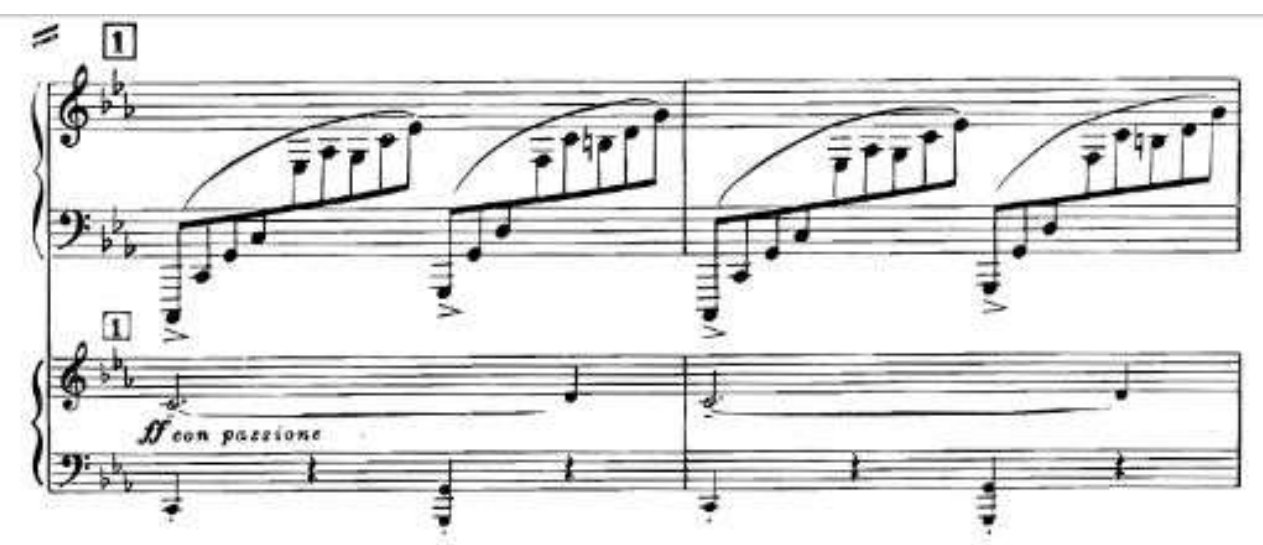

3
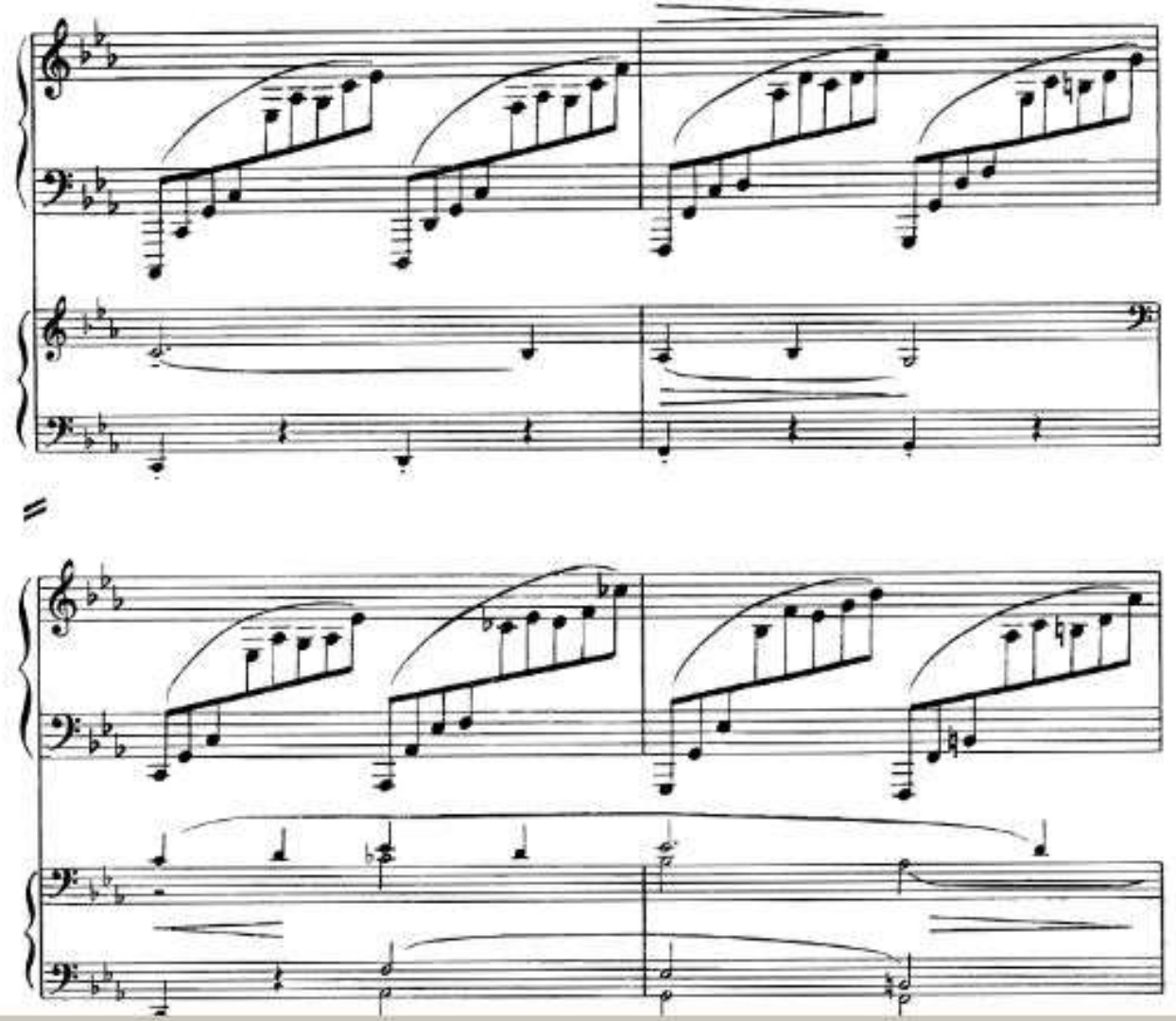

(C) 1947 by Muzgiz. Used with Permission 
Example 2.7. Sergei Rachmaninoff, Piano Concerto in C Minor, mm. 1-12. ${ }^{47}$

At the premier of Hsiao's piano concerto in Vancouver, the conductor of the Vancouver Symphony Orchestra, Clyde Mitchell, said to the audience that he thinks this work is an extremely romantic piano concerto, with a style somewhere between Rachmaninoff's second and third piano concertos. ${ }^{48}$ After listening to the concerto, Hsiao's mentor and friend Dr. Milton Stern told him, "I can find the characteristics of Rachmaninoff in your work, but I can also hear your unique compositional styles that represent your home country in this piece." 49

\section{B. Contemporary Style}

Before starting his study at California State University of Los Angeles, Hsiao wrote several pieces using contemporary writing techniques; but he found that he was uncomfortable with composing music in this style. He then started studying composition with Dr. Kim at CSULA. The piece that perhaps best shows Hsiao's writing in this style is 福爾摩沙幻想曲 (Formosa Fantasia for Flute and Piano), written in 1995 (Example 2.8). This piece was requested by a Taiwanese writer named Jia Yu, who had written a poem as she looked out over a lake during the fall season in Minnesota. The opening of this piece has no bar lines. Hsiao gave the performer great freedom to improvise by writing $a d l i b$. at the beginning of this fantasia. There are many dynamic markings and repetitions of notes.

\footnotetext{
${ }^{47}$ Sergei Rachmaninoff, Piano Concerto in C Minor (Moscow: Muzgiz, 1947), 1-2.

${ }^{48}$ Ming-Yuen, Tsai, The world-class Taiwanese composer, Tyzen Hsiao (Taipei: Yu-San-She, 2006), 140.

49 Tsai, 143-144.
} 


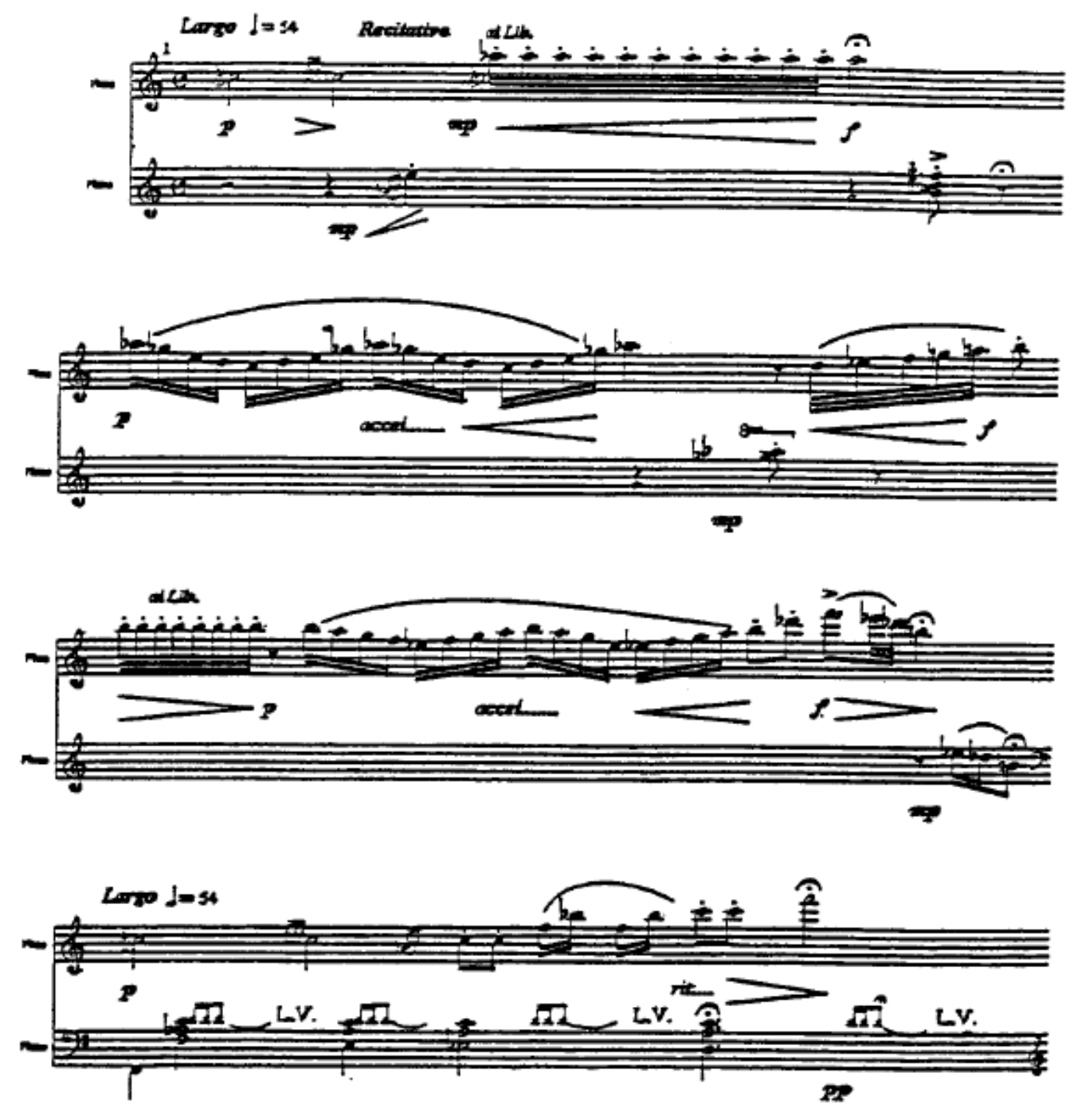

(C) 1995 by Formosa Singers Publisher. Used with Permission

Example 2.8. Tyzen Hsiao, Formosa Fantasia for Flute and Piano. ${ }^{50}$

Bar lines appear only after the introduction. In the piano part, Hsiao wrote "Repeated moving between the given notes in any order" in the piano part. There are four notes in the box revealed in Example 2.9. The pianist does not have to play the four notes in the order they are printed;

\footnotetext{
${ }^{50}$ Lan-Fang Lin, The Study of Hsiao Tyzen's Piano Music with an Analysis of Piano Concerto in C Minor, Op. 53 (National Sun
} Yat-Sen University, 2003), 45. 
instead, the pianist can play E-F-F\#-G in any order that appeals at the moment. The tempo and notes can be altered by the performer. Hsiao inserted three different tempo changes within seven measures.

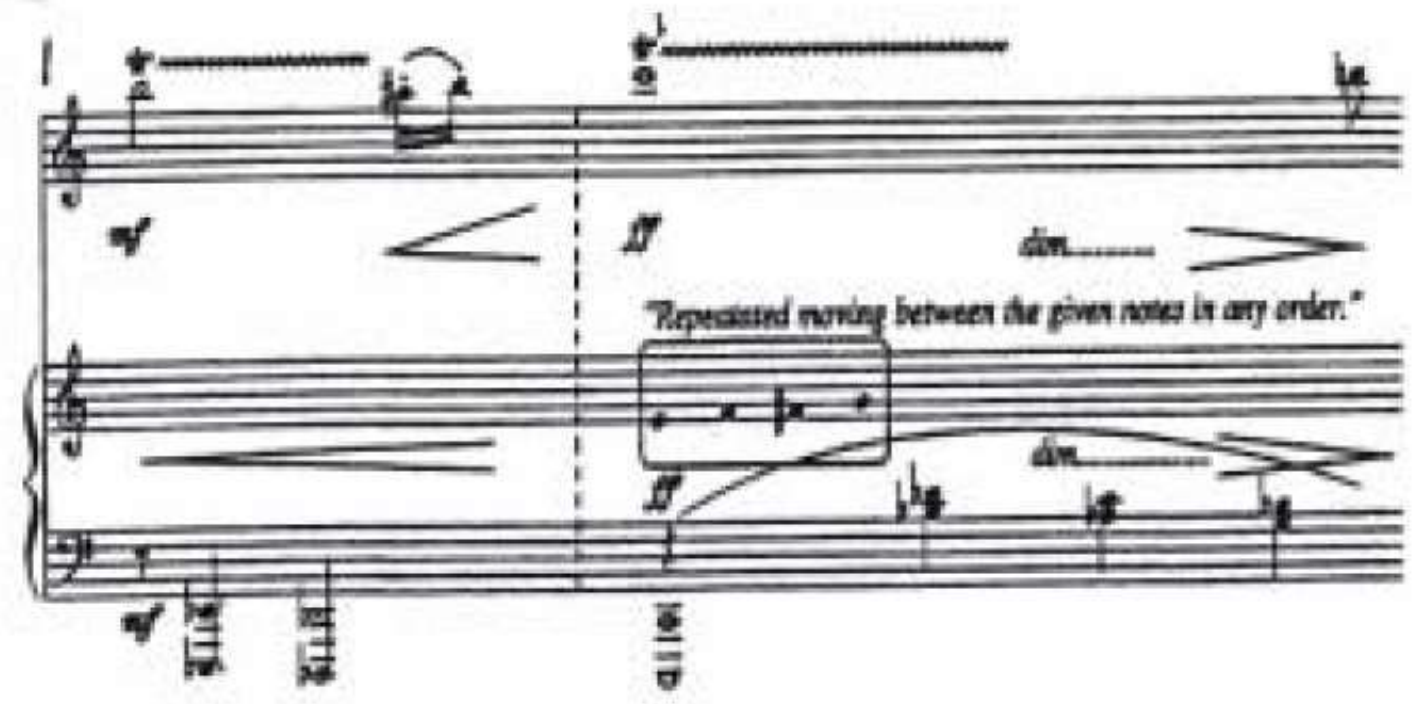

(C) 1995 by Formosa Singers Publisher. Used with Permission

Example 2.9. Tyzen Hsiao, Formosa Fantasia for Flute and Piano, 1-2.51

\section{Church Influence}

Born in a Christian family, Hsiao was strongly influenced by his religion. He wrote many songs based on hymns and Bible verses, to praise God. Hsiao never stopped composing for the church. Most of his lyrics are adapted from Biblical scriptures, such as:

Though I Walk through the Valley of the Shadow of Death, from Psalm 23 Bless the Lord, O My Soul, from Psalm 103 Praise the Lord, from Psalm 150 Faith, Hope, Love, from I Corinthians, Ch.13 The Lord's Prayer, from Matthew 6:9-13, etc.

\footnotetext{
${ }^{51} \operatorname{Lin}, 46$.
} 
He also used material from some ecclesiastical poems, for example, “God's Mercy is Better Than Life," a setting of lyrics by Song Huazhong. ${ }^{52}$ As his church songs gained popularity, he began to transcribe them from a solo voice to a mixed choir of men's and women's voices. Hsiao not only composed songs for churches, but also arranged songs for special events such as the centennial memorial honoring Dr. George Leslie Mackay, who founded the Mackay hospital in Taiwan. Although he wrote his songs in English when he stayed in the United States, he still preferred composing sacred songs in Taiwanese. To him, the Taiwanese language made it easier for Taiwanese people to understand his love for God. The Taiwanese language seemed to speak to his heart.

His sacred songs are not only sung at the church, but also in the concert hall. Dr. Gordon Xi-Wen Jin, also a successful Taiwanese composer and Christian, thinks Hsiao's vocal works intentionally have clear and simple melodic lines, with few difficult and complicated techniques, making them suitable for choirs to sing anywhere. Dr. Jin said, "I believed that there were in fact all but Professor Tyzen Hsiao himself in his music with nothing of Chopin or of Rachmaninoff, and with some of his carefree and intimate feelings to share." ${ }^{53}$ Another translation might be, "I believe it is not Chopin or Rachmaninoff that are in his music; it is the carefree and intimate feelings from Professor Tyzen Hsiao that make it able to communicate with people."

Hsiao considered music, humanity, and religion to be important sources for his works. When he was composing his very first oratorio, Jesus Christ (1971), he regarded himself as a tool of Jesus, because all he had during that time were his faith, his scores, and himself — and he was very content with that situation. ${ }^{54}$ In addition to the texts of his sacred songs, Hsiao also used

\footnotetext{
${ }^{52}$ Lu-Fen Yen, The Contributions of Tyzen Hsiao toward the Music History of Taiwan ( Tzipei: Council for Culture Affairs, 2009), 74.

${ }^{53}$ Gordon, Xi-Wen Jin, Originated from the Heart, Soul, and Honesty (Jer-Shung Lin, Taiwan, 1999), 1.

${ }^{54}$ Hen-Zhe, Lin, A Collection of Tyzen Hsiao's Musicological Forum and Articles (Taipei: Wang-Chun-Feng Wen-Hua, 1999),
} 
Presbyterian hymns in his solo piano works 詩影 (Poetic Echo) and 阿們頌 (A-Men Song) (1993).

\section{Taiwanese Cultural Elements}

When Tyzen Hsiao was in college in Taiwan, his teacher Chen-Huei Hsu used to tell him, "Chopin is your God, but now you should leave Chopin to learn the style of Debussy and then find your own path." ${ }^{" 55}$ Since he had been kept away from his homeland for 18 years (19771995), Taiwan was always on Hsiao's mind. In order to put his feelings of nostalgia aside, he put his heart into composing music with Taiwanese elements. Many of his vocal works were written in the Taiwanese language, the mother tongue for the majority of the island's residents. Hsiao liked to quote Taiwanese folk tunes or arrange Taiwanese folk songs in his own compositions. The main theme of his piano quintet, Lan-Yan Dancer, came from a Yi-Lan folk song, 王王銅 (Diu Diu Tong) (Throwing Coins) $;{ }^{56}$ he also quoted a Taiwanese opera 雙腳踭在地 (Siang-Ka a

Kui a lo a) (Kneel Down with Both Feet) in his 台灣頌 (Ode to Taiwan) (1999).${ }^{57}$ Hsiao used to say, "My music is infused with many traditional Taiwanese elements which are the most important characteristics in my music." 58

There are 16 officially recognized aboriginal peoples in Taiwan: Amis, Atayal, Bunun, Hla'alua, Kanakanavu, Kalan, Paiwan, Puyuma, Rukai, Saisiyat, Tao, Thao, Tsou, Truku, Sakizaya, and Sediq. They are also considered mountain tribes, since most of them are located in the east side of Taiwan near mountains and the ocean. Each of them has developed their own

245.

${ }^{55}$ Min-Yuen Tsai, World-Class Taiwanese Musician Tyzen Hsiao (Taipei: Yu-Shan She, 2006), 54.

${ }^{56}$ Yilan is located in the northeastern part of Taiwan. The streams and rivers provide a constant source of replenishment for the nutrients in the soil here, making Yilan a breadbasket county.

${ }^{57}$ Pei-Ning Ku, Songs By Hsiao Tyzen: The Interaction Between His Music And Taiwan. D.M.A. dissertation, University of Nevada (Las Vegas, 2014), 30.

${ }^{58}$ Chi-Min Chen, Catalogue of Tyzen Hsiao's Compositions (Council for Cultural Affairs, Taiwan, 2009), 32. 
culture, music, dances, and costumes. These mountain-dwelling tribes are known for their heterophonic vocals and strong, syncopated rhythms.

In 1985, Hsiao adapted Amis folk tunes in his piano quintet 原住民組曲 (The Highlander's Suite), op. 47. There are four movements in this work: 阿美之歌 (A Mei Folksong), 初戀 (Love Story), 收割 (Harvest), and 終曲 (Finale). Throughout the work, Hsiao used the Amis folk tune "The Ocean Song," which is eight measures long. He separated the eight measures into two sections, $\mathrm{A}$ and $\mathrm{B}$. The first four measures appear at the beginning of the first movement (Examples 2.10 and 2.11).

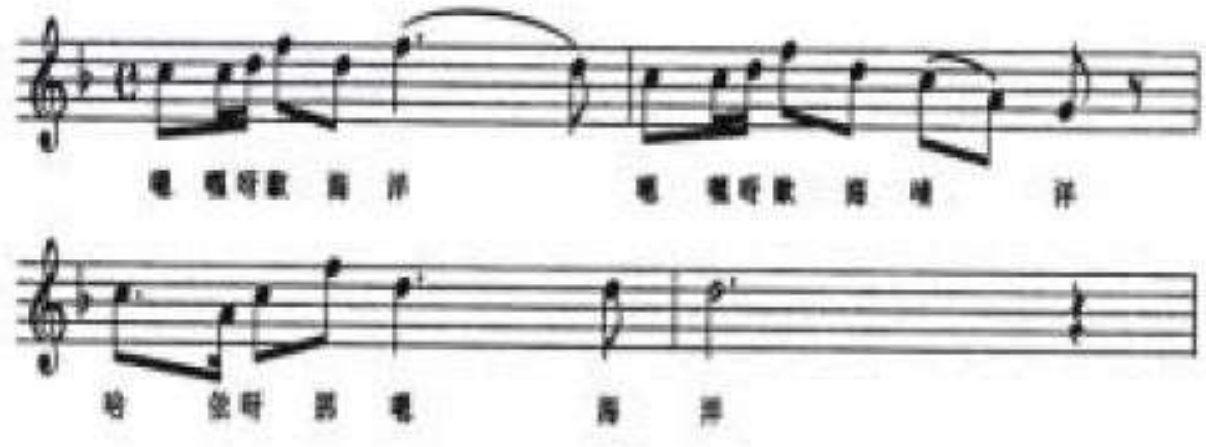

(C) 1985 by Formosa Singers Publisher. Used with Permission Example 2.10. Amis Folk Song, The Ocean Song, 1-4. ${ }^{59}$

\footnotetext{
${ }^{59}$ Lan-Fang Lin, The Study of Hsiao Tyzen's Piano Music with an Analysis of Piano Concerto in C Minor, Op. 53 (National Sun Yat-Sen University, 2003), 34.
} 

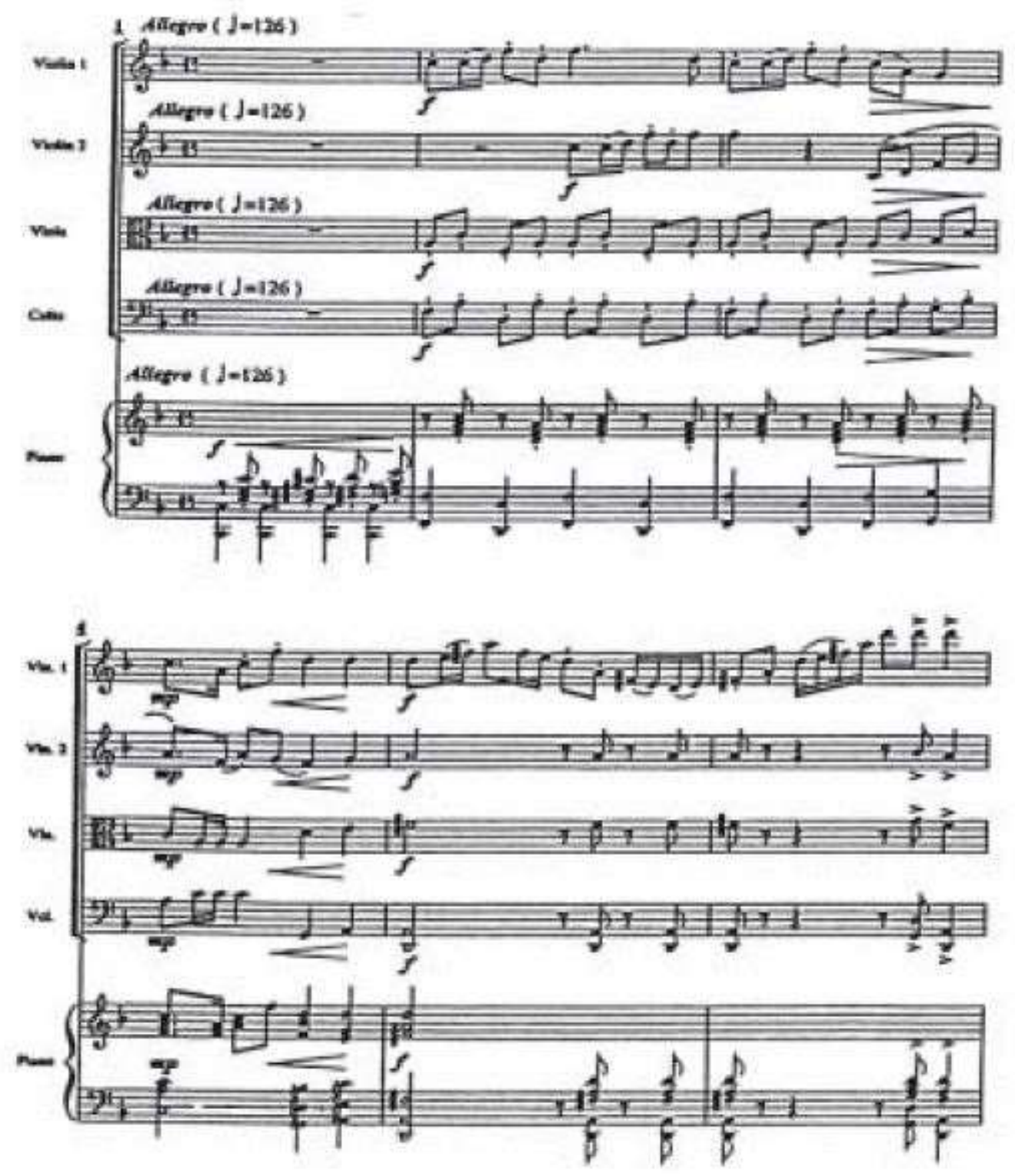

(C) 1985 by Formosa Singers Publisher. Used with Permission

Example 2.11. Tyzen Hsiao, The Highlander's Suite, 1-6. ${ }^{60}$

${ }^{60}$ Ibid. 
The second half of the eight-bar theme of "The Ocean Song" starts from m. 26, in a higher register than the original song. He put his favorite musical term cantabile at the beginning of this section (Example 2-13, with the original folk song in Example 2-12).

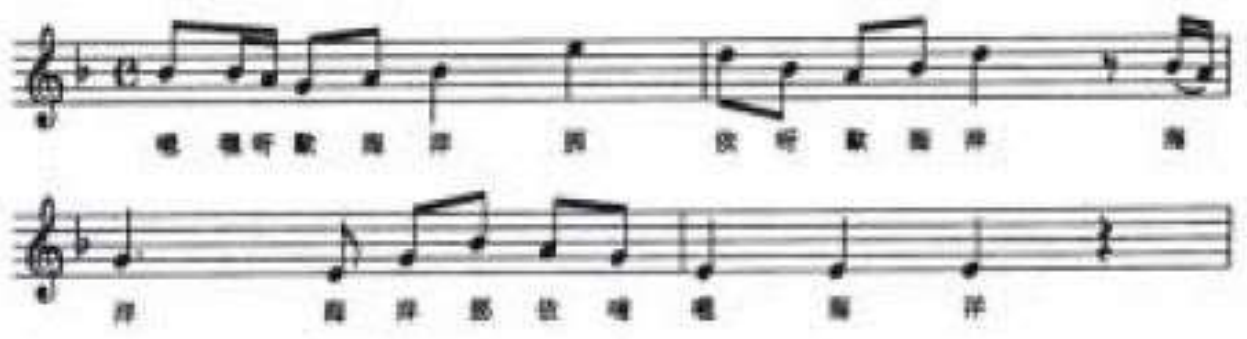

(C) 1985 by Formosa Singers Publisher. Used with Permission

Example 2.12 Amis Folk Song, The Ocean Song, 5-8. ${ }^{61}$

${ }^{61} \operatorname{Lin}, 35$. 

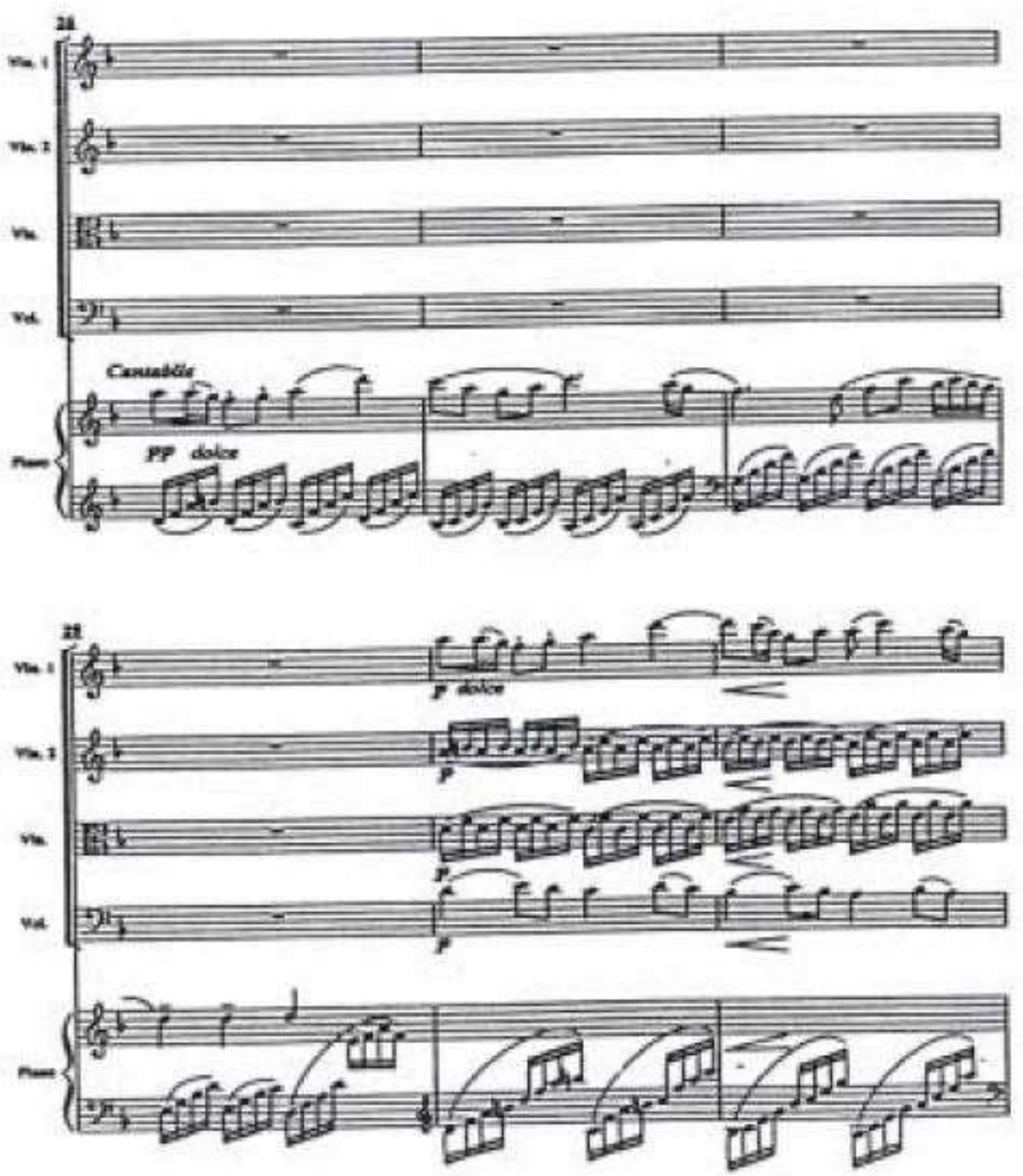

(C) 1985 by Formosa Singers Publisher. Used with Permission Example 2.13 Tyzen Hsiao, The Highlander's Suite, 26-31. ${ }^{62}$

${ }^{62}$ Ibid. 
In the finale of The Highlander's Suite, Hsiao took two Amis folk tunes, Yin-Na-Ya (Example 2.14) and 賞月之舞 (Moon Appreciation Dance) as source material. Hsiao uses the tune of YinNa-Ya in his "The Highlander's Suite" in Example 2.15. In the second half of the material, he raised the pitch an octave higher than the original tune in his own work.

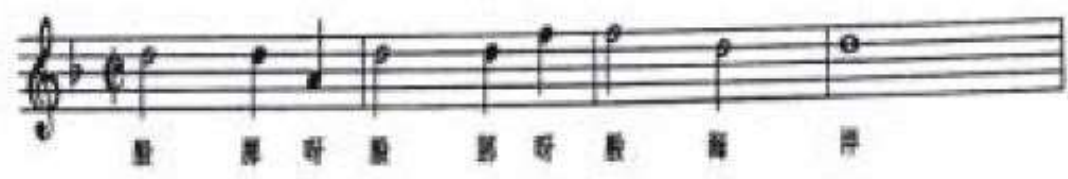

(C) 1985 by Formosa Singers Publisher. Used with Permission

Example 2.14 Amis Folk Song, Yin-Na-Ya 1-4. ${ }^{63}$

${ }^{63} \operatorname{Lin}, 36$. 


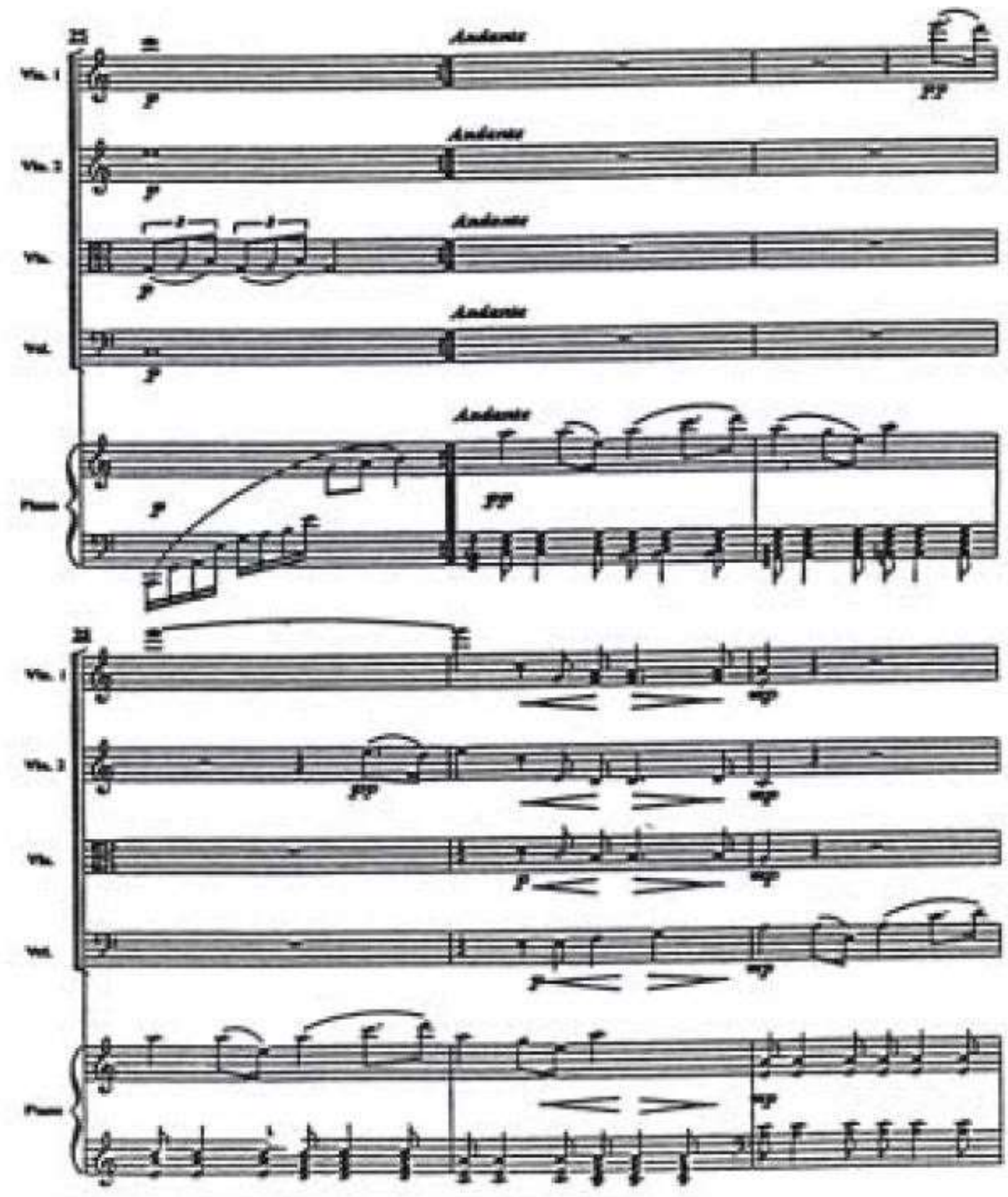

(C) 1985 by Formosa Singers Publisher. Used with Permission

Example 2.15 Tyzen Hsiao, The Highlander's Suite, 25-30. ${ }^{64}$

${ }^{64}$ Ibid. 
The second source material that he borrowed, "Moon Appreciation Dance," starts in a syncopated rhythm, shown in Example 2.16; but Hsiao changed that to three repeated eighth notes, followed by a series of staccatos, which gives the piece a dancing mood (Example 2-17).

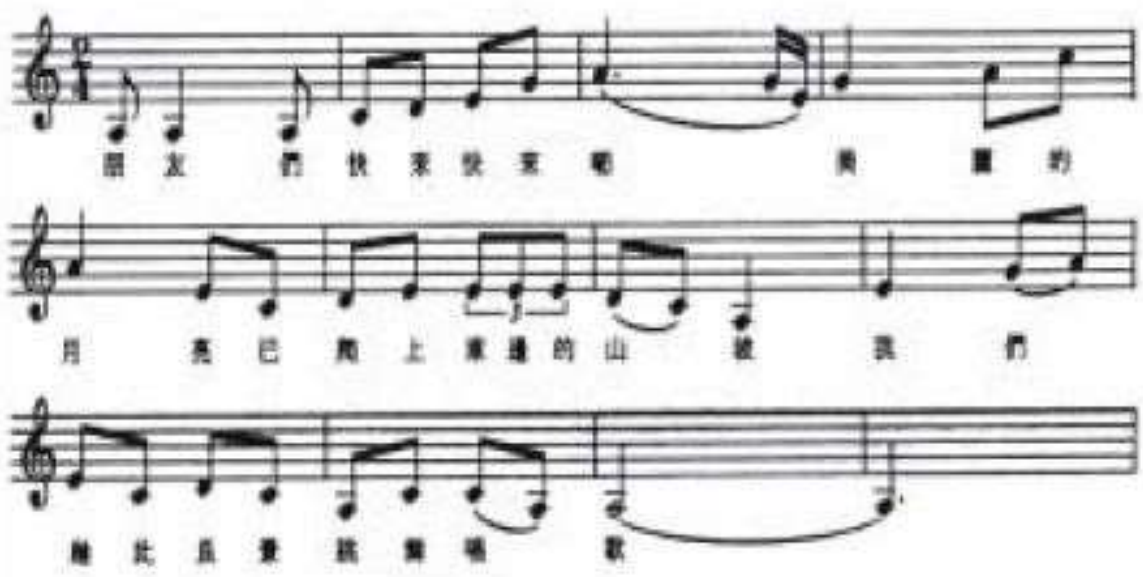

(C) 1985 by Formosa Singers Publisher. Used with Permission

Example 2.16 Amis Folk Song, Moon Appreciation Dance, 1-12.65

${ }^{65}$ Lin., 37. 

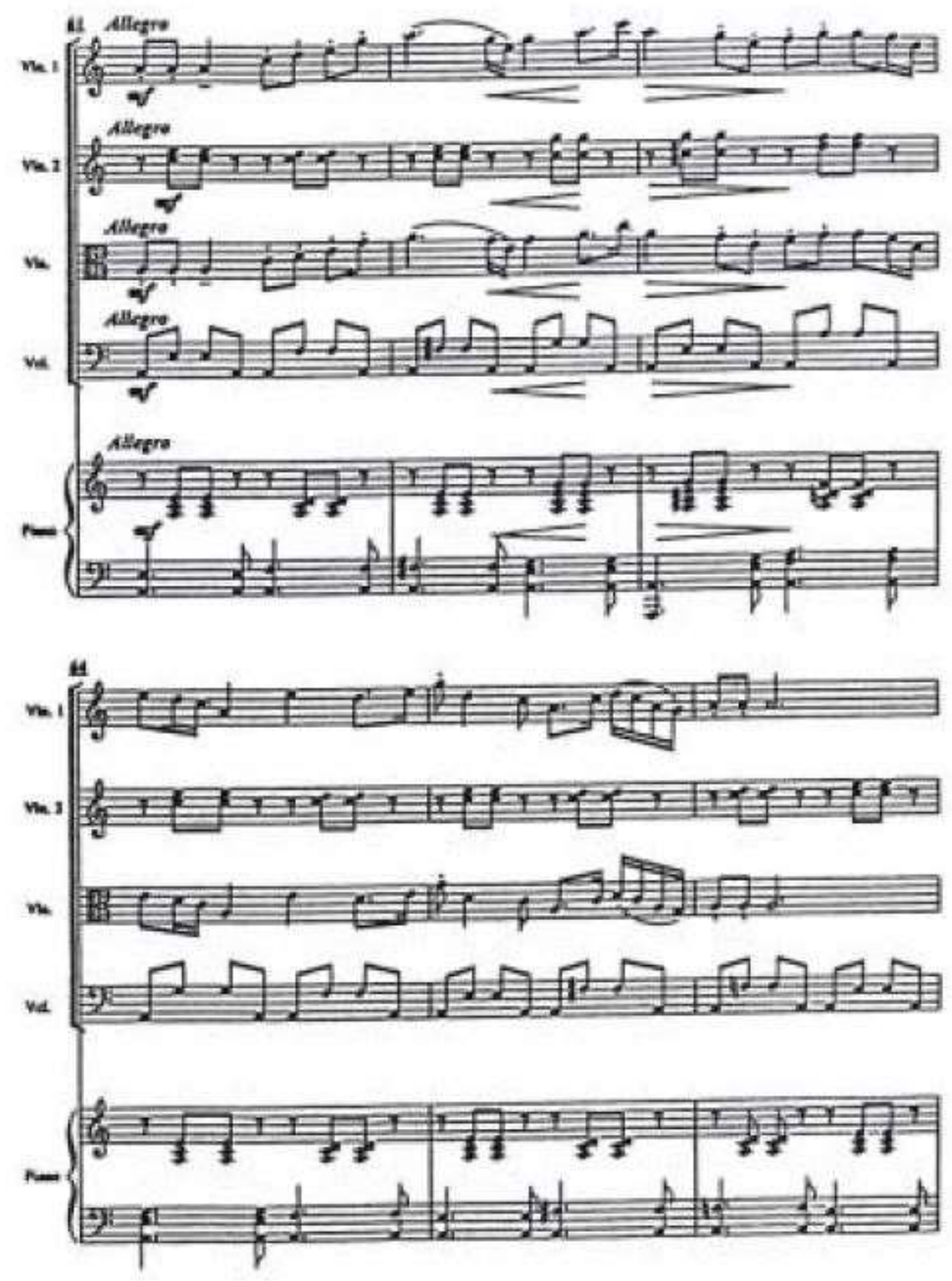

(C) 1985 by Formosa Singers Publisher. Used with Permission

Example 2.17 Tyzen Hsiao, The Highlander's Suite, 61-66. ${ }^{66}$

In Tyzen Hsiao's lifetime, he was one of the most famous Taiwanese composers. He combined the Western music styles of Romanticism and Impressionism with local Taiwanese ${ }^{66}$ Ibid. 
elements, instead of using only contemporary techniques, which many Taiwanese composers during his time preferred to employ. Whether he was writing in his native Taiwanese language or using the aboriginal folk tunes he adapted in his compositions, Hsiao's music stands out and shines in the world as representing Taiwanese music.

Chapter Three 


\section{Memories of Home, Op. 49}

Tyzen Hsiao's solo-piano work, Memories of Home, written in 1987, was inspired by his early life in Taiwan, as a child becoming a young man. This work includes six pieces: "Prelude," "Memory," "Playground," “Ancient Taiwanese Melody," "Elegy," and "Frolic." Memories of Home is equally divided into two opposite moods: "Prelude," "Playground," and "Frolic" are energetic and playful, while the other three pieces in the set tend to be more lyrical and expressive. In 1989, the Taiwan Music Association in Southern California published this set. Hsiao then decided to dedicate this work to his teacher, Dr. Milton Stern. Later on, Lily Chang, who was the founder of the International Chinese Piano Competition in Washington, assigned "Prelude" and "Frolic" as the two pieces for contestants to play in the first round of the competition.${ }^{67}$ Soon after, Memories of Home was published by Formosa Singers in Taiwan in 2007.

In this chapter, I will briefly cover the background for these pieces, along with pedagogical aspects based on phrasing, rhythms, and dynamics.

\section{I. "Prelude"}

\section{Background}

Hsiao composed "Prelude in C" for solo piano and "The Vagabond" for solo voice, when he was staying with his sister in Atlanta in 1978. The beginning and the end of "Prelude in C"

\footnotetext{
${ }^{67}$ Hen-Zhe Lin, A Collection of Tyzen Hsiao's Musicological Forum and Articles (Taipei: Wang-Chun-Feng Wen-Hua, 1999), 316.
} 
became the first piece of this set, while the "The Vagabond" becomes the second piece, now called "Memory."

When Hsiao was a child, he frequently attended the traditional festival, which took place just outside the temple near his home. During the festival, Hsiao and his fellow neighbors would light up firecrackers and watch the dragon shows performing with a traditional Chinese percussion group as they performed in front of the temple. The mood at the beginning of "Prelude" seems to imply a preparation for the festival; after ten measures, the main theme ( $\mathrm{mm}$. 11-12) comes in with melodic line in the right hand in octaves, marked "Articulated," as shown in Example 3.1. The tempo of this piece is Allegro vivace giocoso. Among the 32 measures of this piece, the main melody is only six bars long, while 28 measures belong to the introduction and ending phrases. In the score, Hsiao requires the performer to repeat the main theme along with the transition (mm. 16-25). He also wants the performer to play more softly the second time. When the dragon show occurs outside a temple, it usually starts walking down the street in a grand spectacle, to the amusement of the entire neighborhood. The second repeat reflects the dragon show as it moves away from the temple--and the sound gets softer with distance. Hsiao uses many percussive effects and repetitive motions in the first piece, to represent the sound of gongs (Example 3.2) ${ }^{68}$

\footnotetext{
${ }^{68}$ An Asian percussion instrument that takes the form of a flat, circular metal disc, which is hit with a mallet.
} 


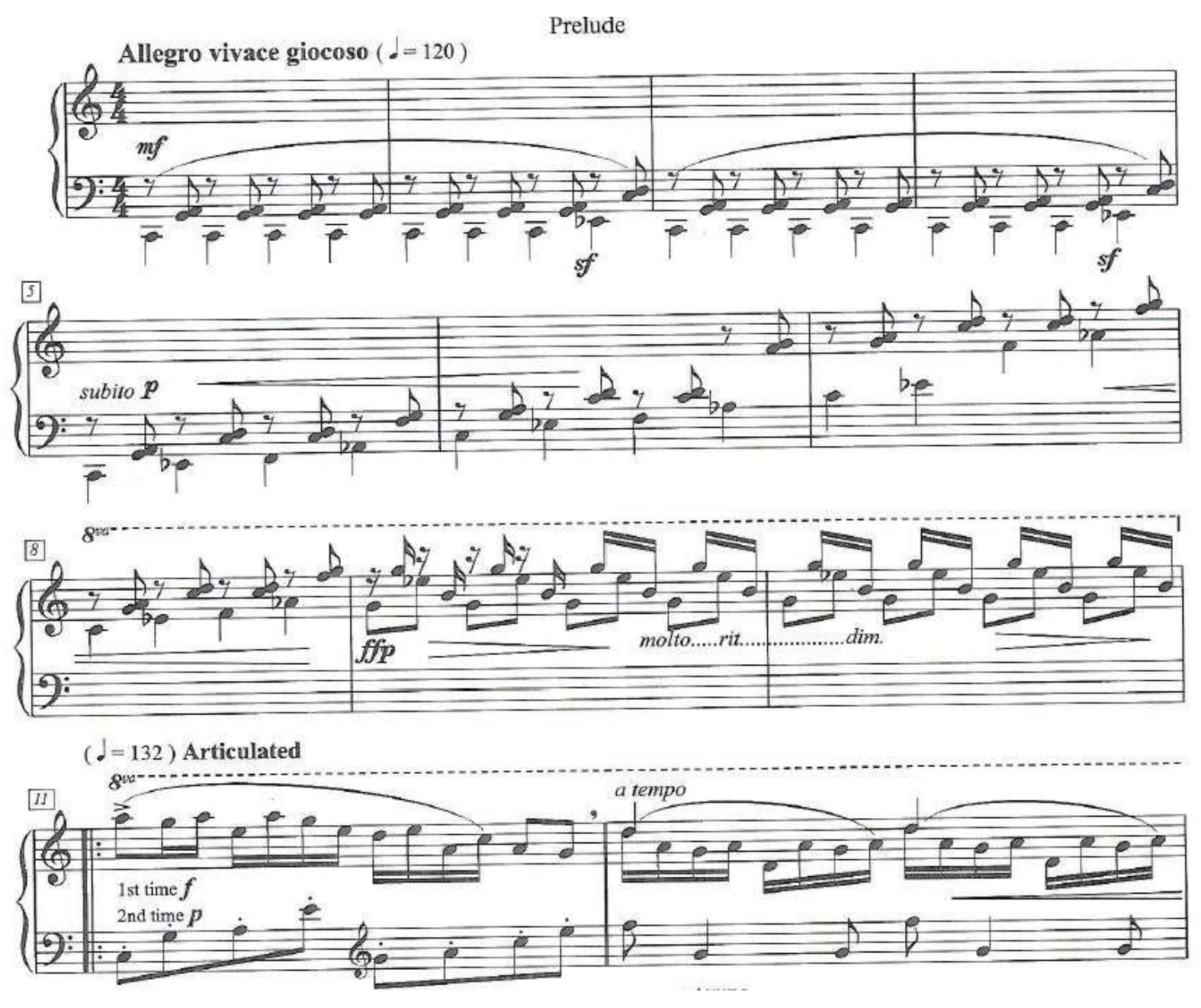

(C) 1989 by Formosa Singers Publisher. Used with Permission

Example 3.1 Tyzen Hsiao, "Prelude" in Memories of Home, 1-12.69

${ }^{69}$ Tyzen Hsiao, Memories of Home, (Taipei: Formosa Singers, 1989), 1. 

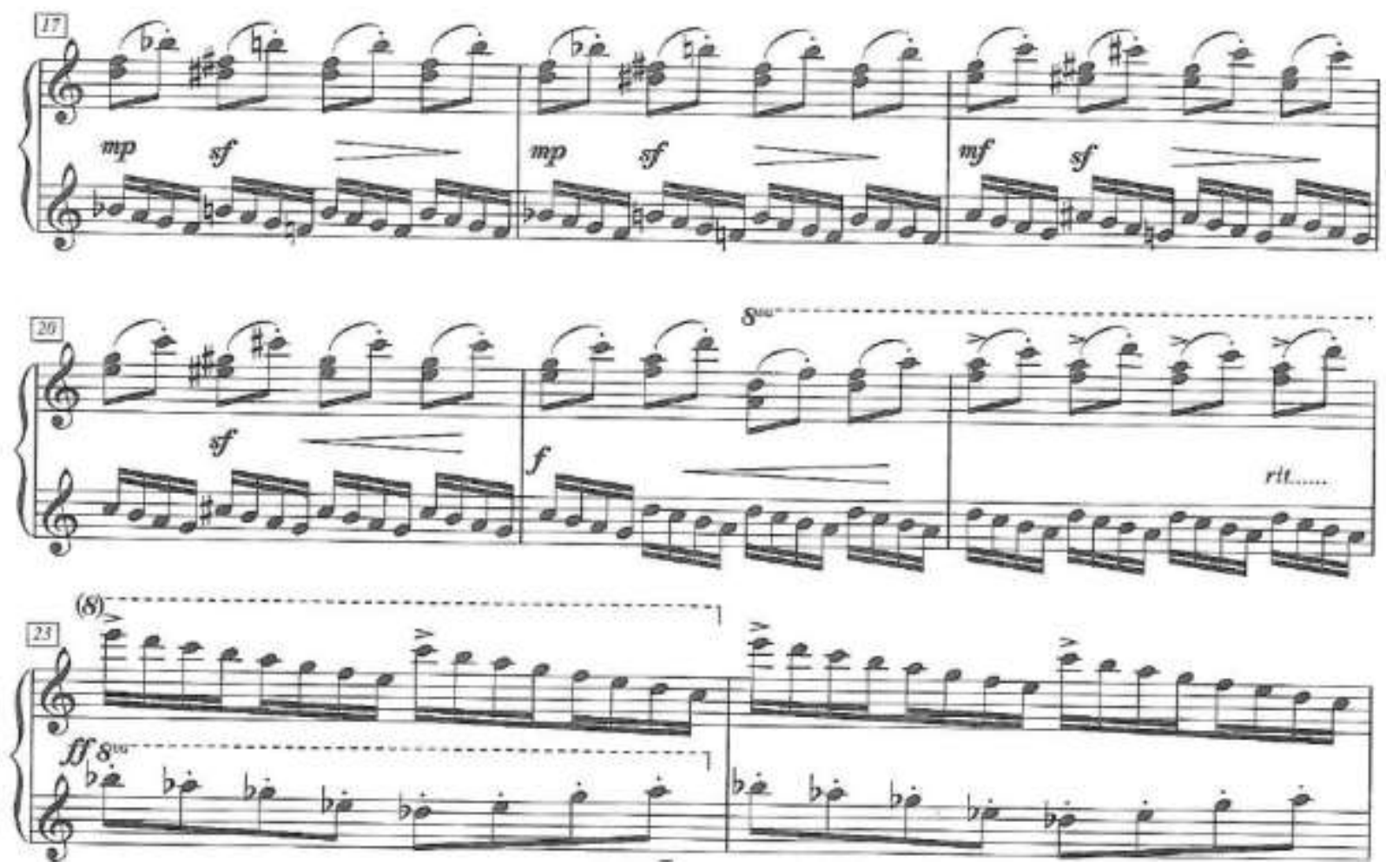

(C) 1989 by Formosa Singers Publisher. Used with Permission

Example 3.2 Tyzen Hsiao, "Prelude" in Memories of Home, 17-24. ${ }^{70}$

Pedagogical aspects:

At the beginning of the first piece, the melodic line is in the left hand, while the right hand plays consecutive repetitions of seconds. The pedal can help when making a crescendo, to create excitement for the dragon show (from mm. 5-9); the dynamic plan of this passage appears in Example 3.3. After the $f f$ in $\mathrm{m} .8$, the sound should fade away gradually so listeners can anticipate what is coming next in $\mathrm{m} .11$, where the main theme appears.

${ }^{70}$ Hsiao, 2. 


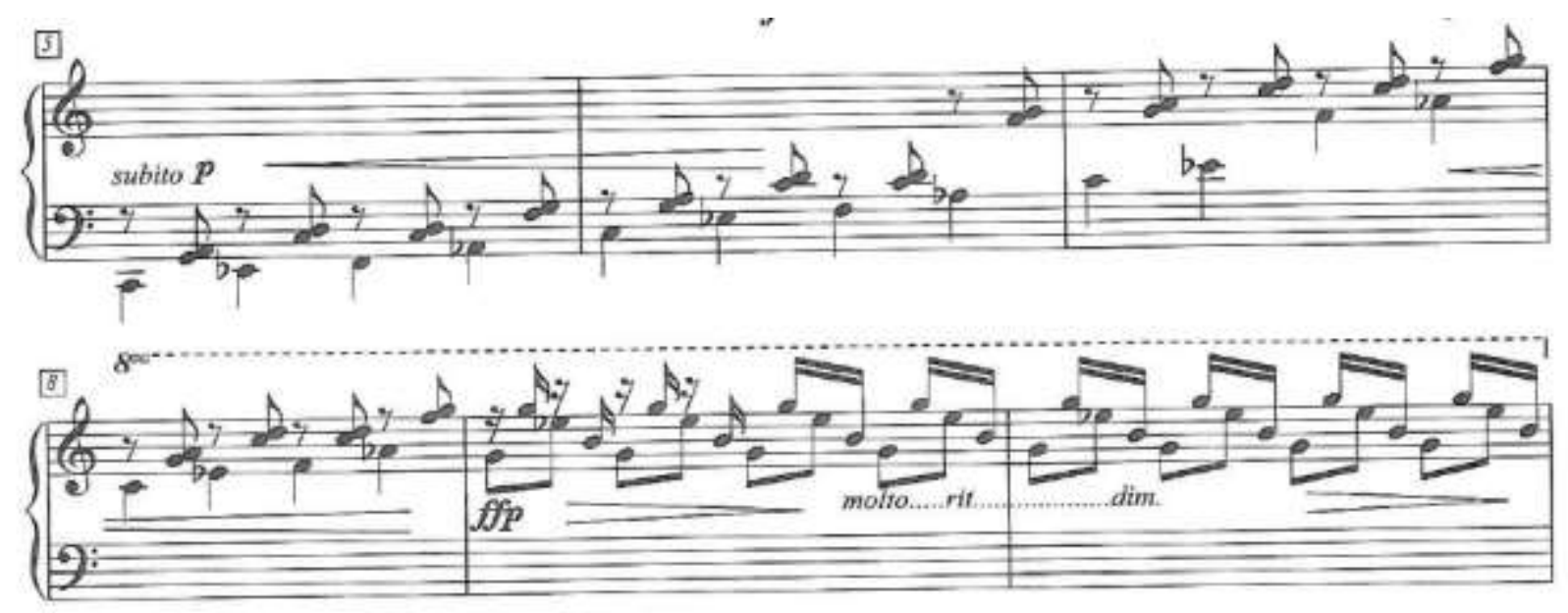

(C) 1989 by Formosa Singers Publisher. Used with Permission

Example 3.3 Tyzen Hsiao, "Prelude" in Memories of Home, 5-10. ${ }^{71}$

Syncopation is one of Hsiao's favorite writing techniques; it appears frequently in this set as shown in Example 3.4. ${ }^{72}$ When there is a syncopation pattern in the piece, the performer has to treat the note value carefully. Playing a pattern that starts with one eighth note followed by one quarter note and another eighth note, the pianist should refrain from connecting the first eighth note to the quarter note; instead, the quarter note should be played with a light accent to show the obvious difference between the note values of eighth and quarter notes.

\footnotetext{
${ }^{71}$ Hsiao, 1.

72 Tzi-Ming Yang, Selected Solo Piano Works of Taiwanese Composers, DMA dissertation, University of Maryland (College Park, 2002), 81
} 


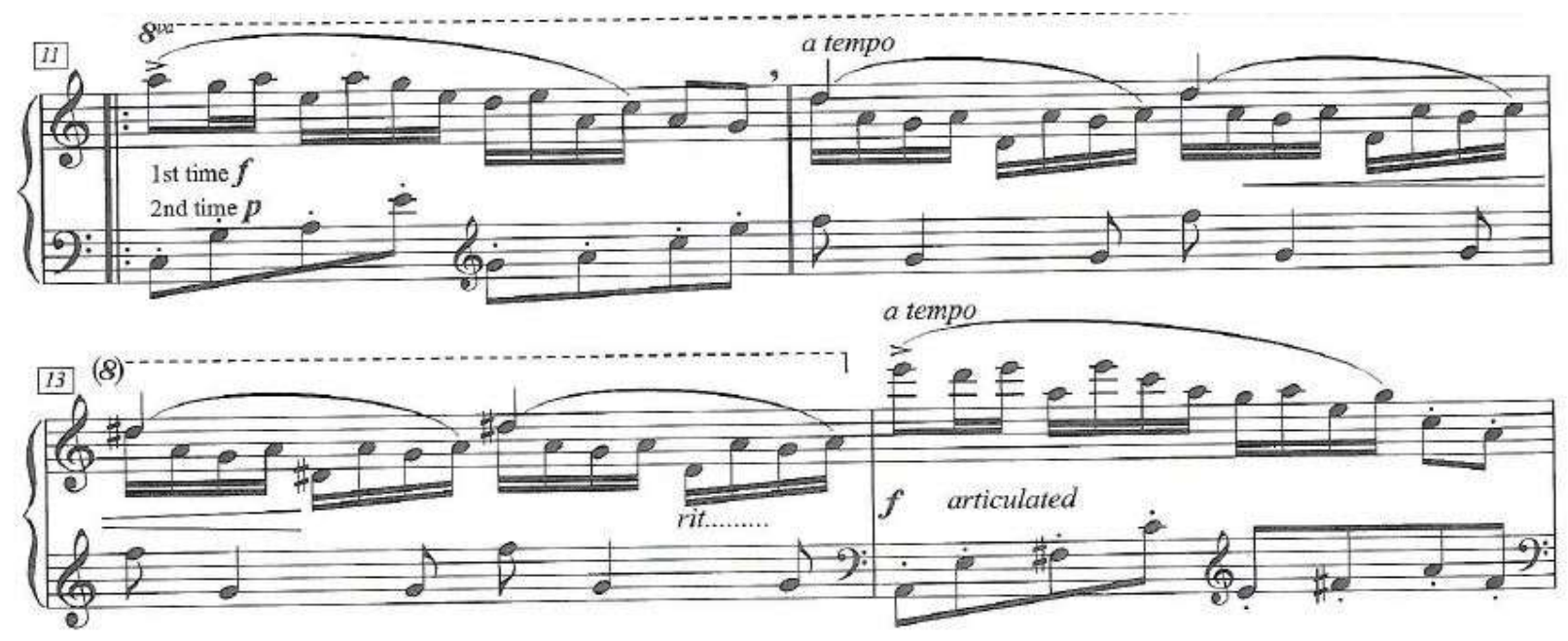

(C) 1989 by Formosa Singers Publisher. Used with Permission

Example 3.4 Tyzen Hsiao, "Prelude" in Memories of Home, 11-14. ${ }^{73}$

To play the same repeated pattern we mentioned previously, the pianist should refrain from connecting the first eighth note to the quarter note; instead, the quarter note should be played with a light accent to highlight the difference of the note values between eighth and quarter notes. In the transition section, mm. 17-22, we find a series of descending four-note groups in the left hand and two eighth notes leaping briskly and playfully under a slur in the right hand, which is another favorite compositional technique for Hsiao (Example 3.5). The interval of a fourth appears in both hands: the $\mathrm{F}$ and F-sharp go up respectively to B-flat and B-natural in the right hand and the B-flat and B-natural go down to F in the left hand. In order to make diminuendo and $s f$, as marked in this section, the performer should play the four-note groups softly and put emphasis on the note that is marked $s f$. When a student plays $s f$, the sound could be harsh. To prevent a harsh sound, the fingers should be directly on the keys and press the key

\footnotetext{
${ }^{73}$ Tyzen Hsiao, Memories of Home, (Taipei: Formosa Singers, 1989), 1.
} 
down quickly from the surface of the key, which I call "fast-attack," instead of hitting the key from above, with the fingers off the keyboard.
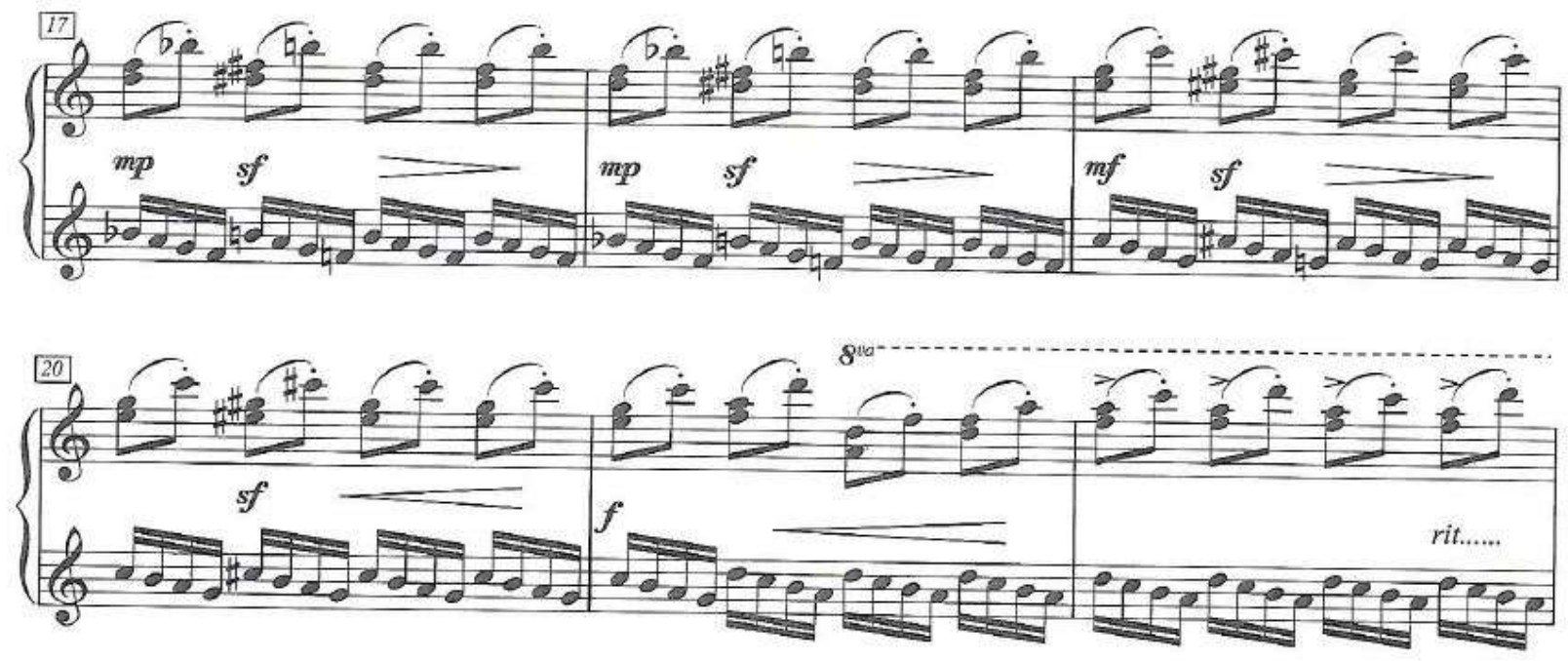

(C) 1989 by Formosa Singers Publisher. Used with Permission

Example 3.5 Tyzen Hsiao, "Prelude"in Memories of Home, 17-22. ${ }^{74}$

The most exciting part of "Prelude" occurs at the end of the piece, where both hands have melodic lines with accents, but play in contrary motion, ending on a C-major chord. The performer should slightly move the hands and forearms ahead when playing the last chord, with the pedal down, and then keep the chord for the full whole-note value, to have a more sustained sound (Example 3.6). In m. 30, the accented notes in the right hand have an ascending chromatic motion, while the accented notes in the left hand present a descending whole-tone scale to C. When playing this section, the performer can lean the right hand toward the right-hand side and relax the thumb, helping the accented notes be heard clearly.

\footnotetext{
${ }^{74}$ Hsiao, 2.
} 

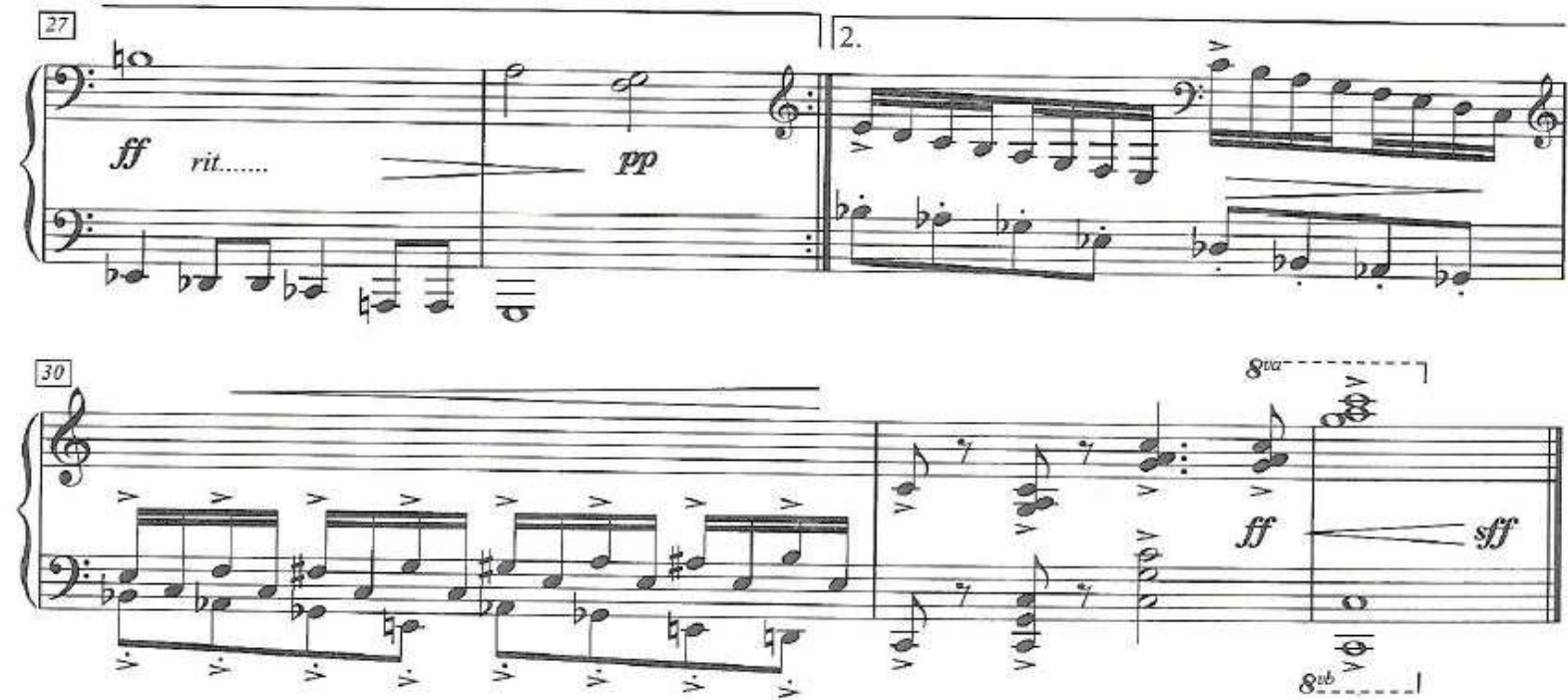

(C) 1989 by Formosa Singers Publisher. Used with Permission

Example 3.6 Tyzen Hsiao, "Prelude" in Memories of Home, 27-32. ${ }^{75}$

\section{Memory}

Background

In 1978, Hsiao wrote "The Vagabond" for Taiwanese immigrants in Los Angeles to sing. Later on, he transcribed this song for mixed voices into a piano-solo work, which became the second piece of Memories of Home. When he transcribed the song to the piano, he changed the key from E-flat major to C major (Example 3.7).

75 Ibid. 


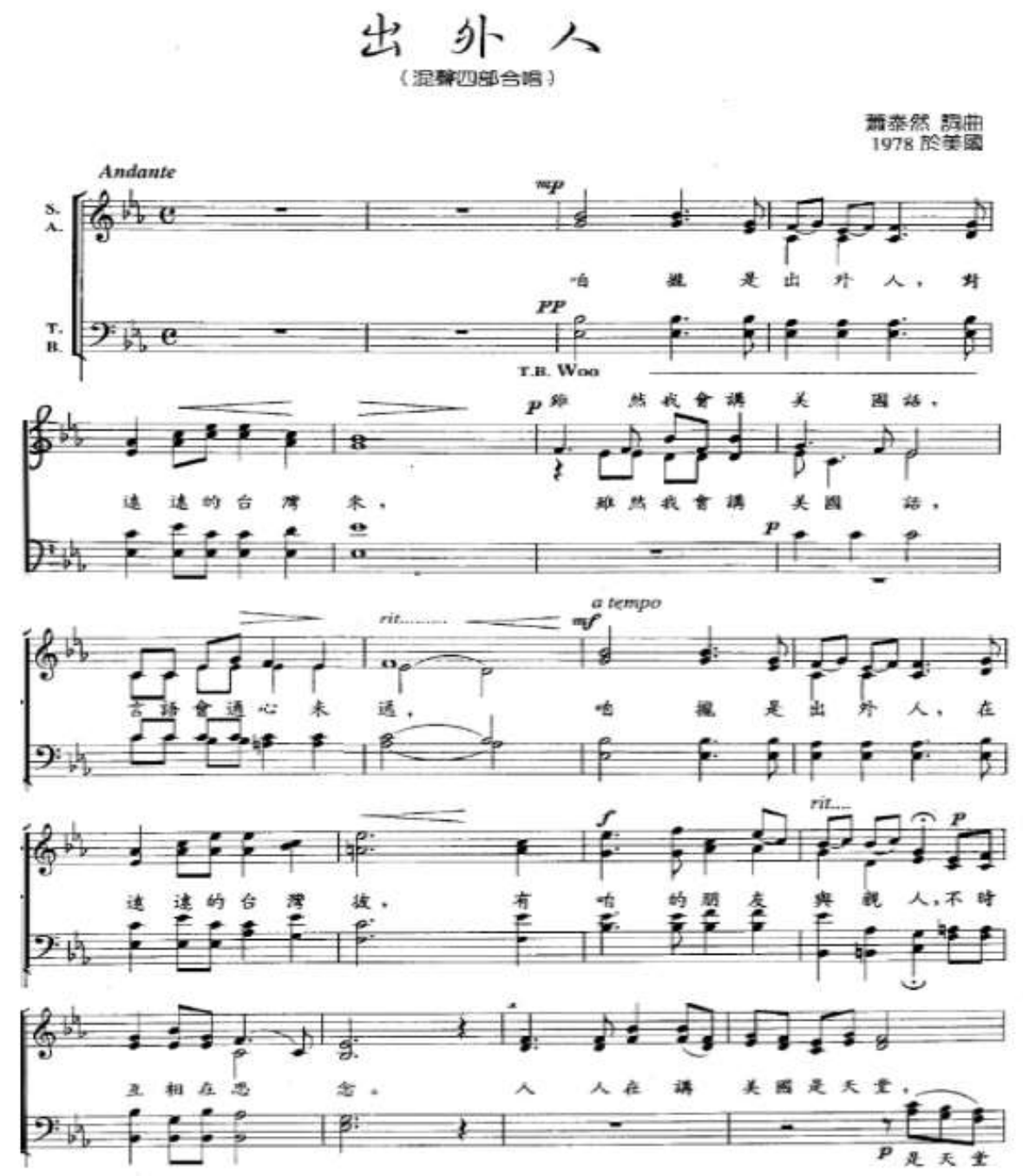

(C) 1978 by Formosa Singers Publisher. Used with Permission

Example 3.7 Tyzen Hsiao, Vagabond, $1-20 .^{76}$

When the Olympics were held in Atlanta, Georgia, in 1996, a German pop group, Enigma, used parts of a Taiwanese aboriginal Amis tune sung by an elderly Amis couple in the group's song “Return to Innocence.” After this, people in Taiwan started paying more attention to aboriginal music. Tyzen Hsiao heard the song and wanted to write more modern Taiwanese art songs for Taiwanese people, especially for those who were living in the United States at the

\footnotetext{
${ }^{76}$ Tyzen Hsiao, Vagabond, (Taipei: Formosa Singers, 1978), 1.
} 
moment. ${ }^{77}$ He then decided to write "The Vagabond" which not only shows the nostalgic feelings of Taiwanese immigrants, but also expresses his concern about the strained relationship between his motherland and China.

Pedagogical aspects:

In Table 3.1, we see that "Memory" was written in ABA form. It has a clear melody in the right hand with triplet arpeggio motion as accompaniment in the left hand (Example 3.8). If we examine the beginning of this piece, we observe that its musical format is similar to Chopin's Nocturne in E minor (Example 3.9). Both of them start with an introduction before the melodic line occurs in the right hand.

\begin{tabular}{|c|c|cc|cc|cc|}
\hline Sections & Piano Introduction & \multicolumn{2}{|c|}{ A } & \multicolumn{2}{|c|}{ B } & \multicolumn{2}{|c|}{ A $^{\prime}$} \\
\hline Subsections & & a & a' & & a & a' \\
& & & $3-11$ & $12-19$ & $20-27$ & $28-36$ & $37-44$ \\
\hline Measures & $1-2$ & & & & & \\
\hline
\end{tabular}

Table 3.1

\footnotetext{
${ }^{77}$ Pei-Ning Ku, Songs by Hsiao Tyzen: The Interaction Between His Music and Taiwan. DMA dissertation, University of Nevada, (Las Vegas, 2014), 42.
} 

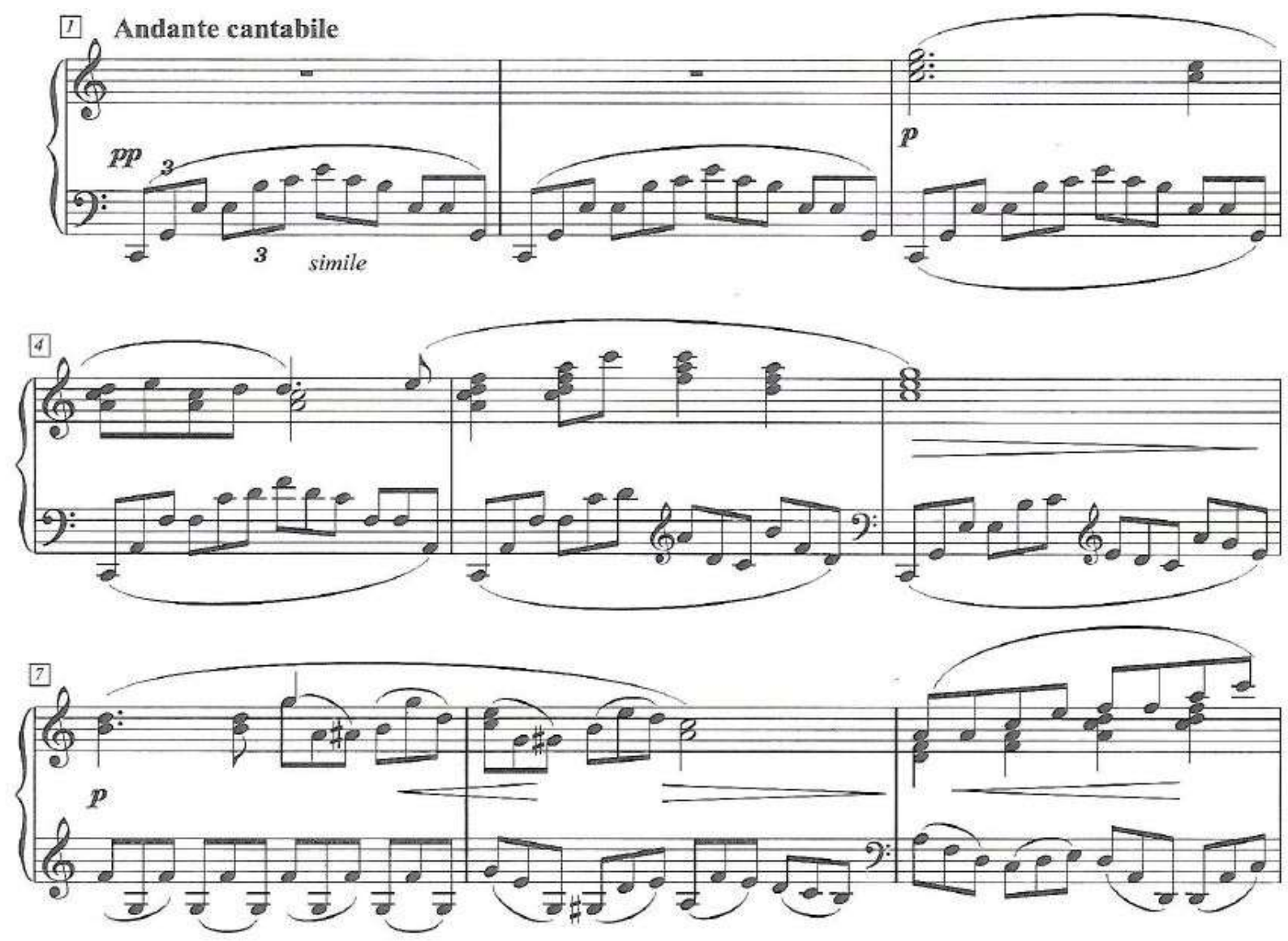

(C) 1989 by Formosa Singers Publisher. Used with Permission

Example 3.8 Tyzen Hsiao, "Memory" in Memories of Home, 1-9. ${ }^{78}$

78 Tyzen Hsiao, Memories of Home, (Taipei: Formosa Singers, 1989), 4. 

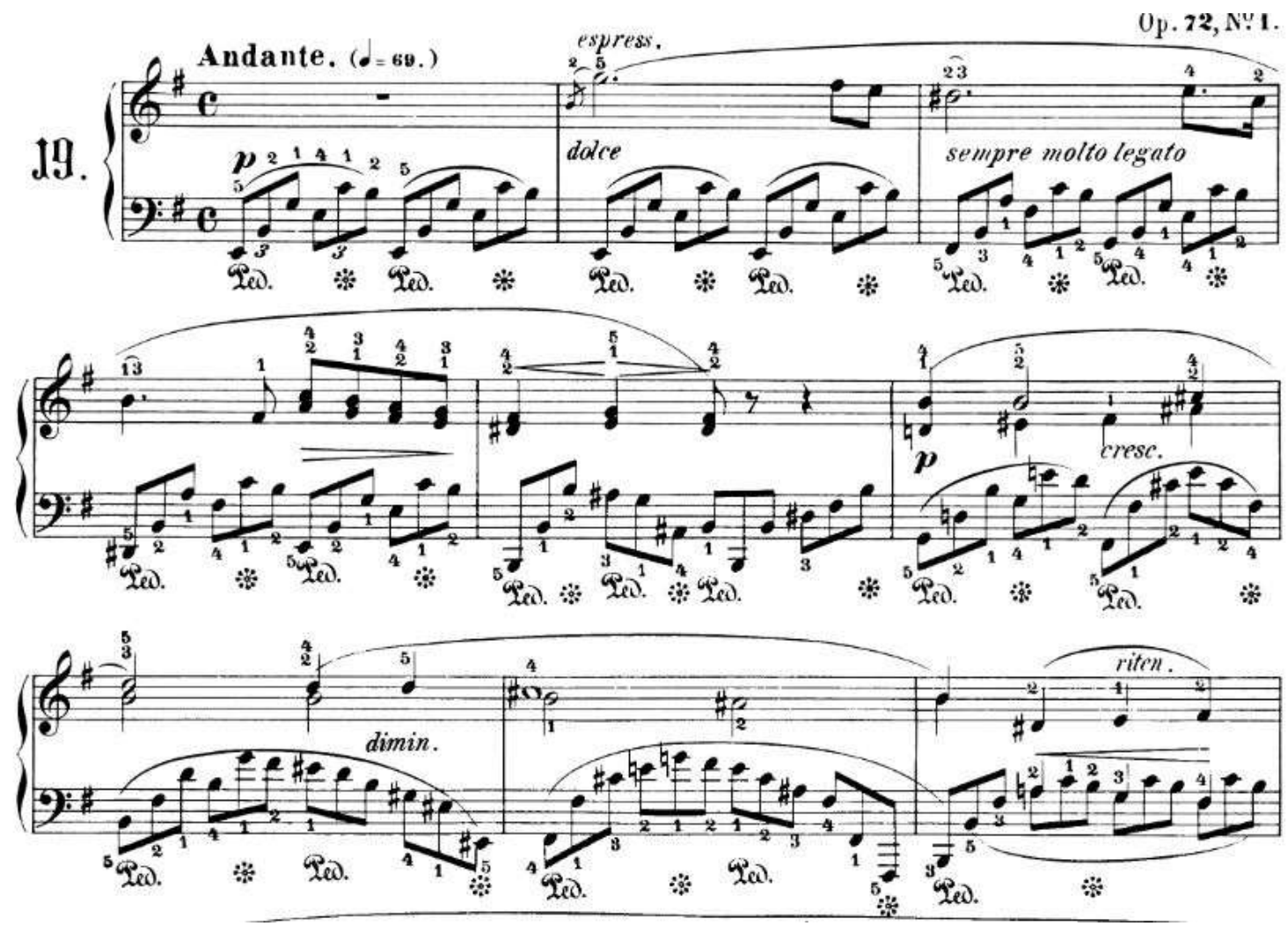

(C) 1880 by Breitkopf und Härtel. Used with Permission

Example 3.9 Frederic Chopin, Nocturnes, op. 72, no. 1, 1-9. ${ }^{79}$

The beginning of "Memory" is marked $p p$ in the left hand until m. 3, where the main melody appears in the right hand, marked $p$. The accompaniment has the same figure, as the left hand spells out the arpeggiated tonic chord. With the goal of achieving a lighter and smoother sound, especially on the repeated E, a recommended left-hand fingering appears in Example $3.10 .^{80}$

${ }^{79}$ Frederic Chopin, Nocturnes for Piano, Op. 72, (Leipzig: Breitkopf und Härtel, 1880), 2.

${ }^{80}$ Pei-Chun Hsieh, A Study of Structure and Performance Interpretation of Tyzen Hsiao's Piano Music: Memories of Home and Selections from Piano Pieces for Children, Master's dissertation, Fu Jen Catholic University, (Taipei, 2012 ), 71. 


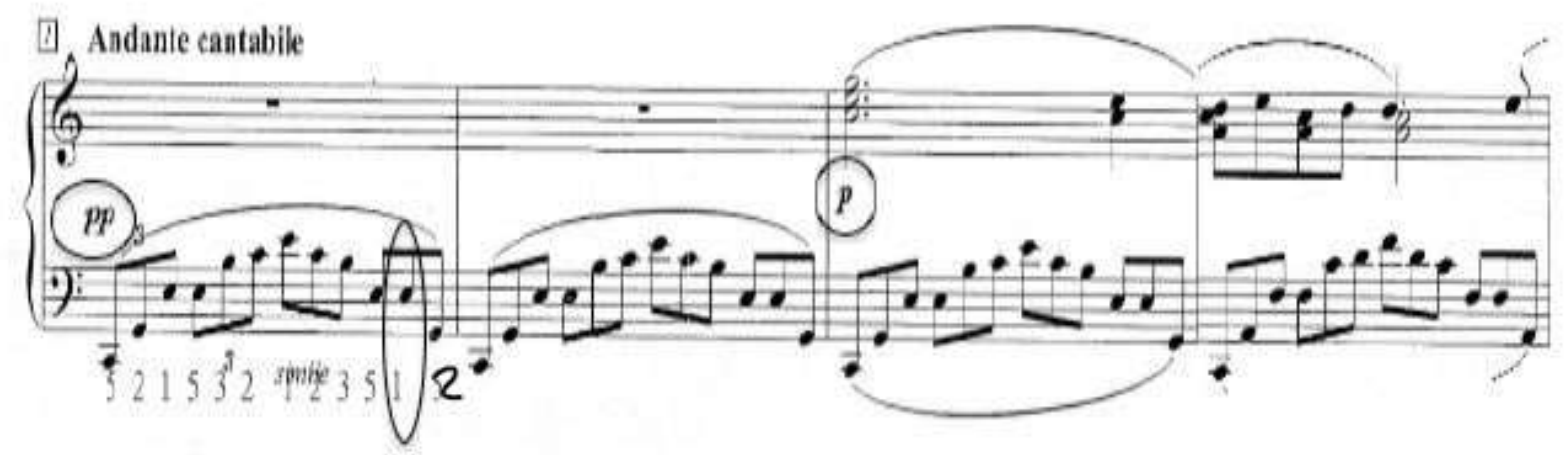

(C) 1989 by Formosa Singers Publisher. Used with Permission

Example 3.10 Tyzen Hsiao, "Memory" in Memories of Home, 1-4. ${ }^{81}$

Using this fingering makes it easier to connect the second $\mathrm{E}$ to $\mathrm{G}$; this fingering system can also be used in similar passages, such as $\mathrm{m} .4$ where the second $\mathrm{F}$ can be played with thumb to connect to low A. In the whole piece, the left hand needs to play softly, since the right hand has the main melody. In this case, the performer can place the left hand close to the keys and press the keys down slowly to create mellow and calm sounds.

Besides providing accompaniment, the left hand plays an important role bringing out its own melody to create a duet effect with the right hand in m. 35 (Example 3.11). From the second beat of measure ten, the left hand has three important quarter notes (D, E, F), which seem to sing along with $\mathrm{E}, \mathrm{D}, \mathrm{C}$ in the right hand. The performer needs to bring out both of these two cantabile lines. When we read through the score of this piece, we see how warm the sound can be because of the rich chordal progression dominated by the top voice in the right hand. In a desire for good voicing, students should first practice the top voice, where the main melody is, by itself before adding more notes. Since Hsiao did not give a time signature in this piece, the

\footnotetext{
${ }^{81}$ Tyzen Hsiao, Memories of Home, (Taipei: Formosa Singers, 1989), 4.
} 
flow of the music could be seen as a single big pulse per bar. The composer gives performers great freedom to express their emotion through the music.

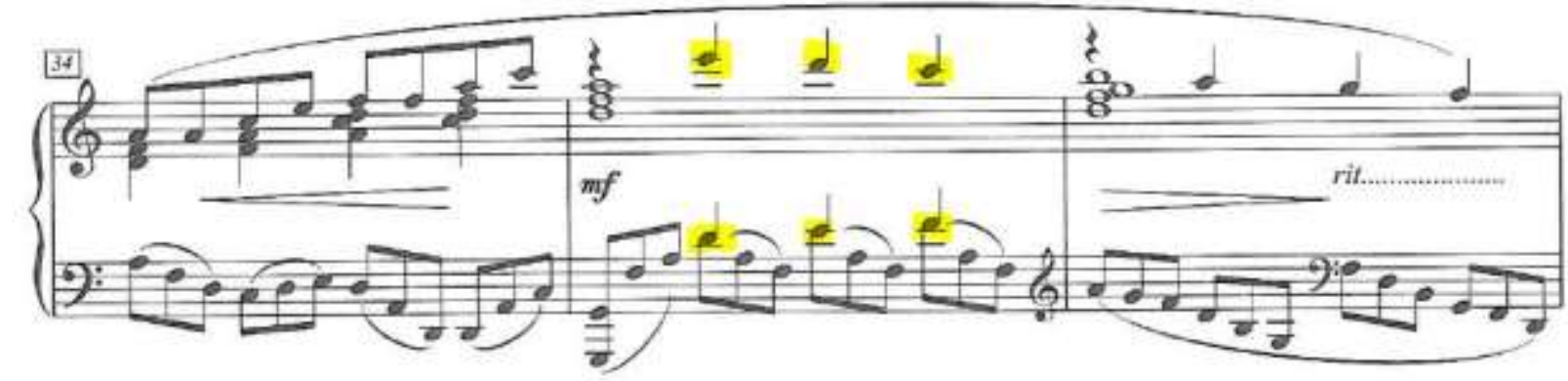

(C) 1989 by Formosa Singers Publisher. Used with Permission

Example 3.11 Tyzen Hsiao, "Memory" in Memories of Home, 34-36. ${ }^{82}$

Although the main theme occurs many times in this piece, each occurrence is presented in a slightly different pattern. The first appearance starts in m. 3 (Example 3.12); the theme is slightly altered by using repeated G's in the right hand in m. 28, as we can see in Example 3.13; the last theme happens in $\mathrm{m} .37$, where the repeated $\mathrm{G}$ becomes melodic sextuplets, as shown in Example 3.14.

${ }^{82}$ Hsiao, 6. 

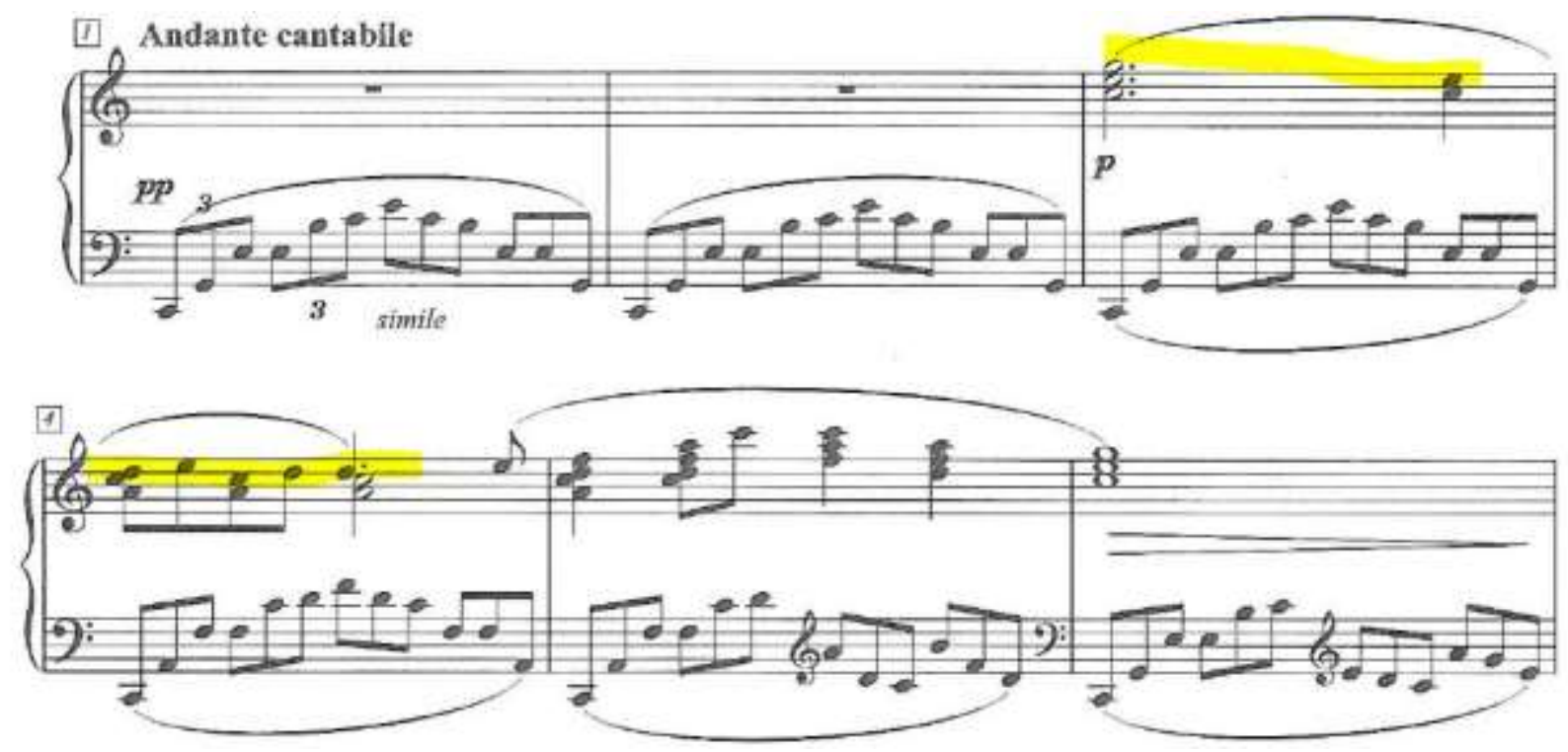

(C) 1989 by Formosa Singers Publisher. Used with Permission

Example 3.12 Tyzen Hsiao, "Memory" in Memories of Home, 1-6. ${ }^{83}$

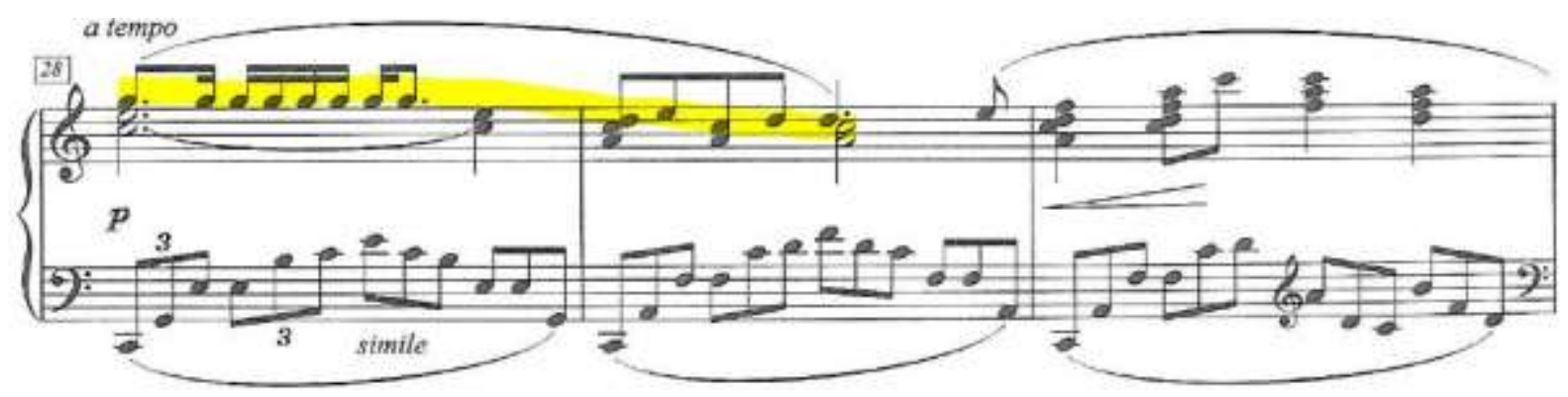

(C) 1989 by Formosa Singers Publisher. Used with Permission

Example 3.13 Tyzen Hsiao, "Memory" in Memories of Home, 28-30. ${ }^{84}$

${ }^{83}$ Hsiao, 4.

${ }^{84}$ Hsiao, 5. 


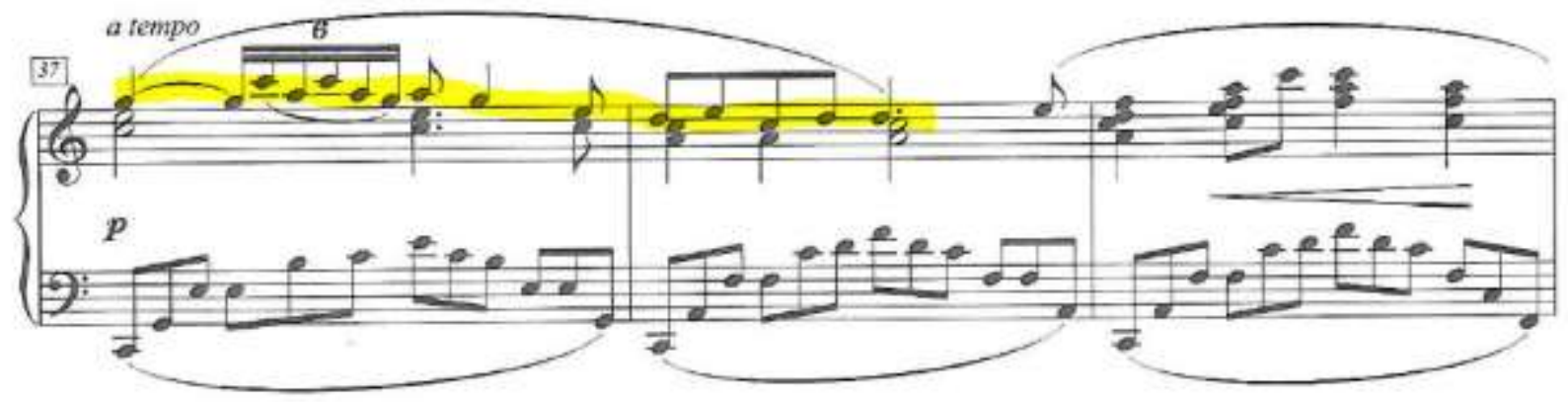

(C) 1989 by Formosa Singers Publisher. Used with Permission

Example 3.14 Tyzen Hsiao, "Memory" in Memories of Home, 37-39. ${ }^{85}$

Each of the three examples above shows different characters, even though the same melodic idea is still there. The first one seems to be calmer and softer, while the second one sounds more pleading; the last one uses a melodic turn to express the mood. When playing the repeated G's, students may find it easier to avoid making a dull sound by using different fingers on different spots of the key.

In this transcription from a song, Hsiao uses varying approaches in "Memory" to present the words. From mm. 20-25, the lyrics say, "They say the America is heaven, and they long to move there; But, if they ask me, "Is that true?" When this question is asked, the music starts slowing down and getting softer in m. 25. Hsiao then responds to his friends in the second half of mm. 25-26, "No, my heaven is not here" (Example 3.15).

\footnotetext{
${ }^{85}$ Hsiao, 6.
} 

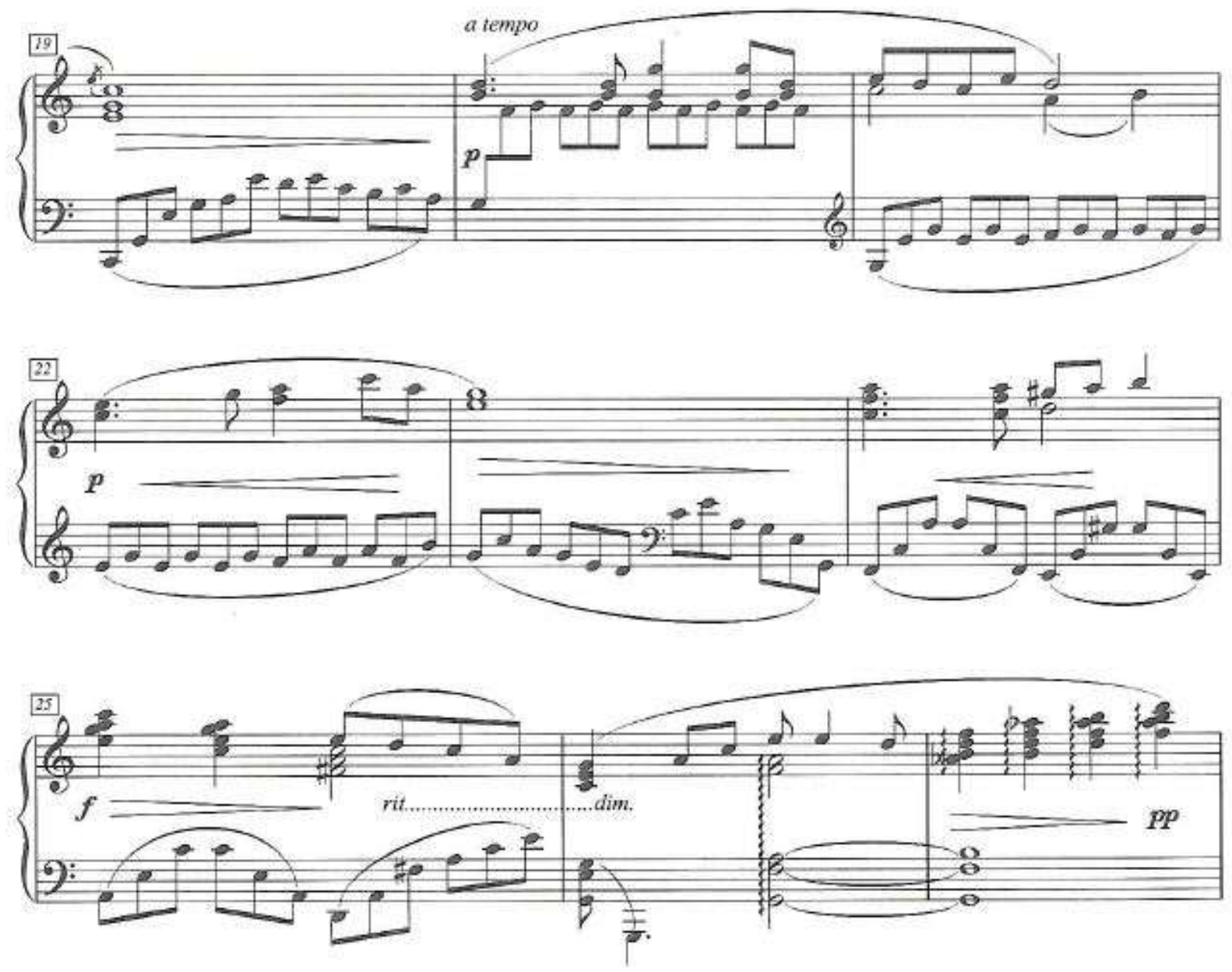

(C) 1989 by Formosa Singers Publisher. Used with Permission

Example 3.15 Tyzen Hsiao, "Memory" in Memories of Home, 19-27. ${ }^{86}$

Compared with the first piece, "Memory" seems to resemble a ballade in which the composer is telling a story about leaving his homeland and moving to another country. This piece ends calmly, marked ppp in the score, as if to imply the composer's state of mind at that moment (Example 3.16). ${ }^{87}$

\footnotetext{
${ }^{86}$ Hsiao, 5.

${ }^{87}$ Hsieh, Pei-Chun, A Study of Structure and Performance Interpretation of Tyzen Hsiao's Piano Music: Memories of Home and
} 


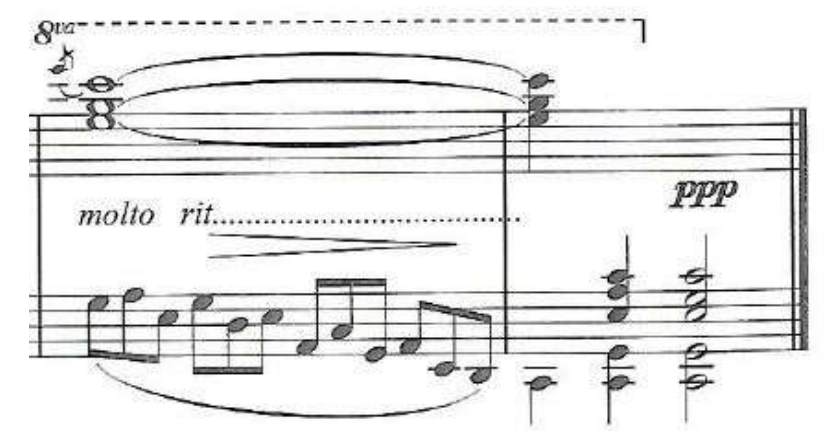

(C) 1989 by Formosa Singers Publisher. Used with Permission

Example 3.16 Tyzen Hsiao, "Memory" in Memories of Home, 45-46. ${ }^{88}$

\section{Playground}

\section{Background}

Hsiao felt that this piece is filled with children's imagination and ambition. He thought about his childhood where he used to play with his friends at the playground nearby his house. ${ }^{89}$ In this two-page work, Hsiao uses more than ten musical terms to tell performers the exact tempos and moods he wants when playing "Playground."

Selections from Piano Pieces for Children. Master's dissertation, Fu Jen Catholic University, (Taipei, 2012 ), 28. ${ }^{88}$ Tyzen Hsiao, Memories of Home, (Taipei: Formosa Singers, 1989), 6.

${ }^{89}$ Hsieh, Pei-Chun, A Study of Structure and Performance Interpretation of Tyzen Hsiao's Piano Music: Memories of Home and Selections from Piano Pieces for Children. Master's dissertation, Fu Jen Catholic University, (Taipei, 2012), 24 


\section{Pedagogical Aspects}

The piece begins playfully and then turns to a march-like passage in $\mathrm{m}$. 9. Within an ABA' form, as shown in Table 3.2, ${ }^{90}$ pentatonic scales give an Oriental flavor while providing melodic material at the beginning of this piece as shown in Example 3.17.

\begin{tabular}{|c|cc|cc|cc|c|}
\hline Sections & \multicolumn{3}{|c|}{ A } & \multicolumn{2}{c|}{ B } & \multicolumn{2}{c|}{ A' Coda } \\
\hline Subsections & a & a' & b & b' & a'” & new materials & \\
\hline Measures & $1-8$ & $9-16$ & $17-24$ & $25-32$ & $33-40$ & $41-56$ & $57-61$ \\
\hline
\end{tabular}

Table 3.2

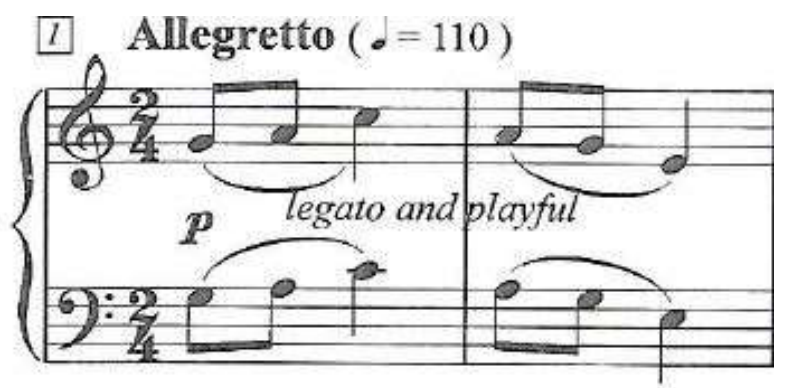

(C) 1989 by Formosa Singers Publisher. Used with Permission

Example 3.17 Tyzen Hsiao, "Playground" in Memories of Home, 1-2. ${ }^{91}$

\footnotetext{
${ }^{90}$ Ibid.

${ }^{91}$ Tyzen Hsiao, Memories of Home, (Taipei: Formosa Singers, 1989), 7.
} 
There are two melodic motives that appear, with transformations, throughout the work.

Hsiao's fondness with syncopated writing shows in $\mathrm{m} .5$, where the melodic pentatonic motive of the first measure appears as an important element. The syncopated passages can be seen in the examples provided below (Example 3.18, 3.19, 3.20, 3.21, 3.22):

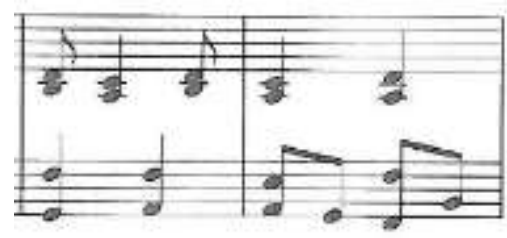

(C) 1989 by Formosa Singers Publisher. Used with Permission

Example 3.18 Tyzen Hsiao, "Playground" in Memories of Home, 5-6. ${ }^{92}$

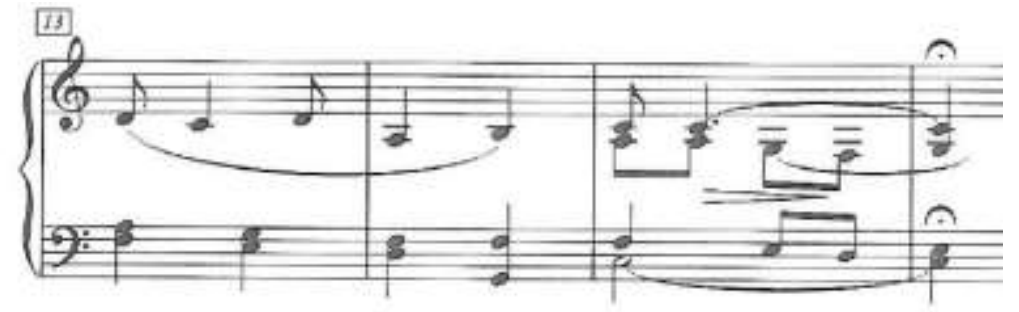

rar

(C) 1989 by Formosa Singers Publisher. Used with Permission

Example 3.19 Tyzen Hsiao, "Playground" in Memories of Home, 13-16. ${ }^{93}$

92 Ibid.

93 Ibid. 


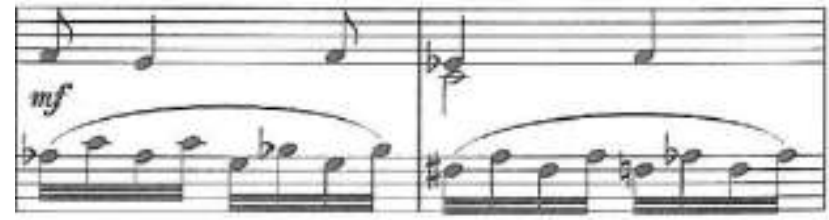

(C) 1989 by Formosa Singers Publisher. Used with Permission

Example 3.20 Tyzen Hsiao, "Playground" in Memories of Home, 29-30. ${ }^{94}$

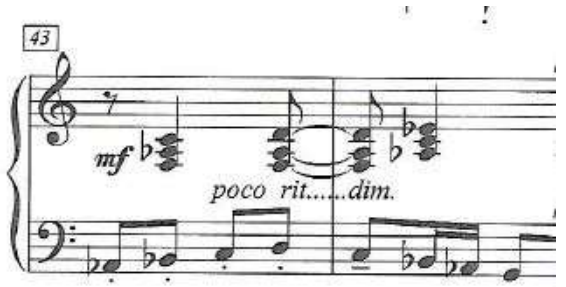

(C) 1989 by Formosa Singers Publisher. Used with Permission

Example 3.21 Tyzen Hsiao, "Playground" in Memories of Home, 43-44. ${ }^{95}$

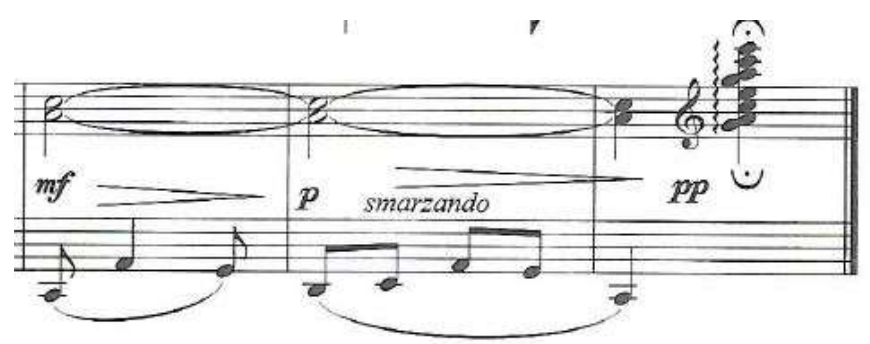

(C) 1989 by Formosa Singers Publisher. Used with Permission

Example 3.22 Tyzen Hsiao, "Playground" in Memories of Home, 19-61. ${ }^{96}$

${ }^{94}$ Hsiao, 8.

${ }^{95} \mathrm{Ibid}$.

${ }^{96}$ Ibid. 
The first measure sets the model for later melodic lines, which Hsiao varies as the piece unfolds. The rhythmic material of the first measure recurs in $\mathrm{m} .9$ in a contrapuntal texture;

Hsiao indicates poco marcato, which contrasts with the legato and playful first measure.

Students should have relaxed arms when playing the opening phrase, with a light touch to the keys, perhaps imagining walking on tiptoes. When a similar passage happens in $\mathrm{m} .9$, students should still be able to play legato but with a steady tempo. The B section starts from mm. 17-32 with the same melodic idea we saw in the first two measures of the piece. However, whole-tone scales and chromaticism create a different sound palette. Please see Example 3.23.
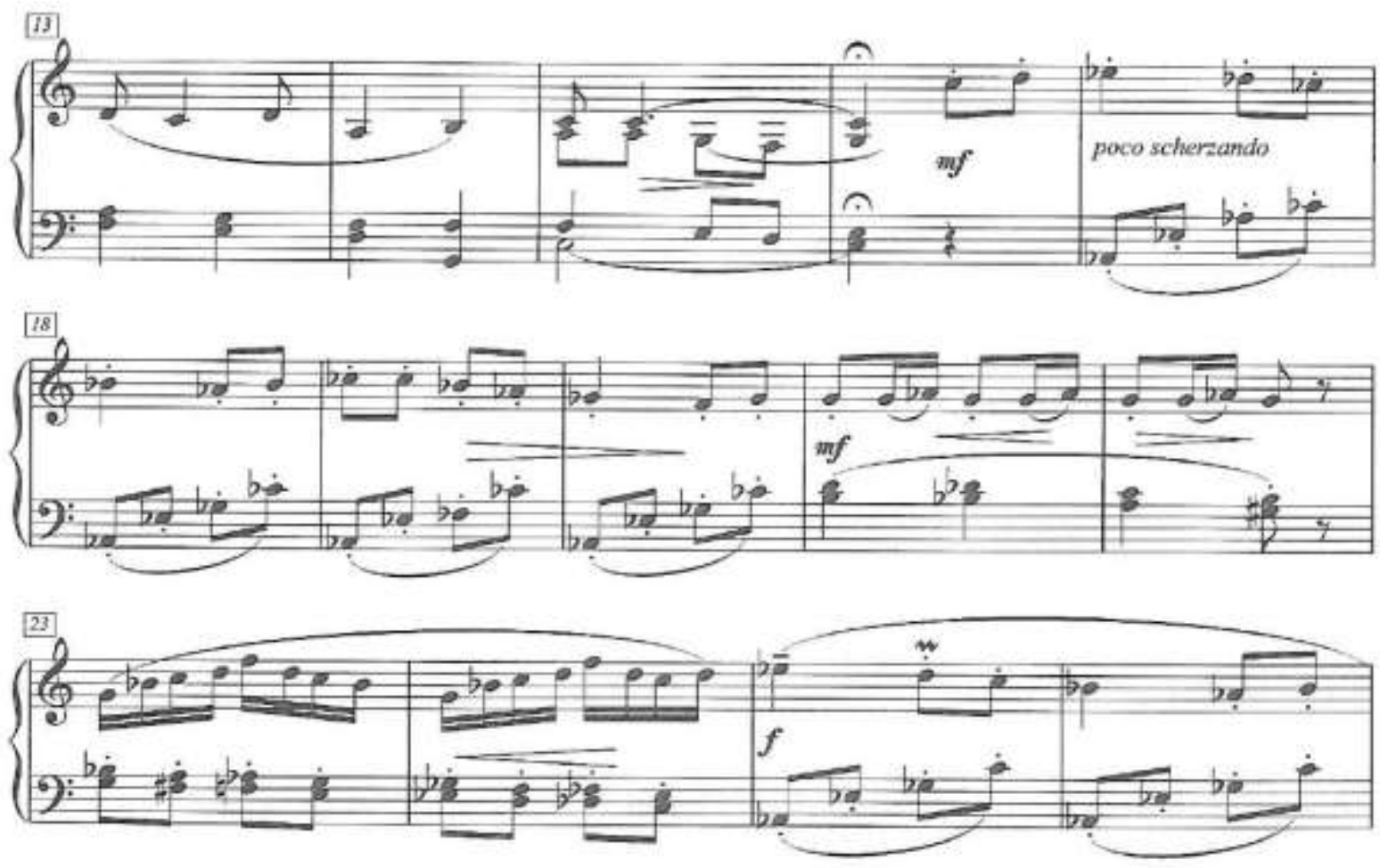

(C) 1989 by Formosa Singers Publisher. Used with Permission

Example 3.23 Tyzen Hsiao, "Playground" in Memories of Home, 13-30. ${ }^{97}$

${ }^{97}$ Hsiao, 7. 
When we compare the material given to each hand from mm. 17-20, mm. 21-22, and mm. 23-24, we see that the articulation starts changing from staccato with legato, to completely legato, to only staccato in the left hand; by contrast, the right hand starts with staccato, to another staccato, followed by legato in mm. 21-22, to completely legato in mm. 23-24 (Example 3.23). In keeping with the playful mood of the piece, students can be encouraged to play with loose arms in this section, as a way to prevent getting a heavy sound.

As in "Memory," "Playground" contains a section, mm. 33-36, in which the music sounds like a conversation between hands, as shown in Example 3.24. The two eighth notes can be played as a response or echo, following the G-A-C in the right hand. A similar call and response effect occurs in mm. 42-44, as revealed in Example 3.25. The legato phrase in mm. 4142 seems to ask a question, while mm. 43-44 answers in a very playful way with staccato, ending on $\mathrm{F}$ with fermata.

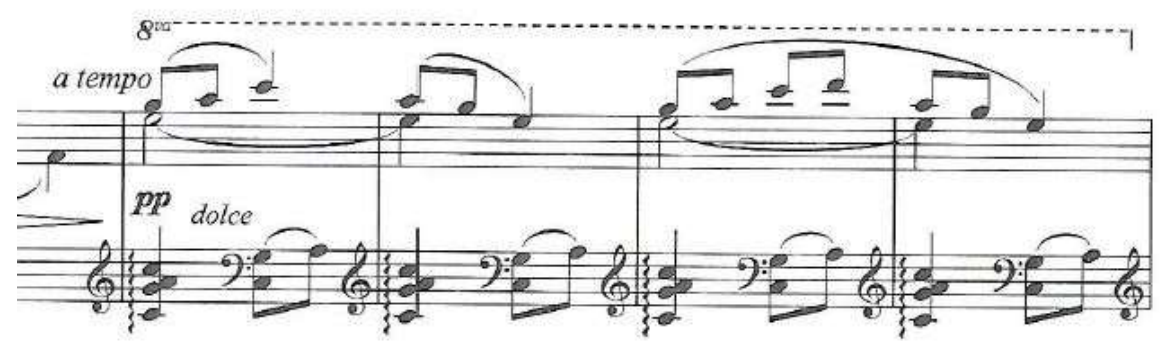

(C) 1989 by Formosa Singers Publisher. Used with Permission Example 3.24 Tyzen Hsiao, "Playground" in Memories of Home, 33-36. ${ }^{98}$

\footnotetext{
${ }^{98}$ Hsiao, 8.
} 


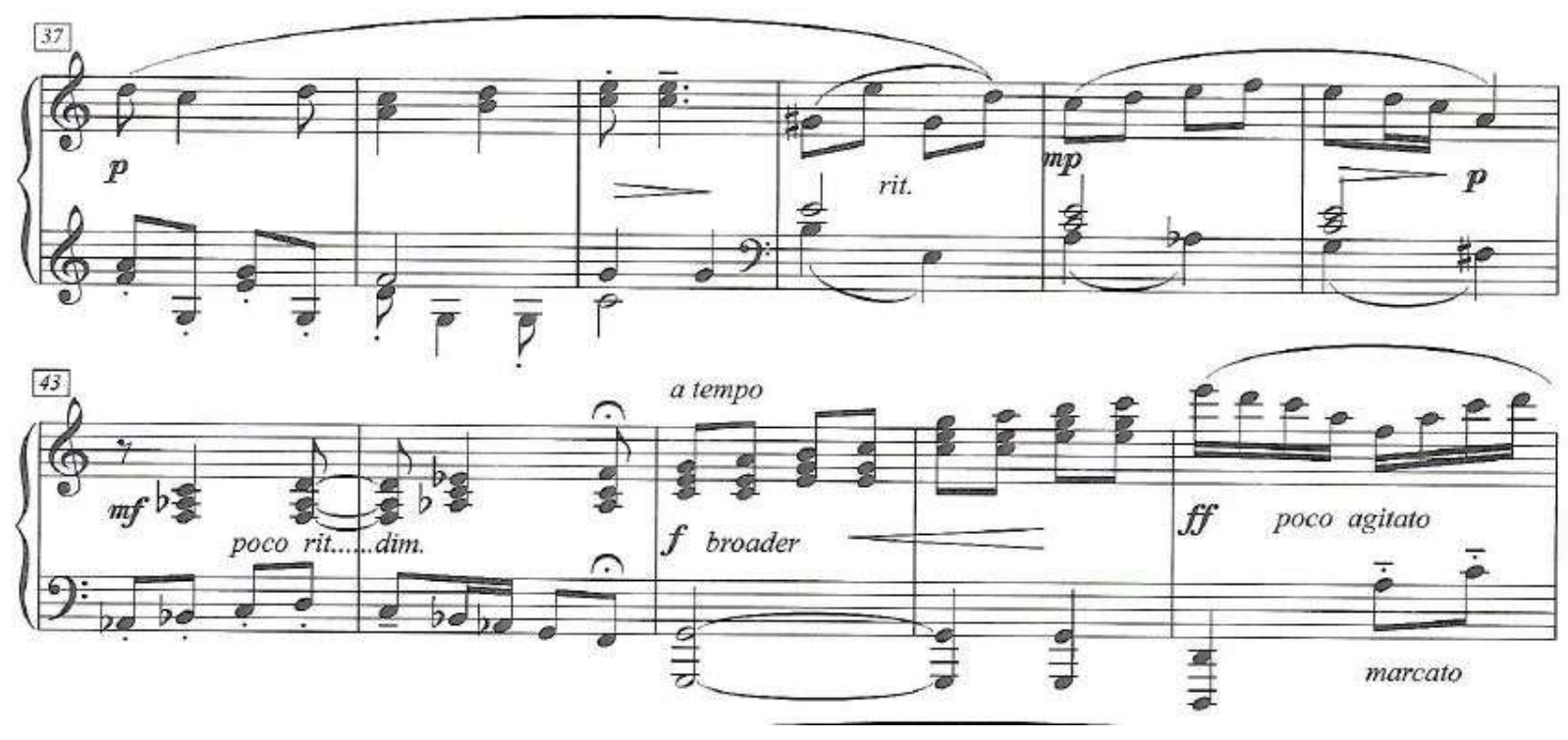

CC 1989 by Formosa Singers Publisher. Used with Permission

Example 3.25 Tyzen Hsiao, "Playground" in Memories of Home, 37-47. 99

The repeated motions in mm. 47-52 (Example 3.26) should be played very carefully. The right arm should describe a circular shape while playing. Instead of being stiff, the performer must be able to play this section smoothly and with energy. Toward the end of the piece, Hsiao inserts four dynamic markings within five measures, from $f f$ to $p p$ (Example 3.27).

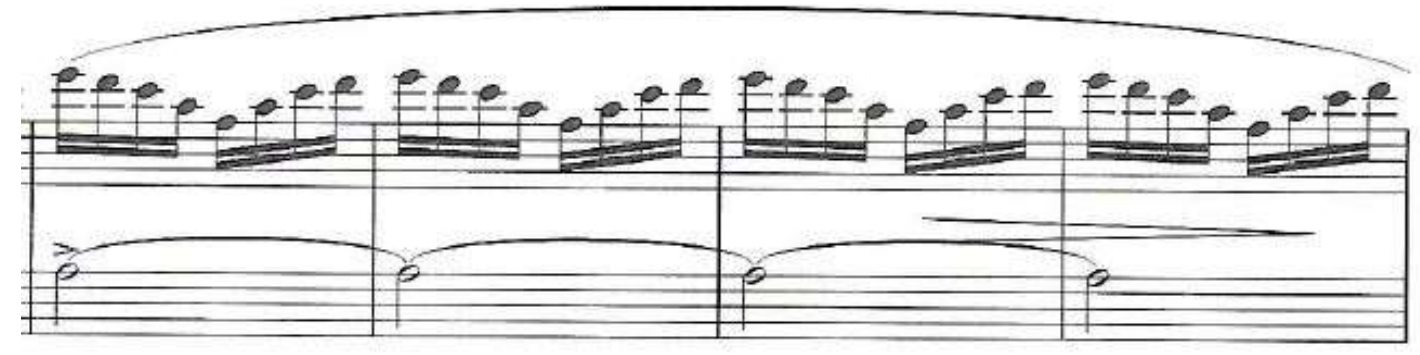

(C) 1989 by Formosa Singers Publisher. Used with Permission

Example 3.26 Tyzen Hsiao, "Playground" in Memories of Home, 49-52. ${ }^{100}$

${ }^{99}$ Ibid. 


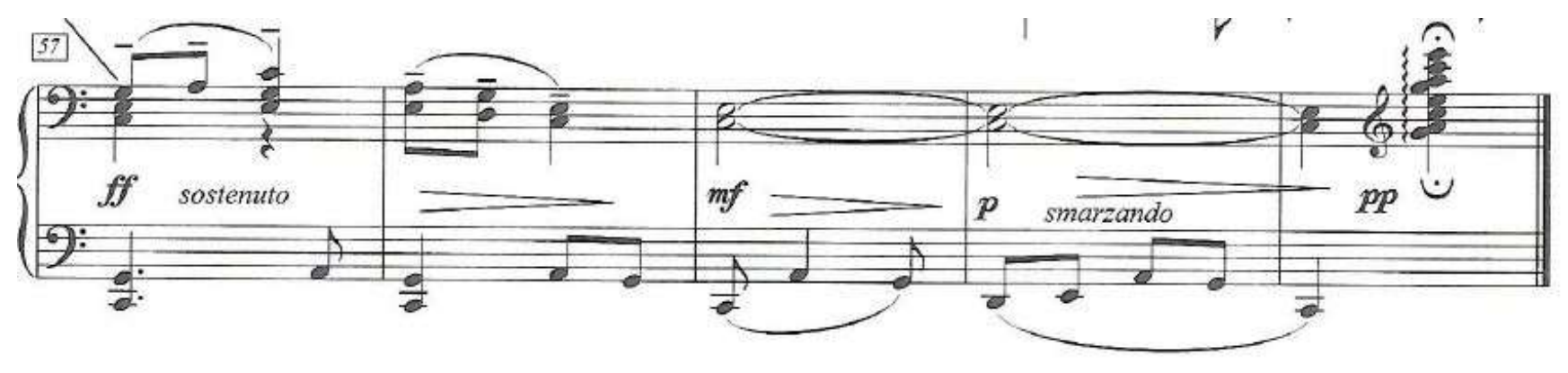

(C) 1989 by Formosa Singers Publisher. Used with Permission

Example 3.27 Tyzen Hsiao, "Playground" in Memories of Home, 57-61. ${ }^{101}$

\section{Ancient Taiwanese Melody}

\section{Background}

When Hsiao was a child, he and his family went to visit their ancestors' graves, to offer their respect on Tomb Sweeping Day, a national holiday in Taiwan. This melody came from his memory of hearing an old person sing. The entire piece conveys a sense of melancholy and the feeling of missing lost loved ones. Compared with the previous three pieces, "Ancient Taiwanese Melody" seems to be slightly easier to play, but with a deeper and sadder mood.

\section{Pedagogical aspects}

As previously indicated, the musical term cantabile appears frequently in Hsiao's music. The Table 3.3 shows that this piece starts with two measures of introduction in F Major,

\footnotetext{
100 Ibid.

${ }^{101}$ Tyzen Hsiao, Memories of Home, (Taipei: Formosa Singers, 1989), 8.
} 
marked Andante cantabile sostenuto. The main melody appears in $\mathrm{mm} .3-8$; the melody is repeated exactly, in octaves, in several following passages, as seen in Example 3.28.

\begin{tabular}{|c|c|c|c|c|c|}
\hline Sections & $\begin{array}{c}\text { Piano } \\
\text { Introduction }\end{array}$ & A & B & A' $^{\prime}$ & Coda \\
\hline Measures & $1-2$ & $3-10,11-18$ & $19-27$ & $28-35$ & $36-40$ \\
\hline
\end{tabular}

Table 3.3 

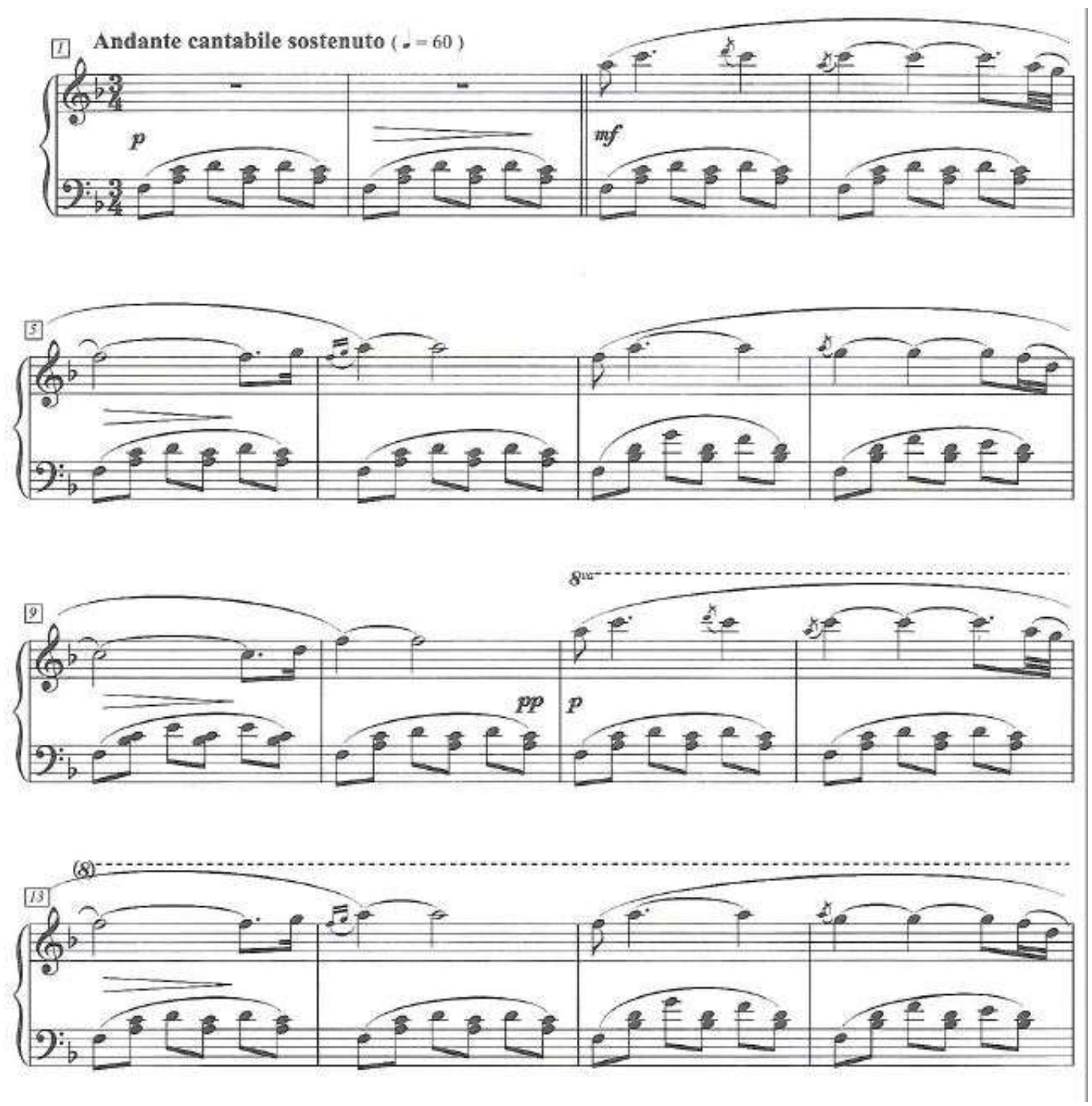

(C) 1989 by Formosa Singers Publisher. Used with Permission

Example 3.28 Tyzen Hsiao, “Ancient Taiwanese Melody” in Memories of Home, 1-16. ${ }^{102}$

When playing these passages, students should avoid creating unwanted accents. The $\mathrm{D}$ in the introduction should be played especially carefully, since it can be too easy to play with accent on

102 Hsiao, 9. 
the thumb. The double thirds need to sound simultaneously. After the introduction, the accompaniment needs to be played more softly.

The score reveals many grace notes in this piece. These grace notes can create an effect called "sliding," which is a common performing style when playing the Chinese stringed instrument called Erhu. ${ }^{103}$ Because the melody came from a sad tune Hsiao heard when he was a child, the performer should play the melody as if humming a song, placing the fingers close to the keys when playing this melody, instead of lifting them up to play the notes. This technique can create a softer sound in the piano.

Although the main melody is in the right hand, there are also other important voices in tenor and bass, with tenuto markings in the left hand, which we can see in Example 3.29. Bringing out melodies in both hands can give the audience the feeling of a vocal duet.

\footnotetext{
${ }^{103}$ A two-stringed bowed instrument that has been played in China for more than a thousand years ago. It consists of a long vertical stick-like neck, at the top of which are two large turning pegs; and at the bottom is a small resonator body (sound box), which is covered with python skin on the front end. Two strings are attached from the pegs to the base, and a small loop of string placed around the neck and strings acts as a nut and pulls the strings towards the skin, holding a small wooden bridge in place.
} 

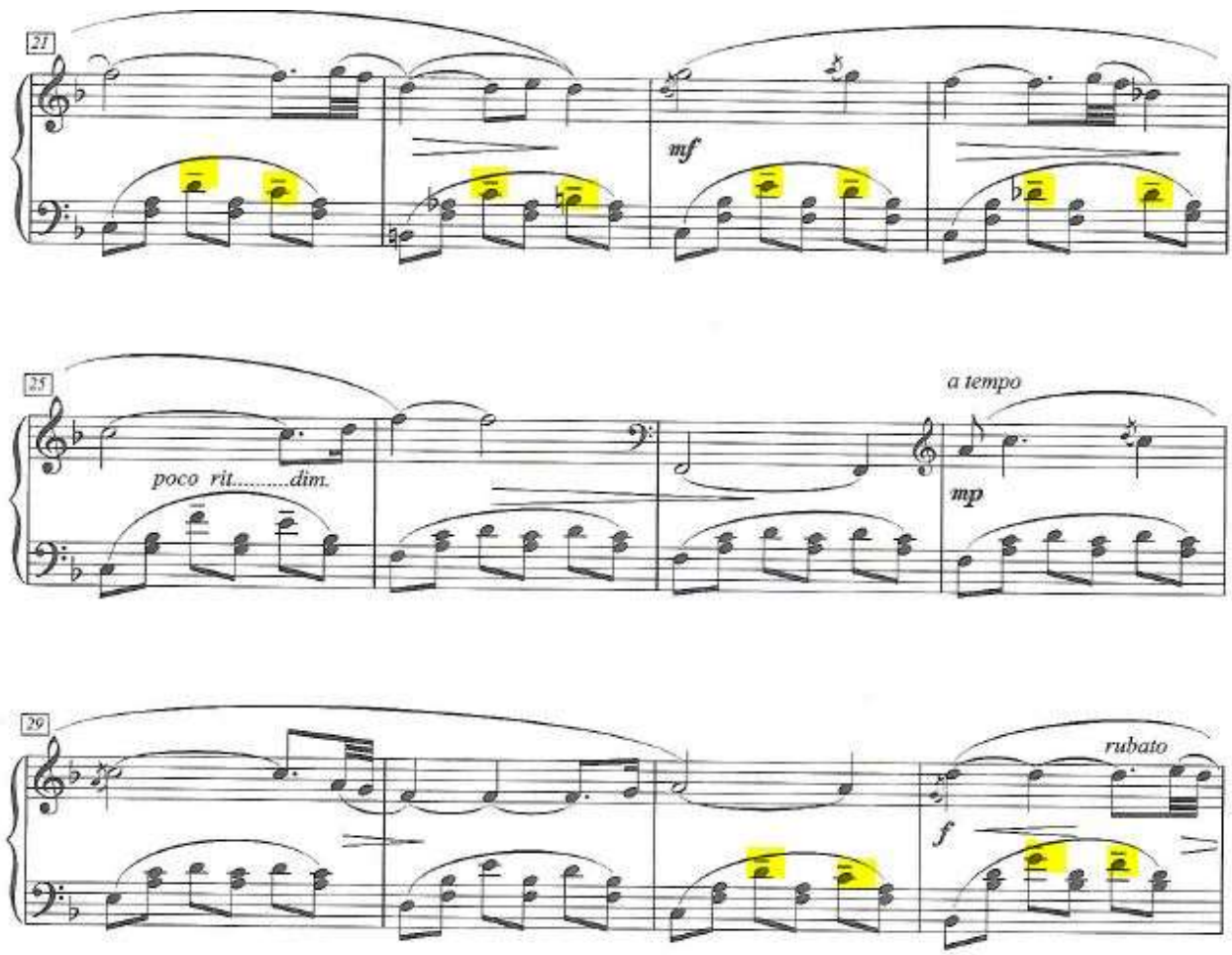

(C) 1989 by Formosa Singers Publisher. Used with Permission

Example 3.29 Tyzen Hsiao, “Ancient Taiwanese Melody” in Memories of Home, 21-32. ${ }^{104}$

There are three bell-like sounds which could resemble a big temple bell; these occur in m. 27 and 37 on the pitch $\mathrm{F}$ in the bass. Performers should strive to imitate the sound of the bell in this section. The last chord of the piece is the second inversion of a $\mathrm{D}$ minor chord in the left hand; however, the right hand has to cross to play the F which is the focal pitch in the piece. This suggests an F major chord with an added sixth. If we include every note in the last measure, the chord will become F-G-A-C-D, an example of the Eastern pentatonic scale (Example 3.30). ${ }^{105}$ The performer is encouraged to slow down slightly on the left three notes in the right hand, as the sorrow comes to an end.

\footnotetext{
104 Tyzen Hsiao, Memories of Home, (Taipei: Formosa Singers, 1989), 10.

105 Chia-Te Liu, A Pedagogical Introduction to the Piano Works of Tyzen Hsiao, DMA dissertation, University of Kansas, (Lawrence, 2013), 28.
} 


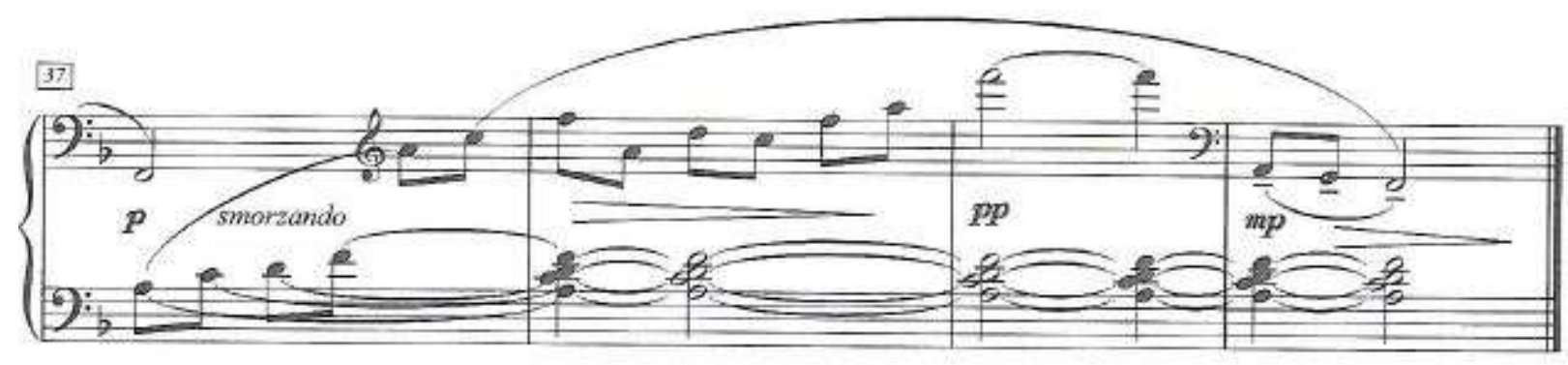

(C) 1989 by Formosa Singers Publisher. Used with Permission

Example 3.30 Tyzen Hsiao, “Ancient Taiwanese Melody” in Memories of Home,.37-40. ${ }^{106}$

\section{Elegy}

Background

Compared to the previous piece, there are more emotional fluctuations and technically challenging passages in "Elegy." Reflecting on his childhood, Hsiao began to feel sad, thinking of all the fun times he had missed. ${ }^{107}$ "Elegy" is very dramatic and expressive. The composer projects his childhood feelings directly into the piece. It starts with lento molto expressive then the piece becomes more dramatic and energetic, with chordal passages marked $f f$. The musical terms in "Elegy" go from meno mosso, poco stringendo (which requires performers to play with an accelerating tempo), to calando at the end of this piece.

Pedagogical aspects

106 Tyzen Hsiao, Memories of Home, (Taipei: Formosa Singers, 1989), 10.

${ }^{107}$ Hsieh, Pei-Chun, A Study of Structure and Performance Interpretation of Tyzen Hsiao's Piano Music: Memories of Home and Selections from Piano Pieces for Children. Master's dissertation, Fu Jen Catholic University, (Taipei, 2012 ), 30. 
Hand-crossing is the most challenging technique in this piece. Besides moving the left hand quickly to play notes in a higher register, students need to pay attention to the articulation of phrasings as well. This piece also reveals ABA' form with a coda at the end, as shown in Table 3.3. However, in section $\mathrm{B}$, there are new materials which are not necessarily related to the main theme.

\begin{tabular}{|c|c|c|c|c|}
\hline Sections & A & B & $A^{\prime}$ & Coda \\
\hline Subsections & $\mathrm{a}^{\prime}$ & d transition & $b^{\prime}{ }^{\prime}$ & \\
\hline Measures & $1-4 \quad 4-8$ & $\begin{array}{llll}9-16, & 17-20, & 21-28, & 29-33\end{array}$ & $34-37 \quad 38-40$ & $41-48$ \\
\hline
\end{tabular}

Table $3.4^{108}$

Most of the time the left hand has to cross over the right hand to play three melodic notes; in addition, when playing these three notes students need to be able to execute the crescendo and diminuendo written in the score (Example 3.31). Besides the difficulty of handcrossing, it could be challenging to play the right-hand accompaniment as well. The first note of each triplet needs to be played softly and evenly. In m. 9 (Example 3.32), the right arm should lead the right hand while playing scale-like passages. Students should have natural hand position on the piano instead of curling the fingers too much, which can create tension while playing.

108 Ibid. 

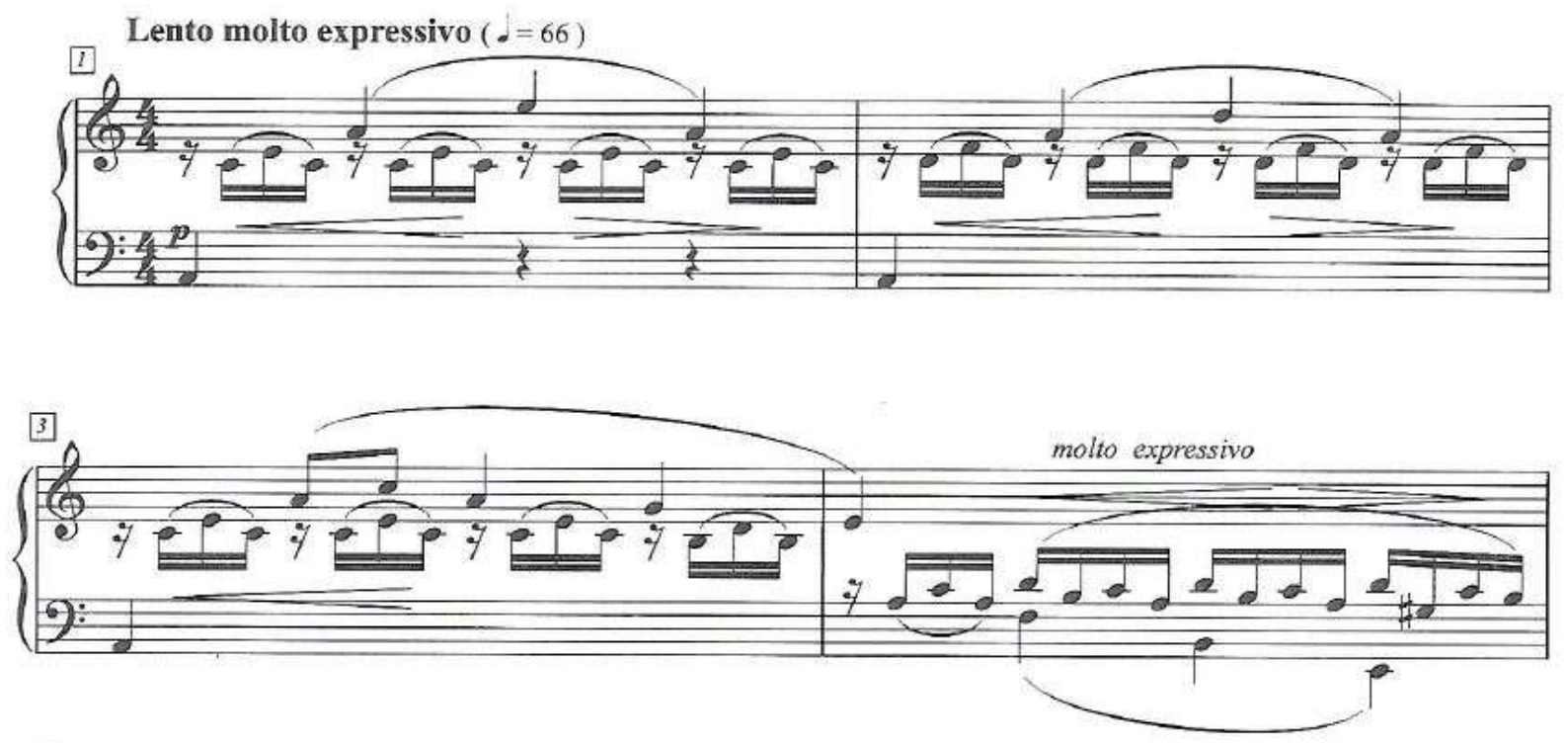

(C) 1989 by Formosa Singers Publisher. Used with Permission Example 3.31 Tyzen Hsiao, "Elegy" in Memories of Home, 1-4. ${ }^{109}$

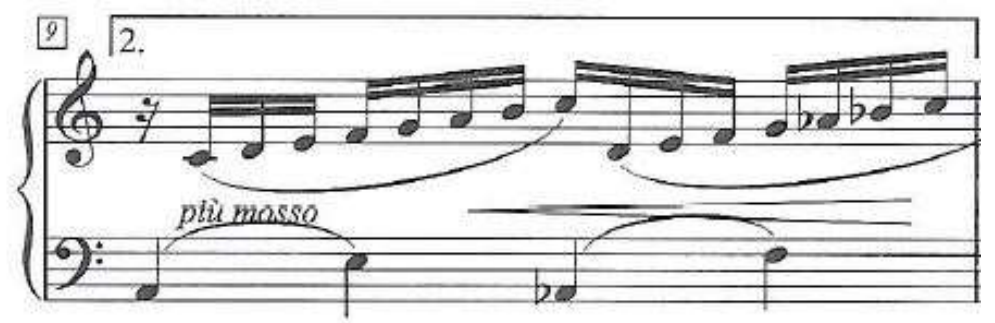

(C) 1989 by Formosa Singers Publisher. Used with Permission

Example 3.32 Tyzen Hsiao, "Elegy" in Memories of Home, 9. ${ }^{110}$

Like the "Ancient Taiwanese Melody", there are many sections where the conversation takes place in both hands, as we can see in Example 3.33. Starting from m. 10, the melody is in the right hand; in the following measure, both hands have melodies. This same pattern happens

109 Tyzen Hsiao, Memories of Home, (Taipei: Formosa Singers, 1989), 11.

${ }^{110}$ Hsiao, 11. 
four times until the climax of this piece occurs in mm. 17-20 (Example 3.34), about which Hsiao has said, "Those imply the good memories I had when I was a child."111
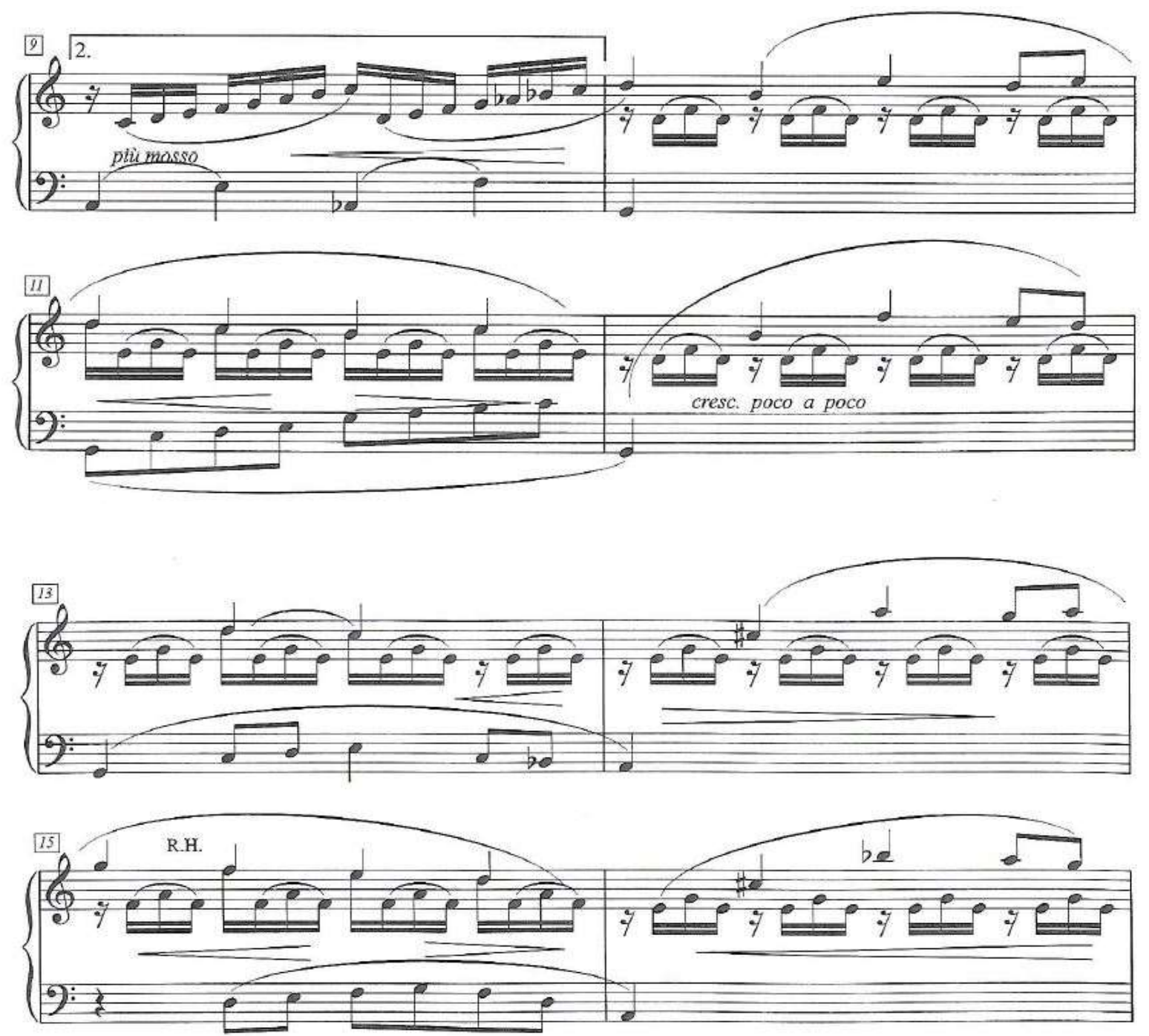

(C) 1989 by Formosa Singers Publisher. Used with Permission

Example 3.33 Tyzen Hsiao, "Elegy" in Memories of Home, 9-16. ${ }^{112}$

${ }^{111}$ Hen-Zhe Lin, A Collection of Tyzen Hsiao's Musicological Forum and Articles (Taipei: Wang-Chun-Feng Wen-Hua, 1999), 36.

${ }^{112}$ Hsiao, 12. 

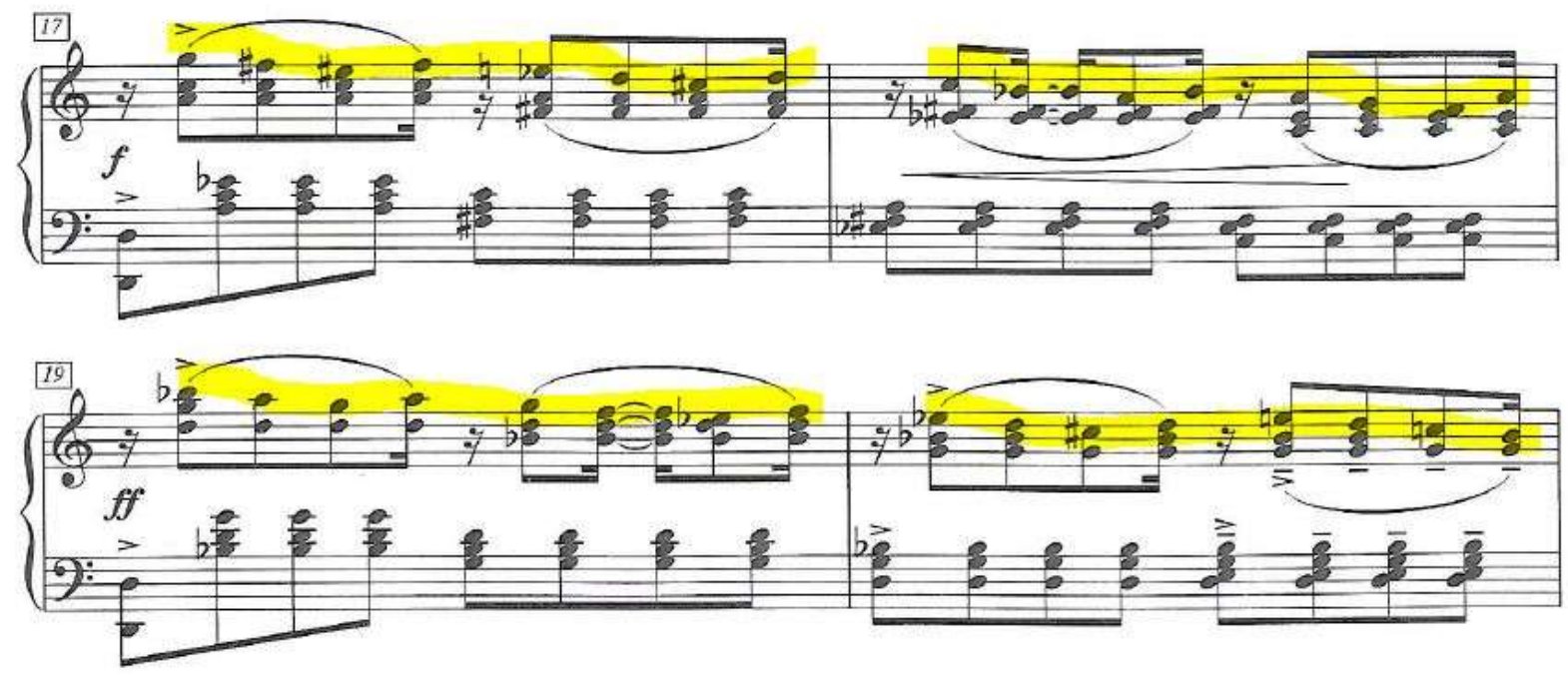

(C) 1989 by Formosa Singers Publisher. Used with Permission

Example 3.34 Tyzen Hsiao, "Elegy” in Memories of Home, 17-20. ${ }^{113}$

The climax of the piece opens with chordal passages marked $f$. The student should bring out the top voice in the right hand and avoid overpowering by the left hand. The tonality moves from $\mathrm{G}$ to B-flat in $\mathrm{m}$. 19. Accents appear frequently, especially in m. 20. After the emotional climax, the syncopated passages start from mm. 21-26, perhaps to pull the composer back to reality. In a syncopated passage like $\mathrm{m}$. 2, the second D-major chord in the right hand cannot be played with as much weight as the first D-major chord. The performer needs to put more depth into the first quarter-note D-major chord, to distinguish the differences between the eighth and quarter notes (Example 3.35).

${ }^{113}$ Hsiao, 12. 


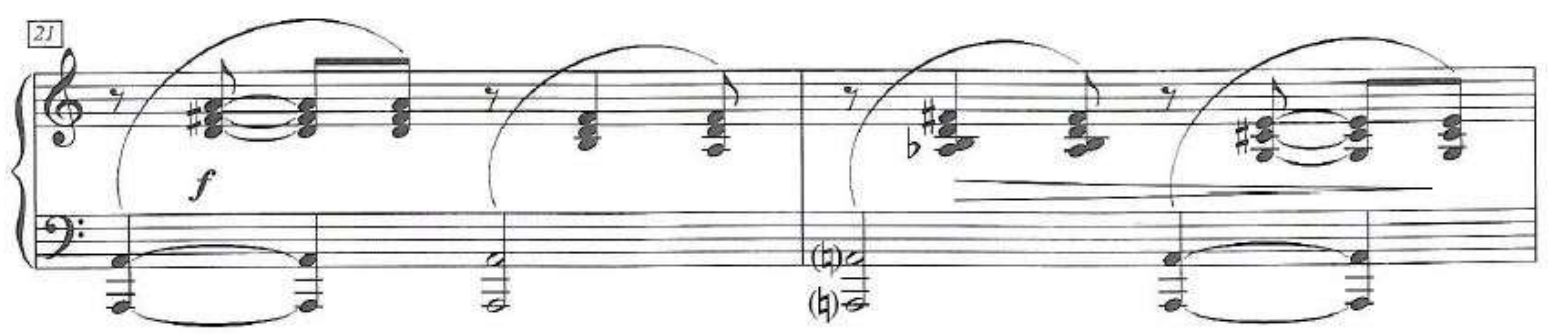

(C) 1989 by Formosa Singers Publisher. Used with Permission

Example 3.35 Tyzen Hsiao, "Elegy" in Memories of Home, 21-22..14

Before the music goes to section A', there are four measures of arpeggiated passages

(Example 3.36). Students are encouraged to alternate hands for a smooth arpeggio, avoiding gratuitous accents while alternating hands.

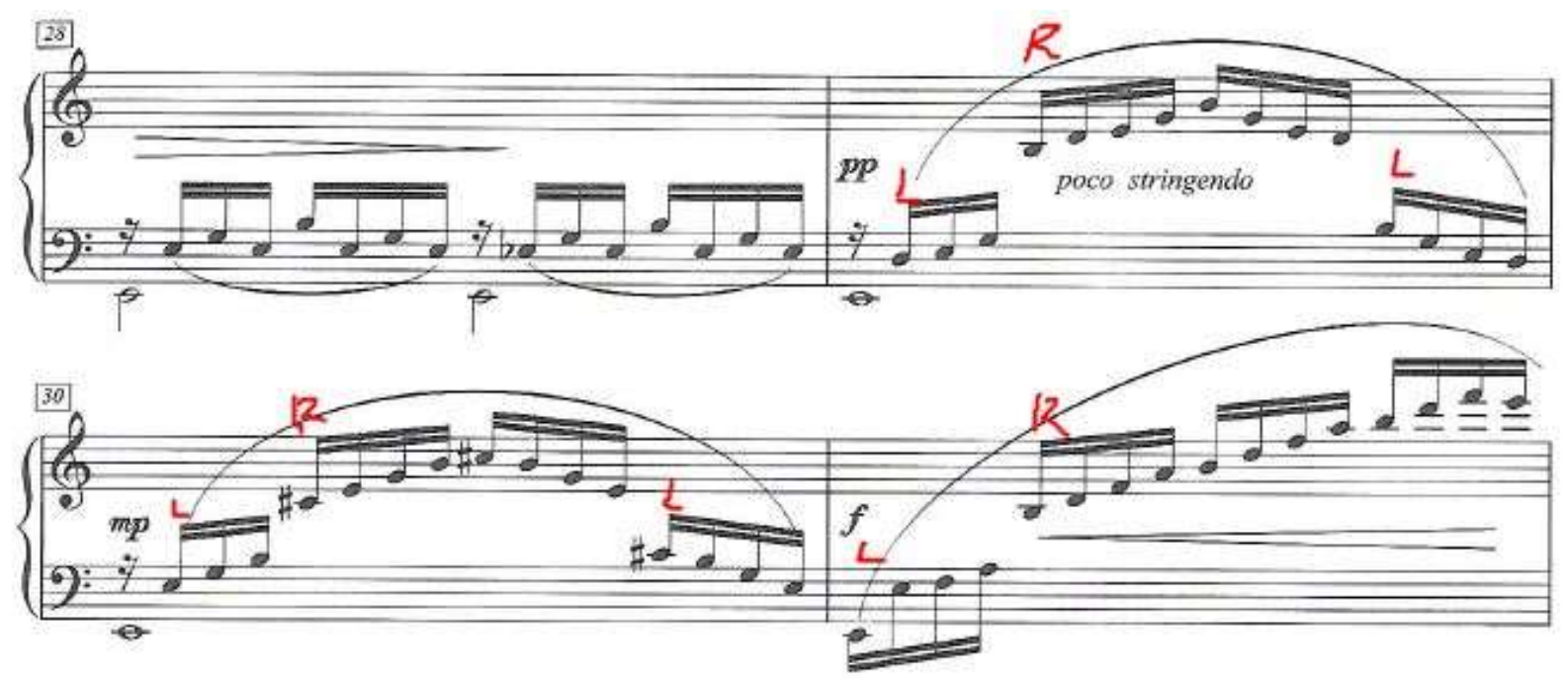

(C) 1989 by Formosa Singers Publisher. Used with Permission

Example 3.36 Tyzen Hsiao, "Elegy" in Memories of Home, 21-22..15

${ }^{114}$ Hsiao, 12.

${ }^{115}$ Hsiao, 13. 
Besides the techniques of hand-crossing and alternating hands, the use of sudden dynamic changes toward the end play an important role in this piece. In m. 44 , the tempo starts slowing down, with dynamic marking $m f p$ in $\mathrm{m}$. 44. This also happens in $\mathrm{m} .45$ and 46 where students need to observe the dynamics carefully, to show an effect of sighing, perhaps suggesting the end of Hsiao's childhood (Example 3.37). ${ }^{116}$ Even though Hsiao does not write ritardando at the end of this piece, slowing down slightly until the end can bring the piece to a peaceful close, as shown in Example 3.38.
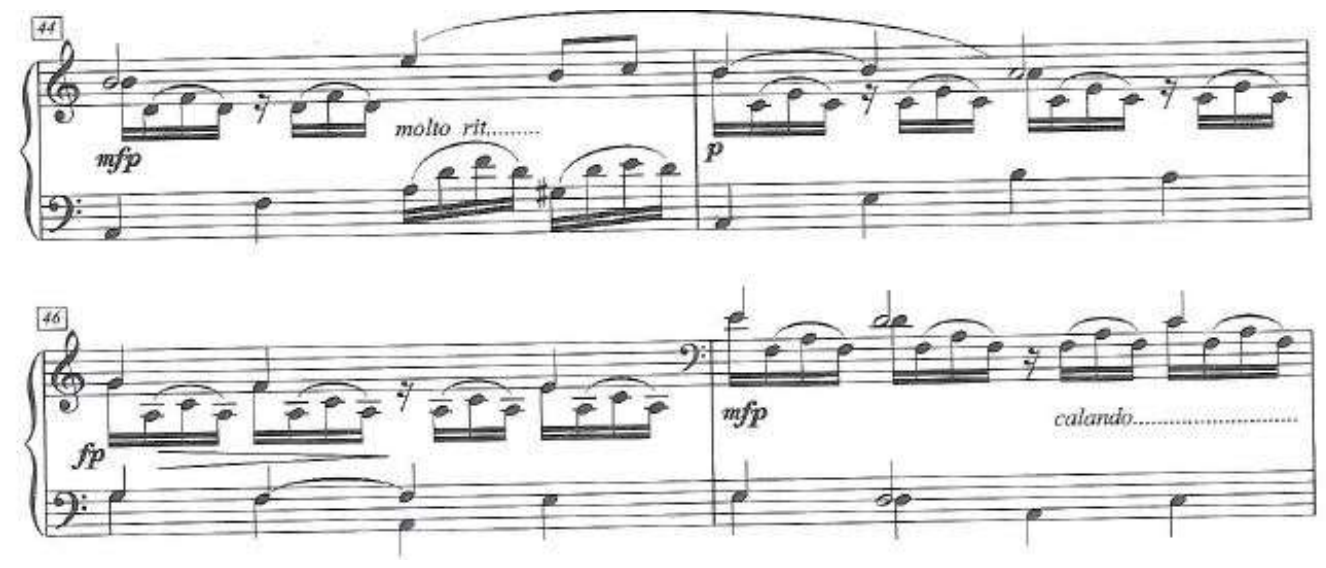

(C) 1989 by Formosa Singers Publisher. Used with Permission

Example 3.37 Tyzen Hsiao, "Elegy" in Memories of Home, 44-47. ${ }^{117}$

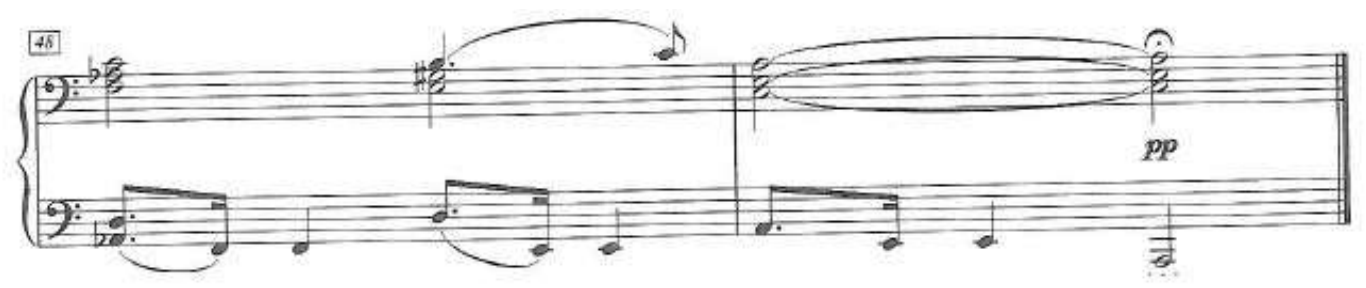

(C) 1989 by Formosa Singers Publisher. Used with Permission

Example 3.38 Tyzen Hsiao, "Elegy" in Memories of Home, 48-49. ${ }^{118}$

\footnotetext{
${ }^{116}$ Hsieh, Pei-Chun, A Study of Structure and Performance Interpretation of Tyzen Hsiao's Piano Music: Memories of Home and Selections from Piano Pieces for Children. Master's dissertation, Fu Jen Catholic University, (Taipei, 2012 ), 30.

${ }^{117}$ Hsiao, 14.
} 


\section{Frolic}

\section{Background}

During Hsiao's teenage years, he used to spend time with his cousin when his parents were not home. They went swimming and smoking by the river in Linbian Township, ${ }^{119}$ which is located in the southern part of Taiwan. ${ }^{120}$ This piece shows that Hsiao had a mischievous side as a child, exploring life while his parents are not around.

Pedagogical aspects

"Frolic" is probably the most difficult piece in this set, due to a few technical problems such as wide jumps in the left hand, fast repeated notes, and articulation. Some of these issues occur already at the opening measure, as shown in Example 3.39. Executing repeated notes can be difficult because they need to be played evenly. Students can experiment with playing the repeated notes at different locations on the keys. Teachers can have their students play a series of repeated notes with one fingering and then let students experience different sounds while playing repeated notes on different places of the same key. After this experiment, students can practice playing in a slower tempo.

\footnotetext{
118 Ibid.

${ }^{119}$ Linbian is known for its year-round warm climate, seafood restaurants, and wax apples.

120 Hsieh, Pei-Chun, A Study of Structure and Performance Interpretation of Tyzen Hsiao's Piano Music: Memories of Home and Selections from Piano Pieces for Children. Master's dissertation, Fu Jen Catholic University, (Taipei, 2012 ), 13.
} 


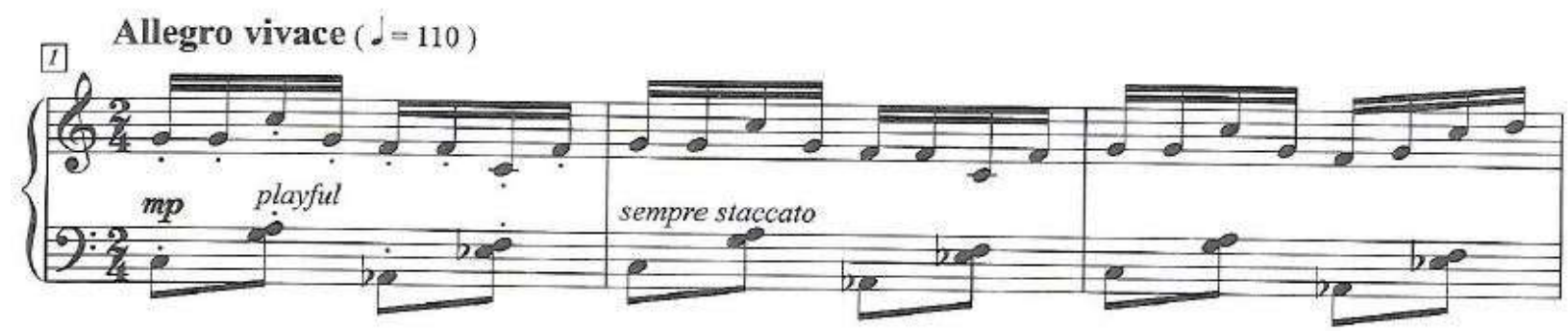

ก

(C) 1989 by Formosa Singers Publisher. Used with Permission

Example 3.39 Tyzen Hsiao, "Frolic" in Memories of Home, 1-3. ${ }^{121}$

On the first page, there are four different articulations. The piece begins with both

hands staccato, then completely legato in $\mathrm{m} .9$, back to staccato in the right hand while the left

hand remains slightly staccato, then back to legato in the left hand in m. 17 (Example 3.40).

Performers need to change the articulation and mood immediately when each difference occurs.

To prevent from making dull sound on repeated intervals, the students are encouraged to use the fingering indicated below. Using this fingering makes it easier to play the repeated intervals (Example 3.41). ${ }^{122}$

121 Tyzen Hsiao, Memories of Home, (Taipei: Formosa Singers, 1989), 15.

${ }^{122}$ Hsieh, Pei-Chun, A Study of Structure and Performance Interpretation of Tyzen Hsiao's Piano Music: Memories of Home and Selections from Piano Pieces for Children. Master's dissertation, Fu Jen Catholic University, (Taipei, 2012 ), 69. 

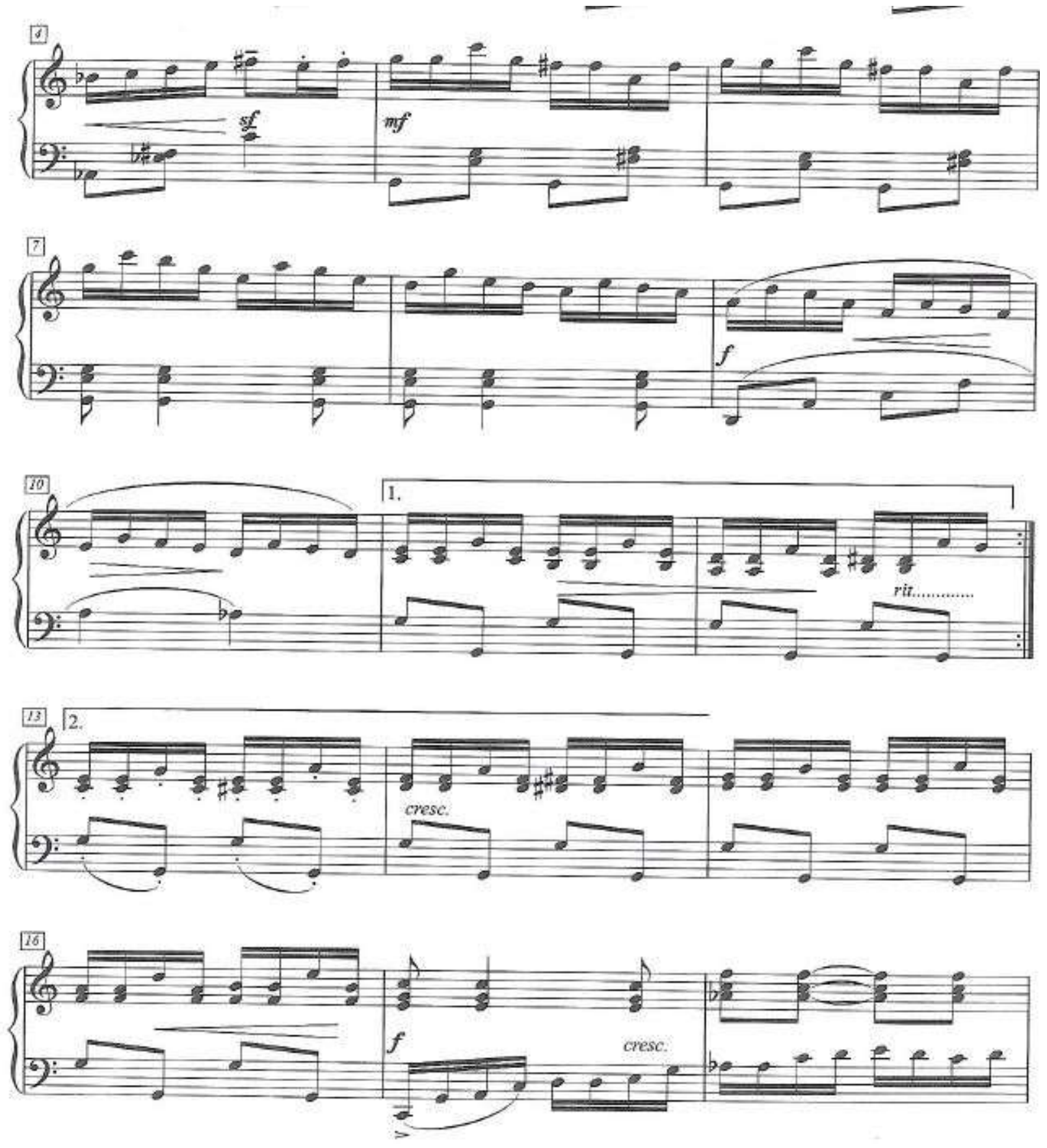

(C) 1989 by Formosa Singers Publisher. Used with Permission

Example 3.40 Tyzen Hsiao, "Frolic" in Memories of Home, 4-18. ${ }^{123}$

${ }^{123}$ Tyzen Hsiao, Memories of Home, (Taipei: Formosa Singers, 1989), 15. 


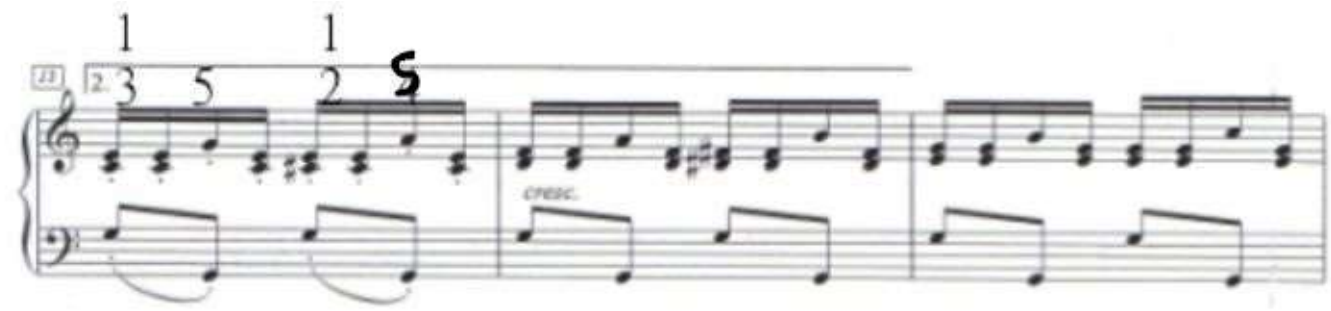

(C) 1989 by Formosa Singers Publisher. Used with Permission

Example 3.41 Tyzen Hsiao, "Frolic" in Memories of Home, 13-15. ${ }^{124}$

The score reveals an ascending melodic line in the top voice and a chromatic ascending melodic line in the right-hand alto voice (Example 3.42). Another articulation which needs to be played carefully occurs in mm. 23-26 (Example 3.43). Hsiao indicates which hand the performer should use to play the four-note group in this section. There are accents on each beat until m. 26, where two four-note groups should be played smoothly and without accent.

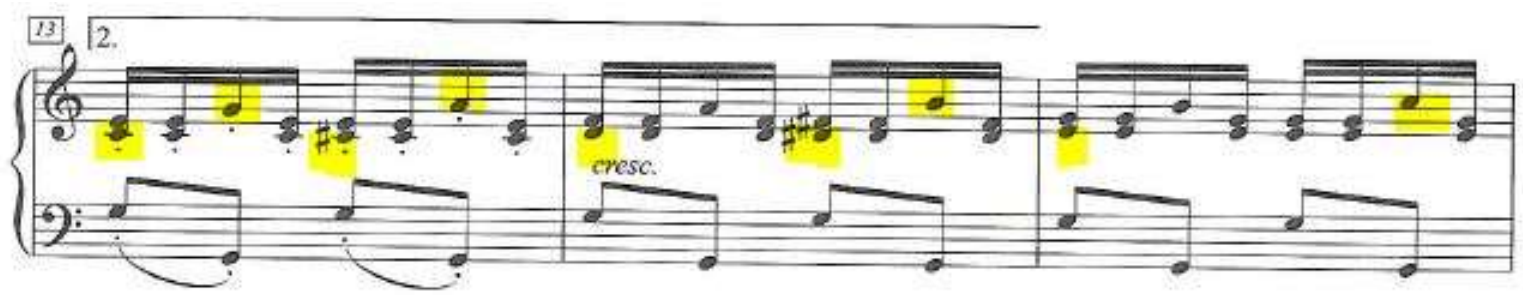

(C) 1989 by Formosa Singers Publisher. Used with Permission

Example 3.42 Tyzen Hsiao, "Frolic" in Memories of Home, 13-15. ${ }^{125}$

124 Ibid.

125 Ibid. 

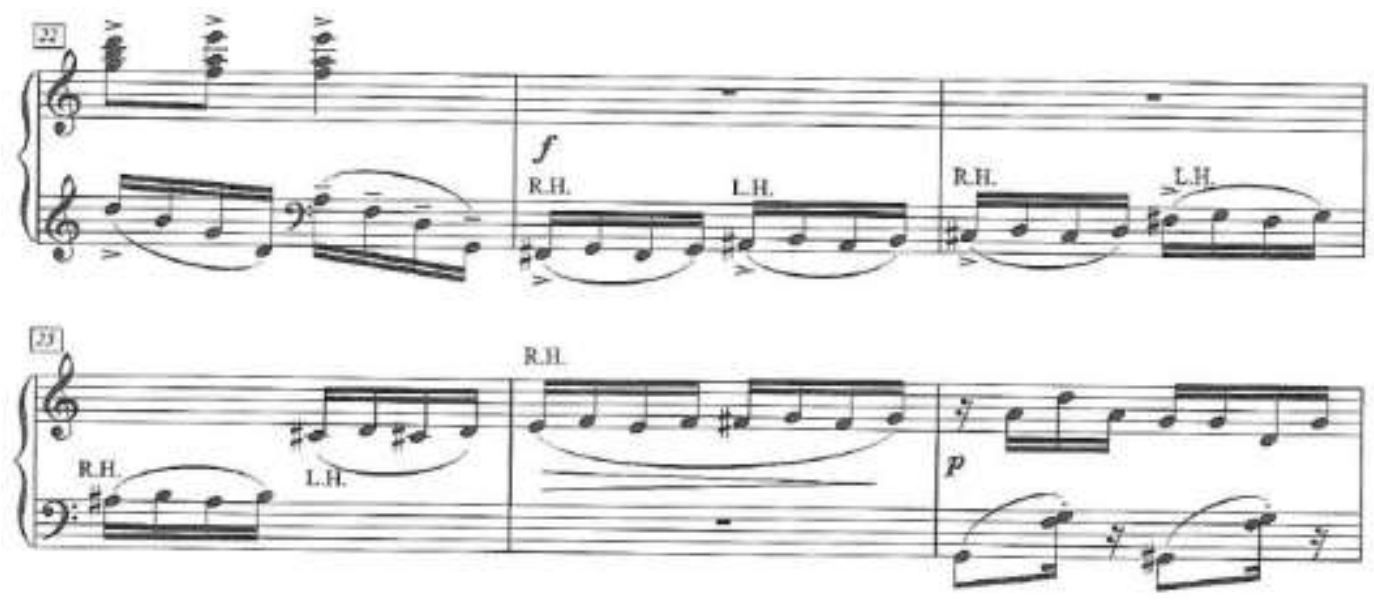

(C) 1989 by Formosa Singers Publisher. Used with Permission

Example 3.43 Tyzen Hsiao, "Frolic" in Memories of Home, 22-27. ${ }^{126}$

Another challenging section of this piece starts in mm. 41-54. (Example 3.44) When playing arpeggiated passages, students should release each finger right after the next note is played. Continuing to hold the previous note while playing the next note can create unnecessary muscle tension. The same passage happens again in $\mathrm{m} .45$, transposed up a fifth, from $\mathrm{F}$ to $\mathrm{C}$. Another interesting section occurs where the right hand and the left hand are moving in contrary motions; this happens in mm. 47-54. In Example 3.45, students are encouraged to practice individual voices separately before starting to put them together.

\footnotetext{
${ }^{126}$ Hsiao, 16.
} 

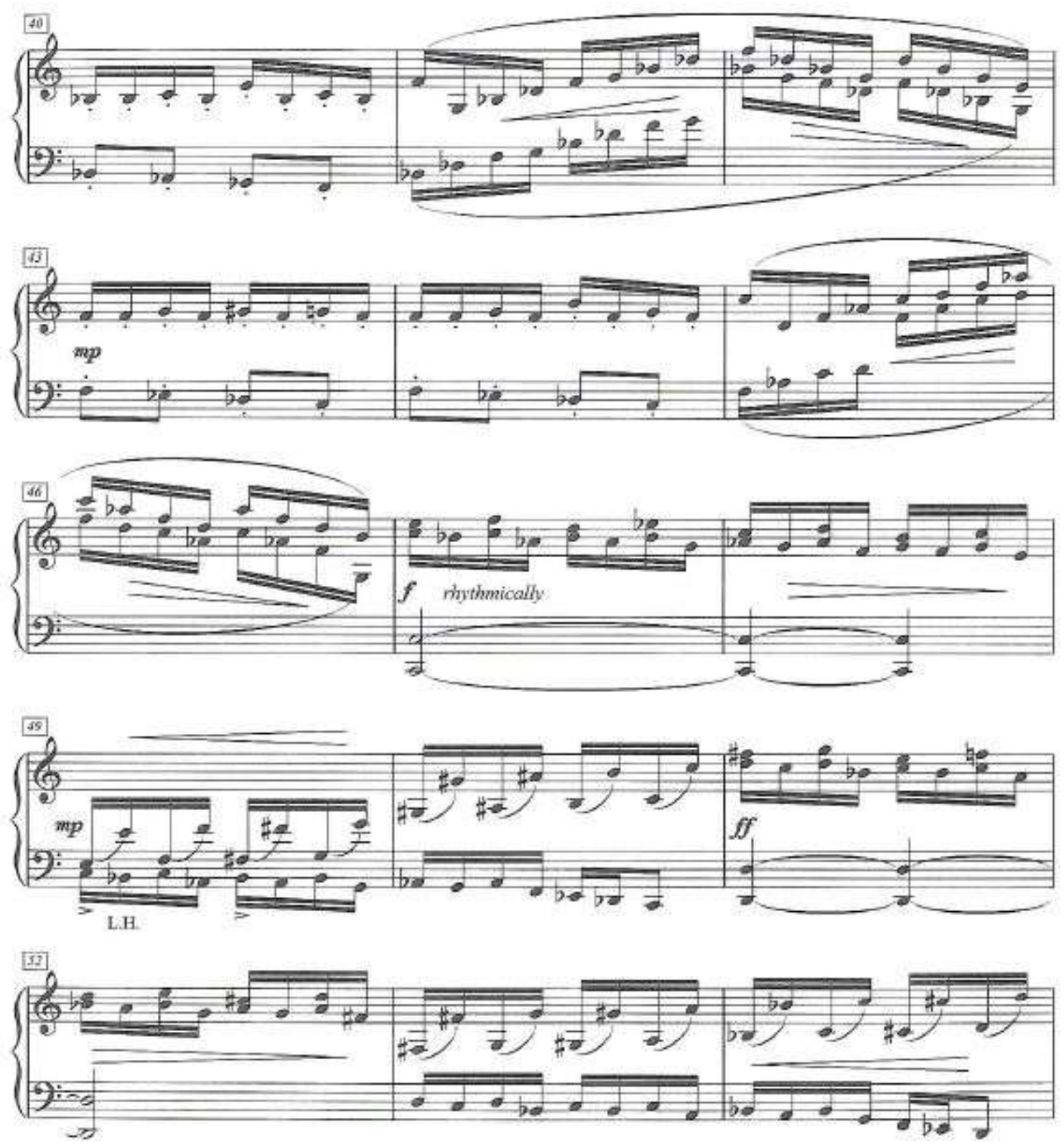

(C) 1989 by Formosa Singers Publisher. Used with Permission

Example 3.44 Tyzen Hsiao, "Frolic" in Memories of Home, 40-54. ${ }^{127}$

${ }^{127}$ Hsiao, 17. 

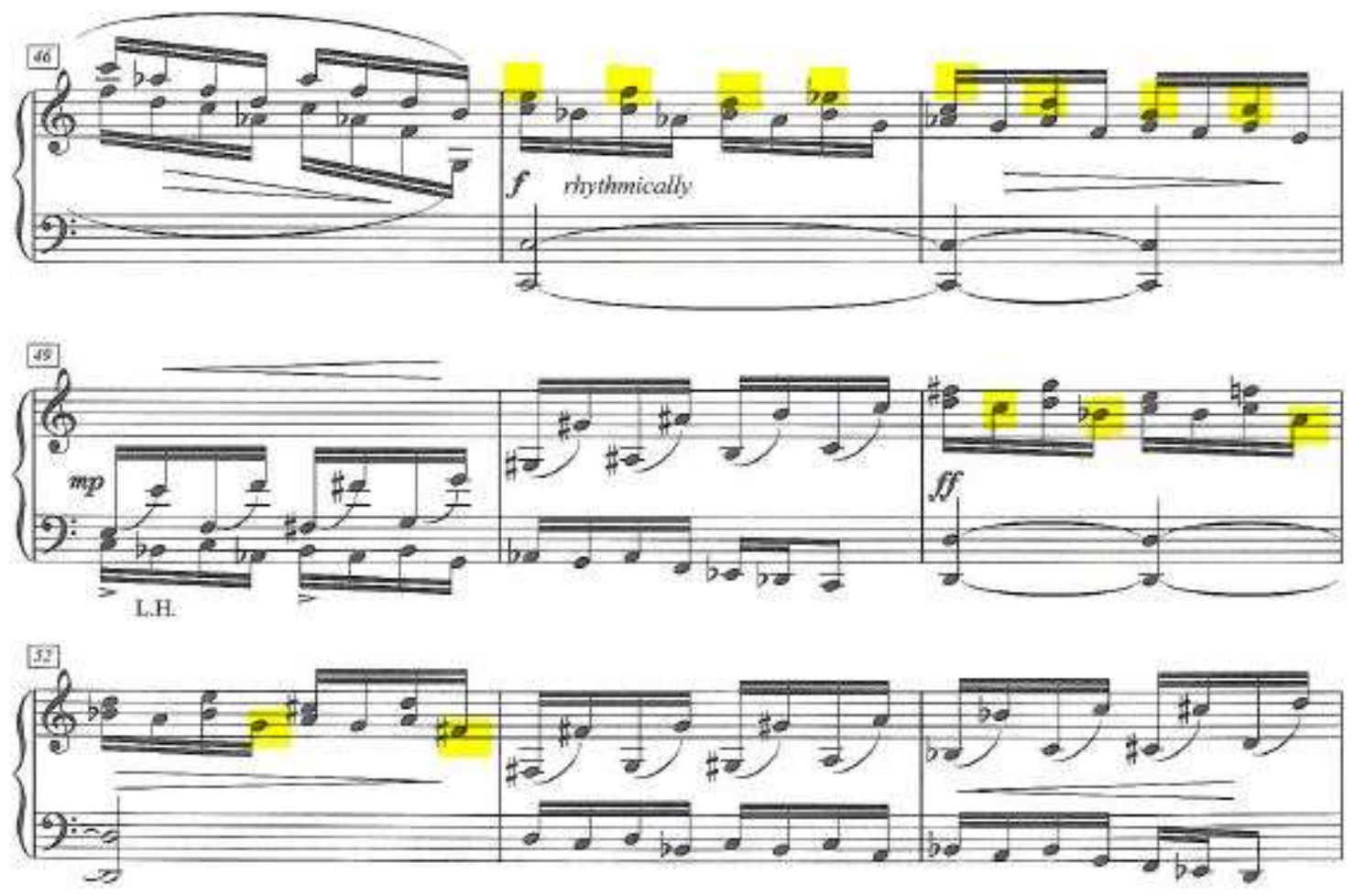

(C) 1989 by Formosa Singers Publisher. Used with Permission

Example 3.45 Tyzen Hsiao, "Frolic" in Memories of Home, 46-54. ${ }^{128}$

As the piece nears its end, Hsiao inserts a G7 chord in m. 57. Then, in m. 59, he transposes the chord up a half-step to A-flat7, creating a surprising effect (Example 3.47). To help point out the unexpected chord, performers could stretch the tempo slightly at the end of $\mathrm{m}$. 58. At the end of this piece, Hsiao sets up the mood for the climax by accelerating the tempo and then ending on a low C, played with the right hand. The tempo of "Frolic" is marked Allegro vivace. It is easy to rush when there are series of sixteenth notes throughout the piece. To prevent rushing, students should practice keeping a steady beat, often seeking the assistance of a metronome in that process.

${ }^{128}$ Ibid. 

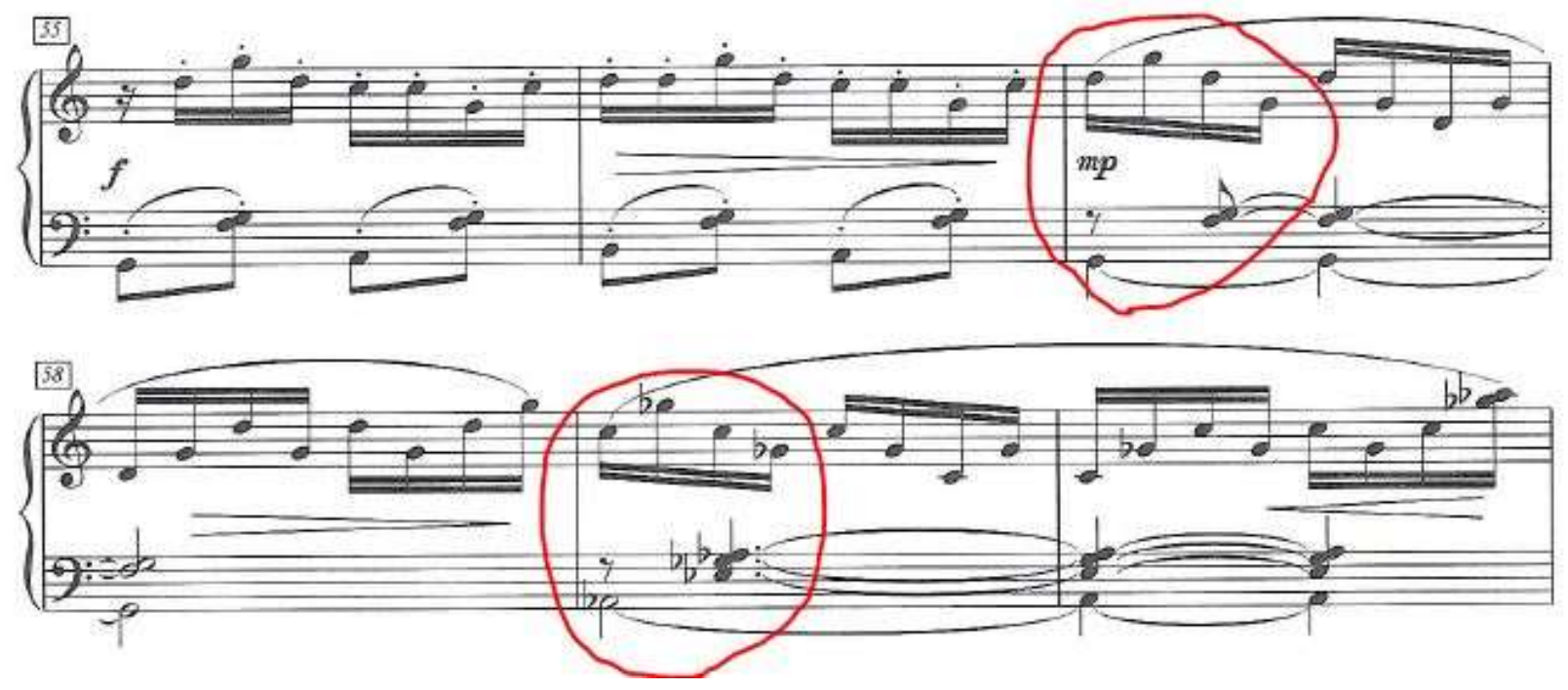

(C) 1989 by Formosa Singers Publisher. Used with Permission

Example 3.46 Tyzen Hsiao, "Frolic" in Memories of Home, 55-60. ${ }^{129}$

Memories of Home is a set that tells an autobiographical story of Hsiao when he was young and lived in Taiwan. Hsiao shares his personality through his music and each piece is quite distinct, marking a different point in his life journey. Among the six pieces, "Elegy" is the only one that was written in a minor key. Throughout these six pieces, the most used musical term is cantabile. Even though much of the set is energetic, there are frequent sections marked cantabile, perhaps to show Hsiao's softer side. This is a good set for children or young college students to learn. Although it might be challenging to tell Hsiao's story through music, this piece is achievable technically and it is certainly worthwhile artistically.

\section{Chapter Four}

${ }^{129}$ Hsiao, 18. 


\section{The Angel from Formosa}

In 1996, through his former piano student Wen-Wan Chen, who lived in Canada, Hsiao was introduced to the Russian conductor Vakhtang Jordania, after Hsiao's first concert in Vancouver. Three years later, Maestro Jordania led the Russian Federal Orchestra in performing Hsiao's Symphony Formosa in Tchaikovsky Concert Hall in Moscow. After the successful concert, both Hsiao and Jordania decided to show their appreciation to Chen for organizing the concert and promoting Hsiao's work. It was in that context that Hsiao composed "The Angel from Formosa," to be performed by the same orchestra in the same venue during $2000 .{ }^{130}$

Although this piece is only four minutes long, it catches the audience's heart immediately. Listeners can feel its purity and elegance when the three simple notes G, B, D come in the right hand. During the premier at Tchaikovsky Concert Hall in Moscow, the performance touched the hearts of the audience and members of the orchestra; many wept with tears, while applause and cheers reverberated in the concert hall. A close friend of Hsiao, Ken Chuang, recalled the concert and said, "Tyzen Hsiao has successfully conveyed Taiwanese people's pureness, elegance, and friendliness to the international community." 131

Pedagogical aspects

\footnotetext{
${ }^{130}$ Chen, Chi-Min, Catalogue of Tyzen Hsiao's Compositions. Council for Cultural Affairs, (Taiwan, 2009), 60.

${ }^{131}$ Ibid.
} 
The piano-solo version of The Angel from Formosa is constructed on a four-measure theme that appears in mm. 5-8 (Example 4.1). This theme recurs throughout the whole piece with slight alterations in rhythm and complexity. Toward the end, the theme becomes thicker and fuller in sound. In the orchestra version, this melodic motive is played by different instruments, started with flute, oboe, and clarinet. Each orchestral instrument possesses a different timbre; in the piano version, students must also strive to communicate the subtle differences in every repeated passage.
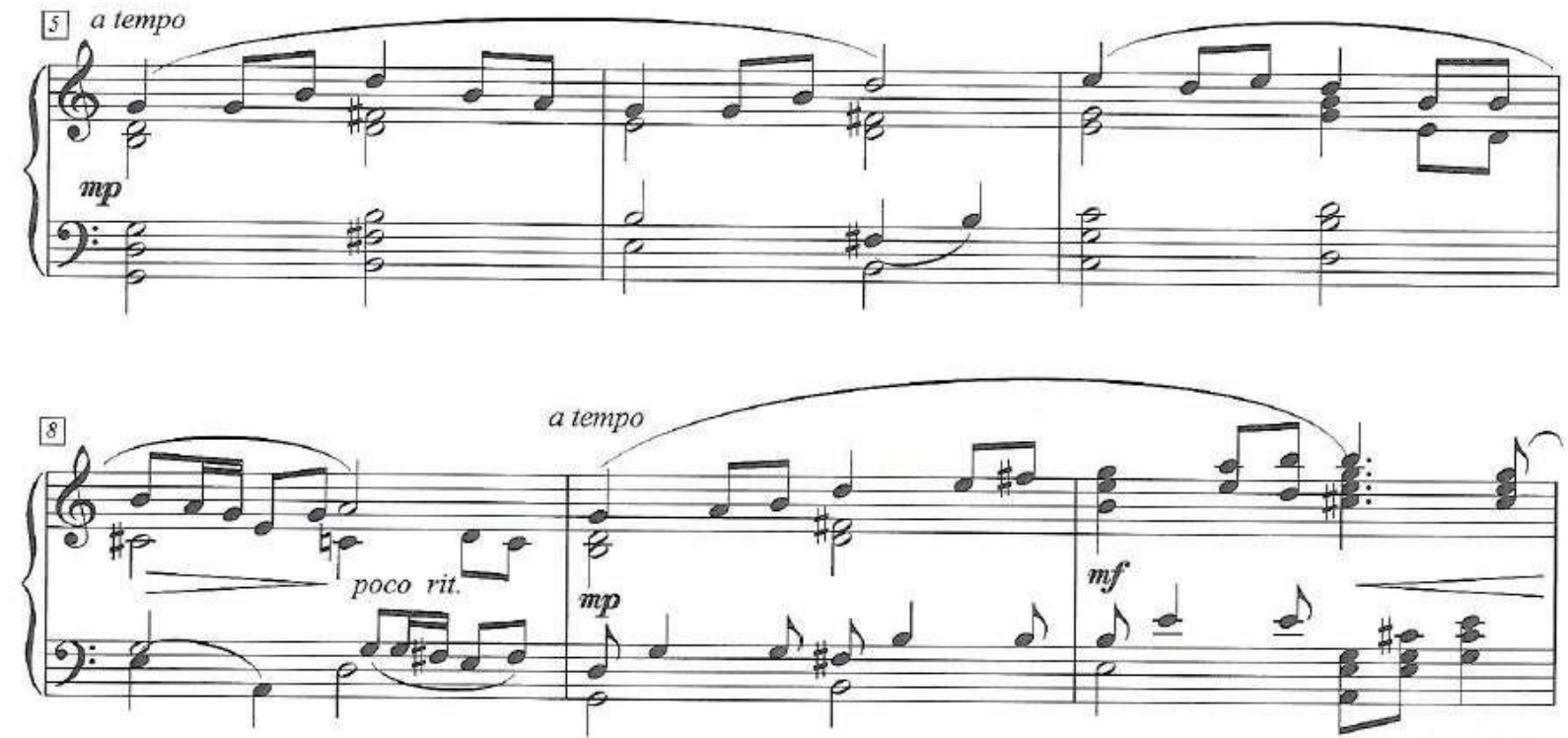

(C) 1999 by Formosa Singers Publisher. Used with Permission Example 4.1 Tyzen Hsiao, The Angel from Formosa, 5-8. ${ }^{132}$

In this work, we often see Hsiao's beloved musical terms "cantabile" and "ritardando," along with the frequent appearance of syncopation. Within four pages, Hsiao uses ritardando eleven times. Syncopation starts in $\mathrm{m} .9$, where the melody is in the right hand (Example 4.2). In

132 Tyzen Hsiao, The Angel from Formosa, (Taipei: Formosa Singers, 1999), 5. 
the left hand, the second repeated note should be played softly without any accent. Teachers can have their students practice each part separately: melody in the top voice, intervals in tenor, and syncopation in the left hand. Students need to play the melodic line louder than the other voices. We can also see that the composer wants performers to create both crescendo and diminuendo within one measure in this section. In m. 11, the first D chord can be played $m f$ in order to facilitate making a crescendo into the second chord. The same theme occurs again in $\mathrm{m}$. 15, but it starts on the note B instead of $\mathrm{G}$, one of several differences among repetitions of the theme.
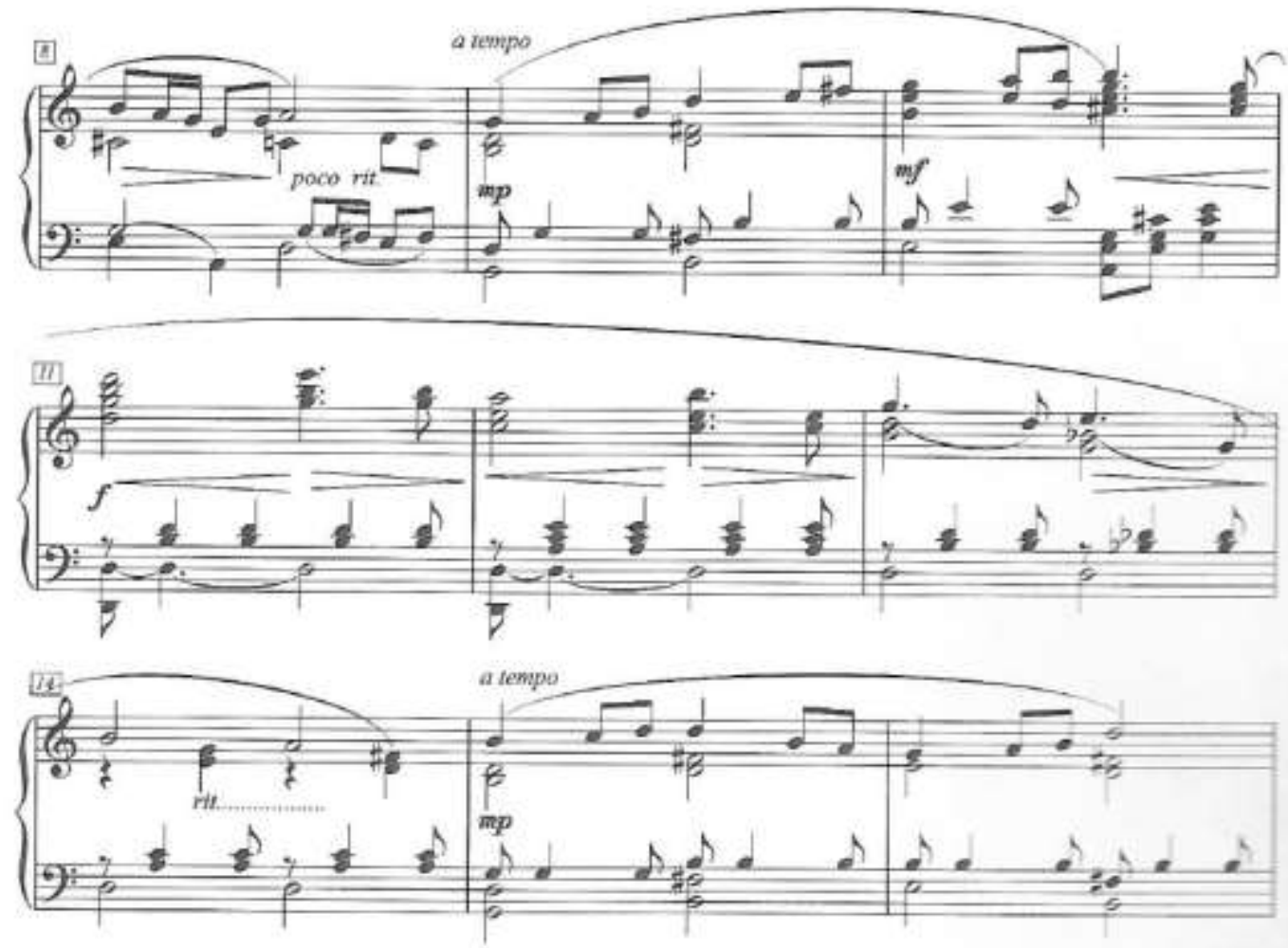

(C) 1999 by Formosa Singers Publisher. Used with Permission

Example 4.2 Tyzen Hsiao, The Angel from Formosa, 9-16. ${ }^{133}$

After a series of repetitions of the main theme, a transition occurs from mm. 30-42

(Example 4.3); then, in m. 43, the main melody returns with a different approach. This extended

133 Ibid. 
transition can be divided into two parts, which are based respectively on eighth-note (section $a$ ) and sixteenth-note (section $b$ ) passages. From mm. 30-36, students need to bring out the melodic line in the right hand, while playing the left-hand accompaniment more softly, so as not to overpower the melodic line. As the composer requires playing legato in the left hand, the student should connect the notes with arm motion, making sure to release the previous note completely, exactly when playing the next one. The students should not hold the notes when doing so is not indicated in the score. Holding the previous notes might cause tension when playing the next note. Performers should always seek to have relaxed arms and firm fingers. 

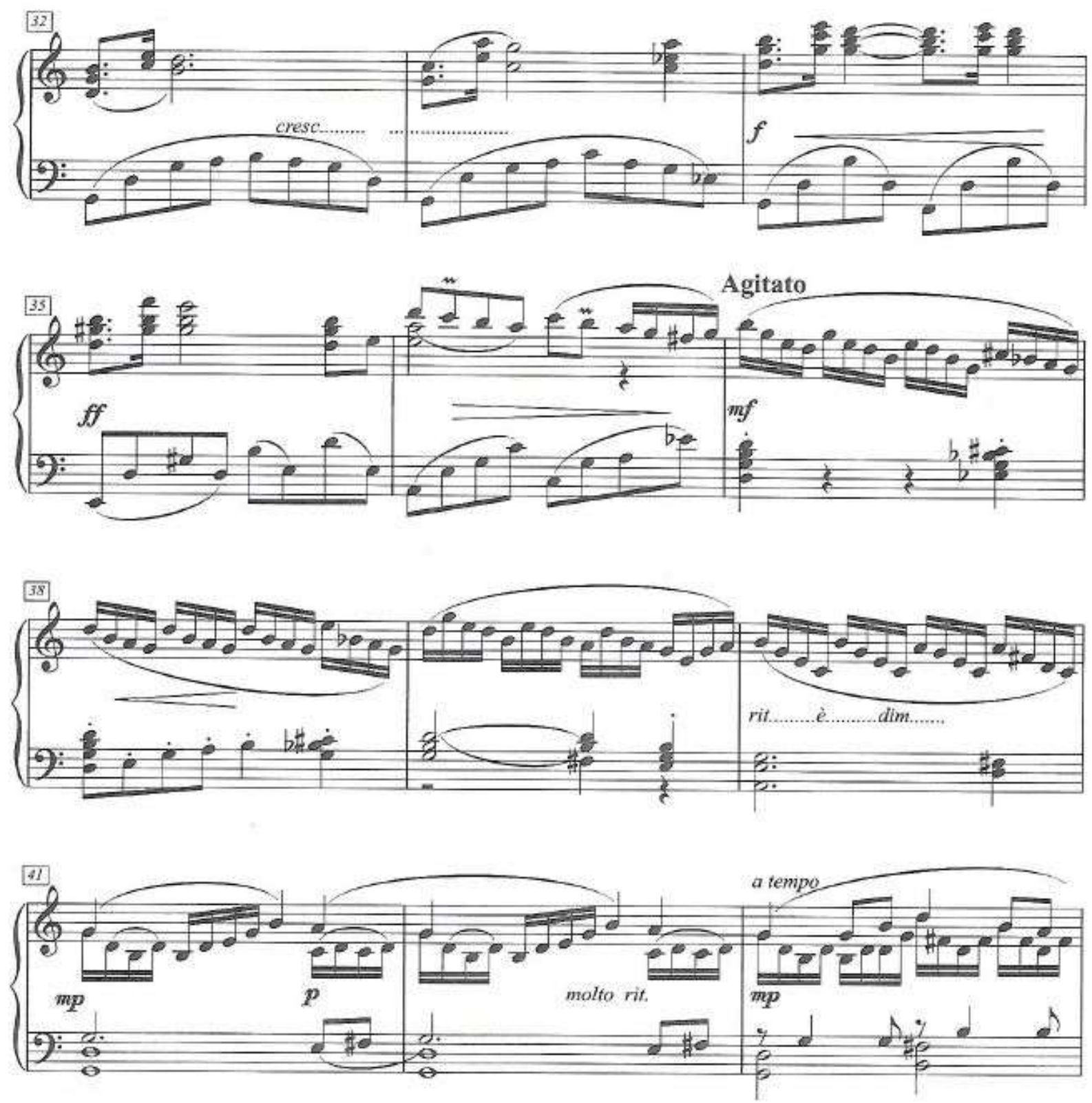

(C) 1999 by Formosa Singers Publisher. Used with Permission

Example 4.3 Tyzen Hsiao, The Angel from Formosa, 32-46. ${ }^{134}$

${ }^{134}$ Hsiao, 7. 
In section $b$, where it is marked Agitato, students can practice with stops. The best way to practice with stops in this part is stop after playing each group of four or five notes, as shown in Example 4.4. The student should make sure that the next set of notes will be played perfectly before they start playing them. This helps both mentally and physically, especially since fast notes are usually harder to play evenly and smoothly.
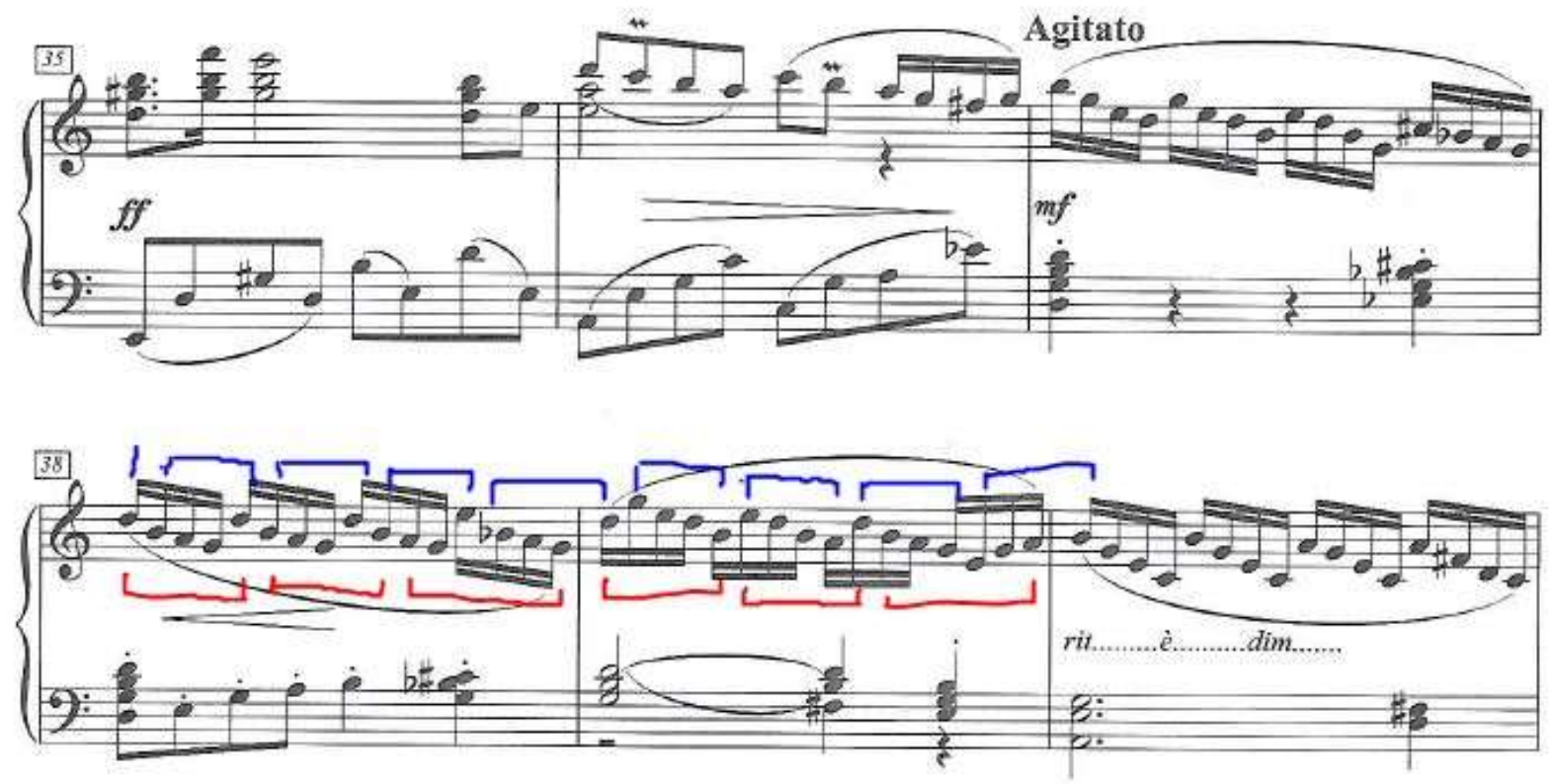

(C) 1999 by Formosa Singers Publisher. Used with Permission Example 4.4 Tyzen Hsiao, The Angel from Formosa, 38-40. ${ }^{135}$

The same theme occurs again in m. 43, marked a tempo, with a more complex texture that includes multiple voices between the hands (Example 4.5). As mentioned before, students would do well to practice each voice separately: top voice, sixteenth-note accompaniment in the right hand, syncopated rhythm in left hand, and bass. The upper and lower voices should be 
louder than inner voices. When playing, it is important to think of a long phrase to have a sense of bigger pulse. Practicing this can help to convey a sense of movement.

Taiwanese folk songs are usually written in a strophic form. Liu observes that near the end of a typical folk song, the texture usually gets thicker and fuller, while the tempo tends to slow down toward the end. ${ }^{136}$ "The Angel from Formosa" displays the same approach. From $a$ tempo in $\mathrm{m} .43$ to the next a tempo, which occurs in $\mathrm{m} .58$, a sixteenth-note accompaniment in the left hand gives the music a vivid sound, compared to the soft and calm opening. At the end, Hsiao writes perdendosi (Example 4.6). To create this effect, the students must gradually slow down and diminish the volume until the sound fades away. A "slow attack" can help to create a soft and warm sound in this section, so as not to miss any note of a chord.
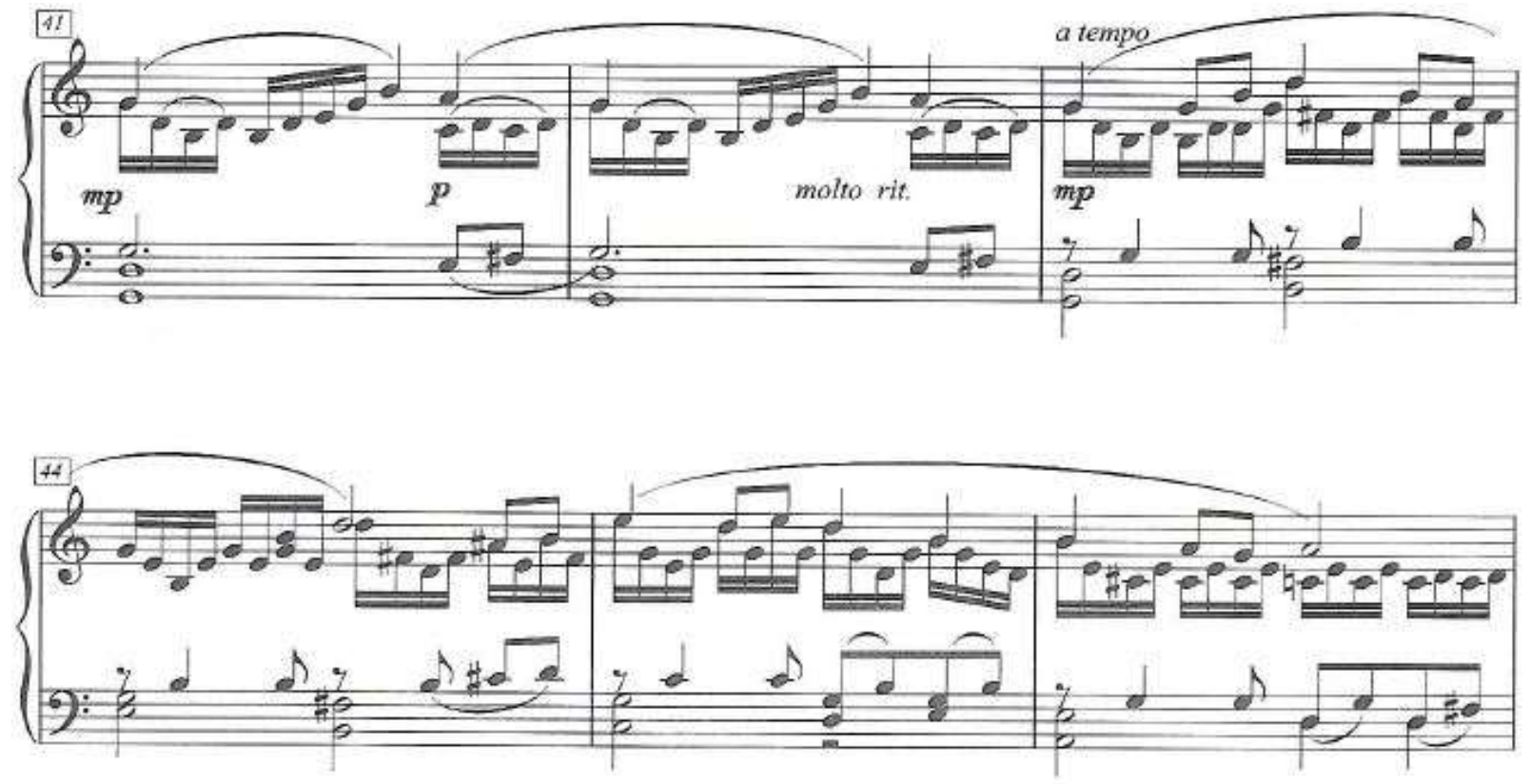

(C) 1999 by Formosa Singers Publisher. Used with Permission

${ }^{136}$ Chia-Te Liu. A Pedagogical Introduction to the Piano Works of Tyzen Hsiao, DMA dissertation, University of Kansas, (Lawrence, 2013), 34. 
Example 4.5 Tyzen Hsiao, The Angel from Formosa, 41-46. ${ }^{137}$

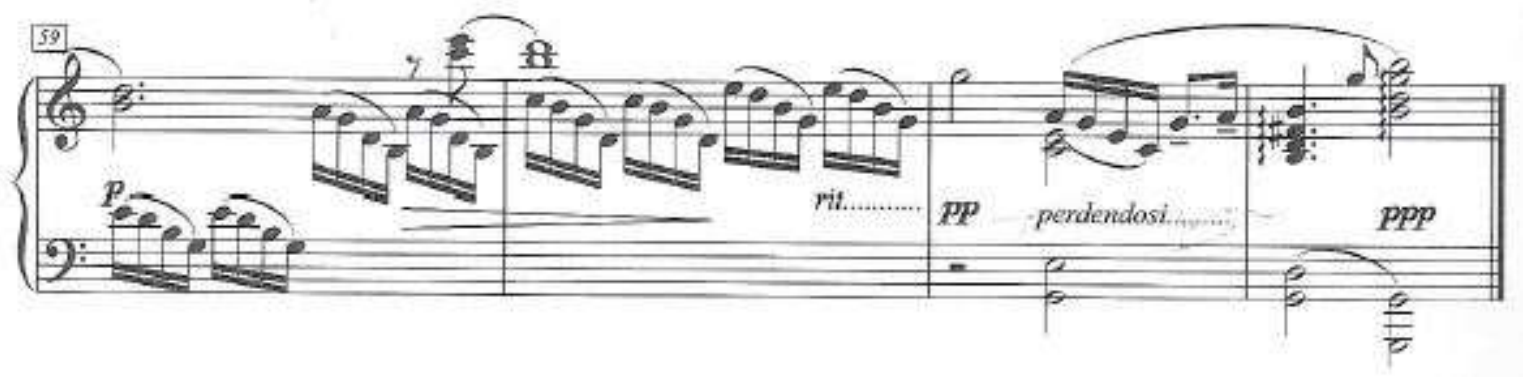

(C) 1999 by Formosa Singers Publisher. Used with Permission

Example 4.6 Tyzen Hsiao, The Angel from Formosa, 59-62. ${ }^{138}$

137 Tyzen Hsiao, The Angel from Formosa, (Taipei: Formosa Singers, 1999), 7.

${ }^{138}$ Hsiao, 8. 


\section{Chapter Five}

\section{Conclusions}

Tyzen Hsiao is a very important figure in the history of Taiwanese music, contributing to many genres that range from Taiwanese church music to Taiwanese art songs. His patriotism shows in his frequent use of local Taiwanese folk tunes in his pieces, promoting his Taiwanese identity to the world. This gives people the opportunity to discover Taiwan through his music, which is elegant and touches the hearts of audiences everywhere. He not only uplifts the spirts of the audience, but also stimulates a musical spark within the performer. In both Memories of Home and The Angel from Formosa, the delicate melodic lines with rich harmonies show his Neo-Romantic language within a Classical form. In the Taiwanese art songs he has written, Hsiao likes to emphasize the meaning of words in his texts through melodic shape, phrasing, and chromaticism.

Within Memories of Home and The Angel from Formosa, we see some of the same writing techniques he also uses frequently in other pieces as well: Syncopated passages, broken chord figures, chromaticism, multiple voices in a passage, intense dynamic changes, and the frequent appearance of musical terms such as cantabile and espressivo. Except for "Memory," which does not have a time signature, in Memories of Home Hsiao writes specific tempo, dynamics, and expression marks in the music. He frequently changes dynamics within four measures and sometimes changes dynamics within a single measure. This certainly helps to provide a more colorful repetition when the main theme recurs in each piece. 
References to Taiwanese culture are an important element in Hsiao's music. There are several pieces in Memories of Home that are related to Taiwanese festivals and holidays; among these are "Prelude," which creates a festive and intense rhythm throughout the piece, and “Taiwanese Ancient Melody," which refers to the Tomb Sweeping Day holiday in Taiwan.

The spirit of Taiwan has always been with Tyzen Hsiao. He wanted to express his love for Taiwan. He did not follow the avant-garde style but kept his heart to the Romantic style instead. According to his words,

The essence of romanticism was totally absent in Taiwanese music because we started our music history from our tribal or indigenous music, traditional stage music, and so forth, then directly jumped into the realm of avant-gardism; therefore, that is to say, we lacked the process of tonal music of three hundred years in the music history of Taiwan. ${ }^{139}$

He provides a myriad of different musical styles, which can challenge performers technically as well as musically. When talking about Hsiao's music, Dr. Lu-Fen Yen from National Taipei University of Arts says, “Tyzen Hsiao’s Taiwanese music of gentleness and elegancy has touched us profoundly and beacons us in the darkness to guide those who beseech to the more cultivated Taiwanese music in the future." ${ }^{140}$ Hsiao's music is a statement of Taiwan's cultural independence and a tribute to the Taiwanese people.

\footnotetext{
${ }^{139}$ Chi-Min Chen, Catalogue of Tyzen Hsiao's Compositions. Council for Cultural Affairs, (Taiwan, 2009), 74.

${ }^{140}$ Chen, 82 .
} 


\section{Appendix}

Complete List of Compositions by Tyzen Hsiao

Compiled by Ken Chuang ${ }^{141}$

\section{Orchestral Works:}

Symphonic Poem, "China" (1973)

Symphonic Poem (1985)

Symphony Formosa, op. 49 (1987)

Violin Concerto in D major, op. 50 (1988)

Cello Concerto in C major, op. 52 (1990)

Piano Concerto in C minor, op. 53 (1992)

The Angel from Formosa, (1999)

\section{Works for Orchestra and Chorus:}

Vegabond (1978)

March of Democracy (1980)

1947 Overture, op. 56 (1994)

I Love Taiwan, op. 58-1 (1996)

Ode to New Taiwan, op. 58-2 (1996)

Spirt of Taiwan (1998)

Ode to Yushan, op. 61-1 (1999)

Ilha Formosa: a Requiem for Mystery of Formosa, op. 63 (2001)

\section{Trios:}

Prelude and Fugue (1973)

The Formosa Trio, op. 58 (1996)

\section{Quartets:}

String Quartet, arranged from the Taiwanese song, Hometown in the Sunset (1987)

String Quartet, arranged from the Taiwanese song, Open the Window of Your Heart (1999)

${ }^{141}$ Chi-Min Chen, Catalogue of Tyzen Hsiao's Compositions (Council for Cultural Affairs, Taiwan, 2009), 121. 


\section{Quintets:}

String Quintet, "Vegabond” (1978)

Piano Quintet, arranged from the Taiwanese song, Hot Dumpling (1982)

The Highlander's Suite, op. 47 (1985)

Piano Quintet, "Our Taiwan” (1985)

Piano Quintet, Lanyang Dance, op. 49 (1987)

Violin Solo and a Quintet, arranged from the Taiwanese song, Spring Breeze (1999)

\section{Piano Works:}

Poetic Echo (1974)

Waltz Brilliant, op. 38 (1975)

Memories of Home, op. 49 (1987)

Festival, op. 50 (1988)

Etude, Farewell, op. 55 (1993)

Toccata, op. 57 (1995)

Character Pieces for Children (1996)

Level 1: Good Morning

Level 1: Evening Sky

Level 2: A Little Soldier

Level 2: A Trumpet Player

Level 3: Lullaby

Level 3: Little Angel's Dream

Level 4: Red Dragonfly

Level 4: Fun time on Black Keys

Level 5: Honeybee

Level 5: Woodpecker

Level 6: Dragon Boat Festival

Level 6: Theme and Variation

Variations on the Theme of Happy Birthday (1996)

Intermezzo (1997)

The Angel from Formosa (1999)

\section{Works for Violin:}

The Song of Taiwan (1970)

A Fantastic Hen-Chun Melody (1973)

Elegy (1974)

The Old Junkman (1974) 
What a Friend We Have in Jesus (1974)

Meditation (1975)

Vegabond (1978)

Nocturne in G (1980)

Just for You (1981)

More Love to Thee, O Christ (1981)

Love Song (1983)

Hope Line (1983)

Blessed Assurance (1988)

Nocturne in D (1994)

Spring Breeze (1998)

I Love Taiwan (1998)

Sewing on the Broken Net (1998)

Wish You Home Soon (1998)

\section{Works for Cello:}

Dancing Wind (1985)

The Separation (1986)

Capriccio in Hakka Melody (1987)

An Evening Sky (1988)

Memory, arranged from Vegabond (1996)

Fantastic Tribal Dance (1999)

\section{Work for Flute:}

Fantasia: A Lonely Shadow Besides the Lake (1995)

\section{Work for Pipe Organ:}

Prelude (1990)

\section{Work for Percussion:}

A Percussion Trio (1985)

\section{Art Songs, Section I: for a Four-Part Mixed Choir:}

Street Food Vendors (1978)

Vegabond (1978)

Three Character Scriptures in Taiwanese (1979) 
Lullaby (1983)

Pais ka lau pa ku u I hi, arranged from Bunun Tribal Song (1983)

No Fear for Sweet Potatoes to Fall on the Muddy Ground (1986)

I Love Taiwan (1987)

Go Forward to the Peak, My Son (1989)

Come and Join the Celebration (1991)

Ode to My Homeland (1991)

Love and Hope (1994)

In Memory of My Mother (1995)

Ode to New Taiwan (1996)

Song of Lilies (1997)

Taiwan, the Nourished Land (1997)

Anthem for Taiwanese Center of Great Los Angeles (1998)

A Piece of Grass (1998)

Eternal Homeland (1998)

Ode to the Lamp of Wisdom (1998)

Spirit of Taiwan (1998)

Taiwan, the Precious Island (1998)

The Green Taiwan Belongs to Us (1998)

The Little Garden in Spring (1998)

The Most Beautiful Flower (1998)

The Thing that I loved the Most (1998)

Yearning for Parents (1998)

A Silent Night (1999)

A Prayer of My Soul (1999)

Egret (1999)

Lily of the Valley (1999)

My Father's Pen (1999)

Song of Scar, in Memory of the Victims in the Earthquake on September 21 (1999)

The Wanderer is Coming Home (1999)

Woods (1999)

Good Morning, Formosa (2000)

American Male's Suits (2001)

America, the Beautiful Country (2001)

Ilha Formosa, a Requiem for Martyrs of Formosa, op .63 (2001)

Please Take Care of Yourself, Mother (2001)

The Beautiful Land (2001)

Vegabond and the Nostalgia (2001)

We Will Sing a New Song, for the National Tragedy on September 11 (2001)

Anthem for the Taichung Lifeline Association (2002)

Spring Breeze, White Clouds (2002)

To Those I love and to Those Who Love Me (2002)

A Father's Prayer (2008)

The Capital of the Ocean: Kaohsiung the Beautiful City (2008)

Wake Up 765 (2008) 


\section{Art Songs, Section II: for a Two-Part or Three-Part Mixed Choir:}

Three Character Scriptures in Taiwanese (1979)

No Fear for Sweet Potatoes to Fall on the Muddy Ground (1986)

Go Forward to the Peak, My Son (1989)

Anthem for the NATWA (1997)

Taiwan, the Nourished Island (1997)

Eternal Homeland (1998)

My Mother's Hair (1998)

Red Dragonfly, arranged from a Japanese Children's Ballad (1998)

Spirit of Taiwan (1998)

Taiwan, the Precious Island (1998)

The Green Taiwan Belongs to Us (1998)

The Most Beautiful Flower (1998)

A Prayer of My Soul (1999)

Song of Scar, in Memory of the Victims in the Earthquake on September 21 (1999)

The Wanderer is Coming Home (1999)

Vegabond (1999)

\section{Art Songs, Section III: Solo Songs}

Farewell (1961)

Autonomy Song (1967)

Silent Evening Sky (1967)

The Magic of Love (1977)

A Chant of a Pen and a Soldier (1978)

Little Wind Chimes (1978)

Martin, a Morning Prayer (1978)

Street Food Vendors (1978)

Vegabond (1978)

The Gift of Friendship (1979)

Three Character Scriptures in Taiwanese (1979)

American Male's Suits (1980)

Beautiful Island, Our Home (1980)

Singing through the Jail (1980)

Song to the Taiwanese Autonomy (1980)

An Aspiration under Oppression (1982)

Taiwan, the Truly Beautiful Island (1984)

Elegy of Vegabond (1986)

Lunchbox (1986)

No Fear for Sweet Potatoes to Fall on the Muddy Ground (1986)

I Love Taiwan (1987)

A Lonely Shadow by the Lake (1988)

Memory of My Father (1989) 
Anthem for the North American Taiwanese Professors' Association (1990)

We are the Masters of Taiwan (1991)

Eternal Homeland (1992)

The Most Beautiful Flower (1992)

Taiwan, the Nourished Island (1993)

Love and Hope (1994)

Beautiful Sun-Moon Lake (1995)

Ode to Music (1996)

Mischievous Child (1996)

Anthem for the NATWA (1997)

Butterfly Loves Flowers (1997)

Resemblance to Our Dream (1997)

Song of Lilies (1997)

A Decision of New Taiwanese (1998)

Anthem for Taiwanese Association of America (TAA-USA) in Los Angeles (1998)

Anthem for Taiwanese Center of Great Los Angeles (1998)

My Mother's Hair (1998)

Spirit of Taiwan (1998)

The Green Taiwan Belongs to Us (1998)

A Prayer of My Soul (1999)

Egret (1999)

Song of Freedom (1999)

Taiwanese Citizens (1999)

A Love Song for Silver Wedding Anniversary (2000)

Ode to Jinling (2000)

We Will Sing a New Song: for the National Tragedy on September 11 (2001)

A Reunion (2002)

Taiwan Affiliation with United Nations (2002)

To Those I love and to Those Who Love Me (2002)

Celebration of the New Year (2005)

\section{Art Songs, Section IV: Songs for Male/ Female Voice(s):}

Singing through the Jail (1980)

I Love Taiwan (1987)

Wordlessness (1999)

\section{Art Songs, Section V: Songs for Children:}

Chicks Follow Their Hen (1968-1969)

My Beloved Puppy (1968-1969)

Tadpoles Grown into Frogs (1968-1969)

Welcome Guests (1968-1969)

What a Joy in Fishing (1968-1969) 
Song of Lilies (1997)

A Piece of Grass (1998)

Yearning for Parents (1998)

I Love Taiwan (2000)

\section{Sacred Music}

Farewell (1965)

Oratoria, "Jesus Christ" (1971)

God's Mercy is Better than Life (1978)

His Name shall be Called Wonderful (1978)

Yesterday, Today, and Forever (1978)

Now is the Time of Youth (1080)

Prayer of Silence (1980)

Psalm 23: Through I Walk through the Valley of the Shadow of Death (1980)

A Dedicated Poem (1981)

Anthem for TAAC on Aging (1981)

Hark! The Voice of Jesus is Calling (1981)

He Leaded Me (1981)

One Foundation of the Church (1981)

A Thanksgiving Prayer (1982)

Let Us Sing and Praise (1982)

Psalm 84: Your Dwelling Place (1982)

Enter His Gates with Thanksgiving (1985)

Bright Angel (1990)

Psalm 103: Bless the Lord, O My Soul (1990)

Come, Holy Spirit for Pentecost (1991)

See in Yonder Manger Low (1996)

Praise the Heavenly Father Altogether (1998)

The Lord Bless You and Keep You (1998)

The Lord's Prayer (1998)

Psalm 150: Praise the Lord (1999)

Cantata, "the Prodigal Son," op. 62 (2000)

Anthem for Tamkang High School (2001)

Good Christian Men Rejoices (2001)

To Tell a Gospel Everywhere in Taiwan: Anthem of Zhanghua Presbyterian Church (2001)

The Spirit of Dr. Mackay: A Centennial Song after Dr. George Leslie Mackay's Death (2001)

God's Grace: A Dedication to the Tenth-year Anniversary of Grace Presbyterian Church (2002)

Psalm 121: I Lift My Eyes to the Hills, arranged from a Paiwan Tribal Tune (2002)

The Gospel of Christ to Redeem Taiwan: A Commemoratory Song for the 130-year Anniversary of Tamsui Presbyterian Church (2002)

\section{Stage Music, Operettas}


Happy Farmhouse (1968)

How Beautiful My Garden is (1969)

Auntie Tigress (1984)

\section{Bibliography}

Chen, Chi-Min. Catalogue of Tyzen Hsiao's Compositions. Council for Cultural Affairs, Taiwan, 2009.

Chen, Jui-Wen Ginger. Selected Contemporary Taiwanese Composers and Their Piano Works. $\mathrm{Ph}$.D. dissertation, Northwestern University, 1995.

Chen, Yi-Chiao. An Analysis and Performance Interpretation of Piano Works by Tyzen HsiaoTaking Memories of Home, op. 49 and Poetic Echo op. 37. M. M. research paper, the National University of Tainan, 2012.

Cheng, Ching-Ming. An Annotated Bibliography of Taiwanese Piano Music by Selected Composers Born After 1950. D. M. A. dissertation, University of Miami, 2006.

Chopin Frederic. Mazurkas for Piano. Leipzig: Breitkopf und Härtel, 1880.

. Preludes for Piano. Leipzig: Breitkopf und Härtel, 1880.

Hinson, Maurice. Guide to the Pianist's Repertoire: Supplement. Bloomington: Indiana University Press, 1979.

Hsiao, Tyzen. Piano Concerto in C Minor. Formosa Singers, 1992.

Hsieh, Pei-Chun. A Study of Structure and Performance Interpretation of Tyzen Hsiao's Piano Music: Memories of Home and Selections from Piano Pieces for Children. Master's dissertation, Fu Jen Catholic University, 2012.

Lee, Zong-Rong. Yu Hsiao Tyzen de dui-hua (An Interview with Tyzen Hsiao, In Romanticism with Deep Affection). Taipei: Wang-Chuan-Feng, 1999.

Lin, Hen-Zhe. Shen-ching de lang-man (A Collection of Tyzen Hsiao's Musicological Forum and Articles). Taipei: Wang-Chun-Feng Wen-Hua, 1999.

. Hsiao Tyzen yuan-jheng mo-sih-ke (Tyzen Hsiao in Moscow).

Taipei: China times, 2000.

Lin, Lan-Fang. The Study of Hsiao Tyzen's Piano Music with an Analysis of Piano Concerto in C 
Minor, Op. 53. Master's dissertation, National Sun Yat-Sen University, 2003.

Liu, Chia-Te. A Pedagogical Introduction to the Piano Works of Tyzen Hsiao, D.M.A. dissertation, University of Kansas, 2013.

Jin, Xi-Wen. Originated from the Heart, Soul, and Honesty. Jer-Shung Lin, Taiwan, 1999.

$\mathrm{Ku}$, Pei-Ning. Songs by Hsiao Tyzen: The Interaction Between His Music and Taiwan. D.M.A. dissertation, University of Nevada, Las Vegas, 2014.

Kuo, Rita C. Foreword. Tyzen Hsiao: Memories of Home, Suite No. 1 for Piano. California: Taiwanese Composers Foundation, 1989.

Rachmaninoff, Sergei. Morceaux de fantaisie, Op.3. Moscow: Muzgiz, 1947.

Roy, Denny. Taiwan. New York: Cornell University Press, 2003.

Sho, Jennifer. Hsiao Tyzen's 1947 Overture: The Intersection of Music and Politics of Taiwan. D.M.A. dissertation, New England Conservatory of Music, Boston, 2006.

Tsai, Ming-Yuen. The world-class Taiwanese composer, Tyzen Hsiao. Taipei: Yu-San-She, 2006.

Tzeng, Chen-Li. The Development of Piano Pedagogy in Taiwan, with Portraits of Eight Important Teachers. D. M. A. dissertation, University of Maryland, 1994.

Wu, Ling-I. Taiwan chien-pei yin-yue-jia chun-hsiang (The Stories of Taiwan's Music Pioneers). Taipei: Ta-Lu Chu-Pan-She, 1993.

Wu, Yu-Ting. Music and National Identity: A Study of Cello Works by Taiwanese Composers. D.M.A. dissertation, The City University of New York, 2010.

Yang, Tzi-Ming. Selected Solo Piano Works of Taiwanese Composers. D. M. A. dissertation, University of Maryland, 2002.

Yen, Hua-Rong. Hsiao Tyzen: lang-man de Tai-Wan wei (The Romantic Taiwanese Composer: Tyzen Hsiao). Taipei: Times Cultures, 2002.

. Hsiao Tyzen gang-chin yu chu tan, Hsiao Tyzen yin-yue yan-tao-hui lun-wen-ji (Tyzen Hsiao's Piano Music, Tyzen Hsiao Musicological Forum and a Collection of Articles). edited by Dan, Chu-Ming. Kaoshiung: Kaoshiung Government Cultural Center, 2004.

Yen, Lu-Fen. Hsiao Tyzen zai Tai-Wan yin-yue-shih shang de gong-sian (The Contributions of Tyzen Hsiao toward the Music History of Taiwan). Tzipei: Council for Culture Affairs, 2009. 
Yen, Lu-Fen, and Mei-Lin Hsu. Tai-Wan de yin-yue (Music of Taiwan). Prospects of Taiwan No. 12. Taipei: Lee's School, 2006.

Yu, Su-Feng. Tai-Wan sian-dai yin-yue fa-jhan tan-suo (The Development and Exploration of Modern Music in Taiwan). Taipei: Yueh-Yun Publisher, 2000.

Zhuang, Chuan-Xian. Shi-jie ji de Tai-Wan yin-yue-jia: Hsiao Tyzen (The Greaet Taiwanese Composer: Tyzen Hsiao). Taipei: Yu-Shan-Sheh, 2006. 